\title{
Evaluation of Process and Economic Feasibility of Implementing a Topping Cycle Cogeneration System
}

\author{
Unique Karki \\ uk0005@mix.wvu.edu
}

Follow this and additional works at: https://researchrepository.wvu.edu/etd

Part of the Energy Systems Commons

\section{Recommended Citation}

Karki, Unique, "Evaluation of Process and Economic Feasibility of Implementing a Topping Cycle Cogeneration System" (2020). Graduate Theses, Dissertations, and Problem Reports. 7737. https://researchrepository.wvu.edu/etd/7737

This Thesis is protected by copyright and/or related rights. It has been brought to you by the The Research Repository @ WVU with permission from the rights-holder(s). You are free to use this Thesis in any way that is permitted by the copyright and related rights legislation that applies to your use. For other uses you must obtain permission from the rights-holder(s) directly, unless additional rights are indicated by a Creative Commons license in the record and/ or on the work itself. This Thesis has been accepted for inclusion in WVU Graduate Theses, Dissertations, and Problem Reports collection by an authorized administrator of The Research Repository @ WVU. For more information, please contact researchrepository@mail.wvu.edu. 
Evaluation of Process and Economic Feasibility of Implementing a Topping Cycle Cogeneration System

Unique Karki

Follow this and additional works at: https://researchrepository.wvu.edu/etd

Part of the Energy Systems Commons 


\title{
Evaluation of Process and Economic Feasibility of Implementing a Topping Cycle Cogeneration System
}

\author{
Unique Karki \\ Thesis submitted to the Benjamin M. Statler College of \\ Engineering and Mineral Resources at \\ West Virginia University \\ in a partial fulfillment \\ of the requirement for the degree of \\ Master of Science \\ in \\ Industrial Engineering \\ Bhaskaran Gopalakrishnan, Ph.D., P.E., Chair \\ Ashish Nimbarte, Ph.D. \\ Kenneth H. Means, Ph.D., P.E.
}

Department of Industrial and Management Systems Engineering

Morgantown, West Virginia

July 2020

Keywords: Topping Cycle CHP, Cogeneration, Steam Boilers, Economics

Copyright 2020 Unique Karki 


\title{
Abstract \\ Evaluation of Process and Economic Feasibility of Implementing a Topping Cycle \\ Cogeneration System
}

\author{
Unique Karki
}

Industrial applications that require steam for their end-uses generally utilize steam boilers that are at higher size than what is typically required. Similarly, gas turbine-based power plants corroborate the gas turbine system and eventually relieve the exhaust into the atmosphere. These facilities include food, paper, chemicals, refining, and primary metal manufacturing industries. This research focuses on the scope of a topping cycle combined heat and power (CHP) system by pushing the load on the boiler to a higher limit, or a gas turbine operation in place of a boiler system for a topping cycle CHP and its economic feasibility by utilizing the turbine exhaust to achieve the technological and economical evaluation of a CHP system. The excess steam is run through a condensing steam turbine to generate power that can offset the facility's electricity usage cost and under favorable conditions, sell electricity back to the grid. Similarly, the steam turbine outlet water can be used to satisfy the plant's heating needs in the form of comfort and district heating. A decision tool was developed to evaluate the technical and economic feasibility of a topping cycle CHP system, which can emulate a given facility's steam or gas system and its operational parameters with steam turbines. It will help the user realize the point of breakeven (in terms of fuel cost incurred and overall cost savings) at the desired steam flow rate for a corresponding boiler system. Similarly, sensitive analysis of energy, power, cost savings, and payback of investment to boiler and steam parameters is also carried out. The research would provide necessary insights into the most appropriate parameters that will enable a CHP system to be advantageous in technical and economic aspects. The research determines that the fuel cost, electricity cost, and the steam quantity flowing through the turbines are the most important parameters for a desirable payback on the investment. 


\section{Dedication}

To my beloved Dad, Bharat, and my late mother, Jamuna, for endless love, compassion and support, and my little brother, Aryan; the pillar of my life. 


\section{Acknowledgment}

I would like to wholeheartedly express my sincerest gratitude and appreciation to my research advisor and committee chair, Dr. Bhaskaran Gopalakrishnan for his motivation, persistence, and immense knowledge that he bestowed upon me during this adventure. My journey throughout graduate school, academic research, and later, the profession I chose arose from his continual and everlasting support. With his unwavering guidance and humility, he made me believe that big things happen if you work enough. Needless to say, without his mentorship and assistance, this research would not have been possible. I would also like to sincerely thank my committee member Dr. Ashish Nimbarte for assisting me academically and professionally during my studies and research. He was a constant mentor and a confidante, who always helped me in every instance. I would like to thank my committee member, Dr. Kenneth Means, for his time and support, and for alternative feedbacks to the research.

I would also like to acknowledge my friends and family, who were always there in the form of constant joy and support. And finally, my little brother, who is more like a big brother to me, for always showering me with advice. 


\section{Table of Contents}

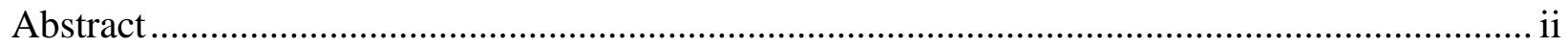

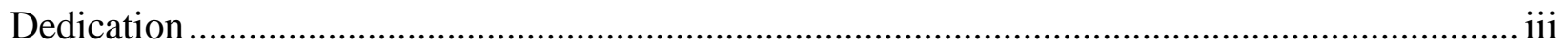

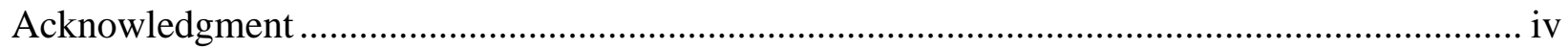

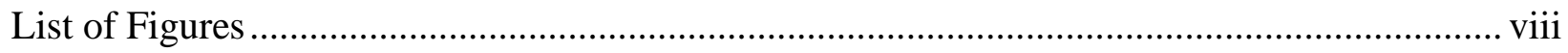

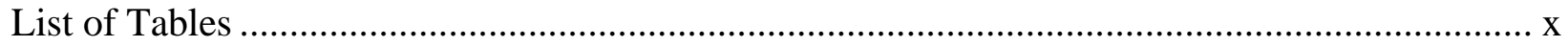

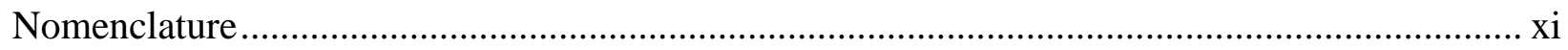

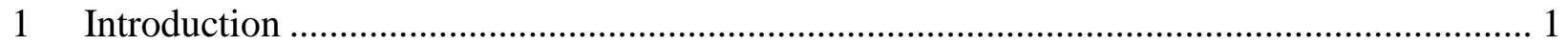

1.1 Fossil fuel usage and need for energy efficiency measures ...................................... 4

1.1.1 Energy efficiency significance .......................................................................... 4

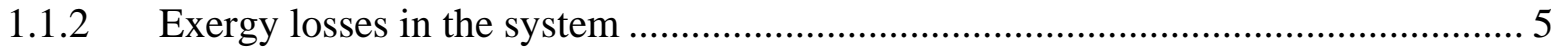

1.1.3 Shale gas vs. conventional fuels in energy-efficient systems ............................. 6

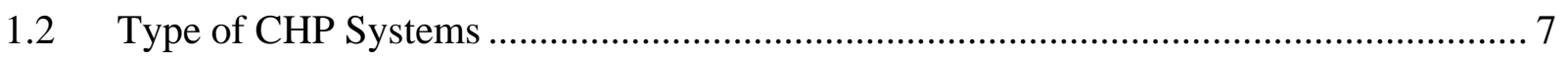

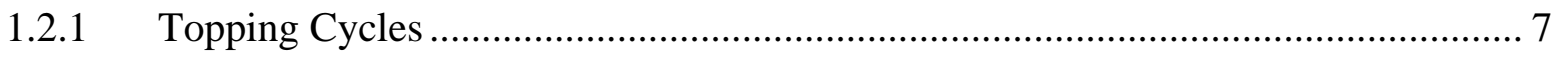

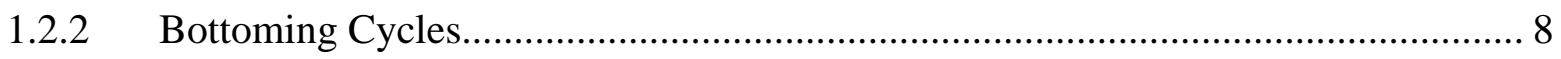

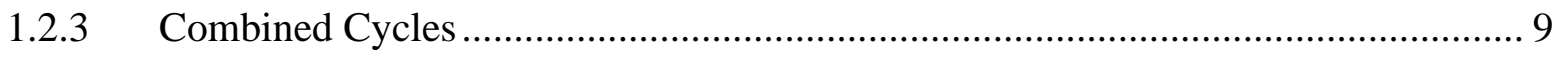

1.3 Discussion on topping and bottoming cycles .................................................... 10

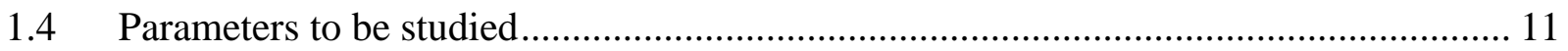

1.4.1 Boiler Parameters .......................................................................................... 12

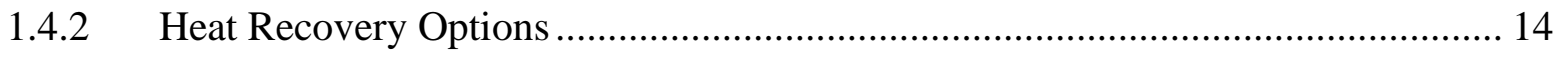

1.2.3 Process Support Equipment ................................................................. 16

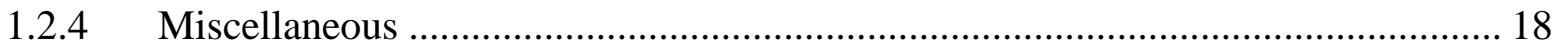

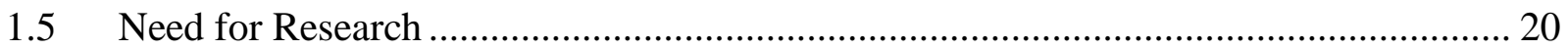

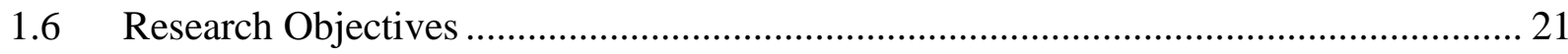

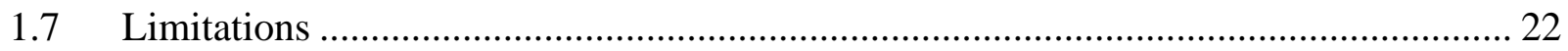

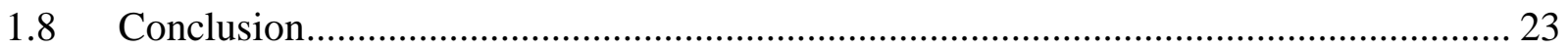

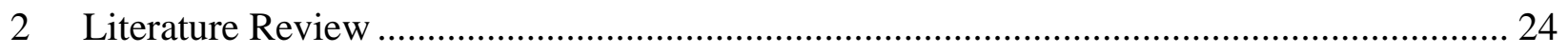


2.1 Applications and workings of CHP systems ............................................................... 24

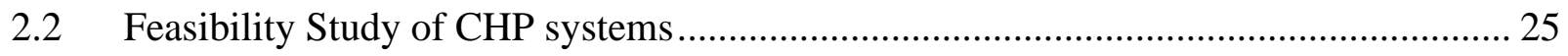

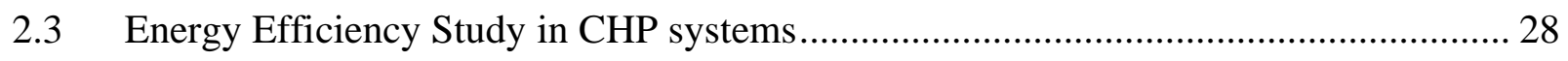

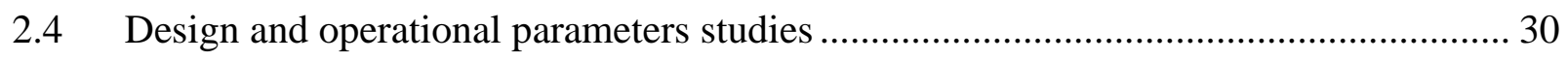

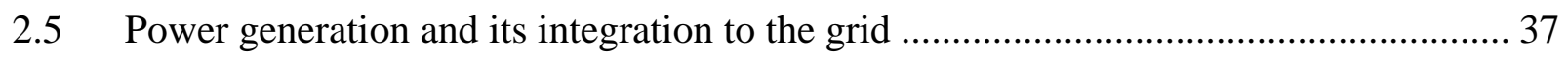

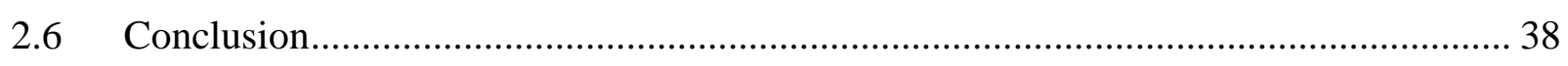

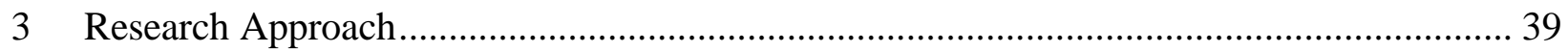

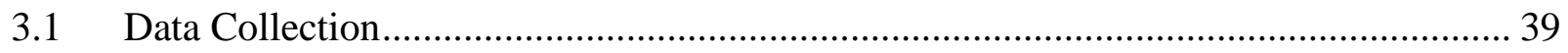

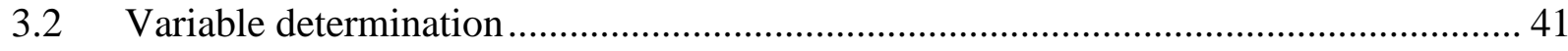

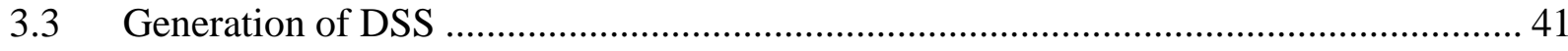

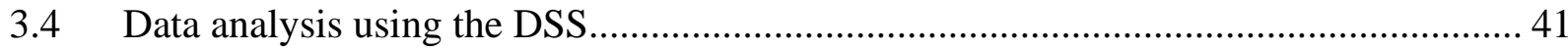

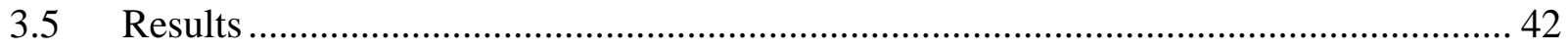

3.5.1 Block diagram of the CHP system..................................................................... 42

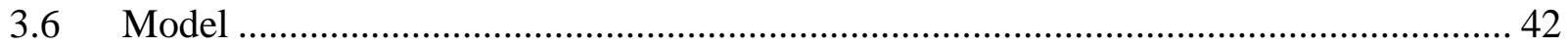

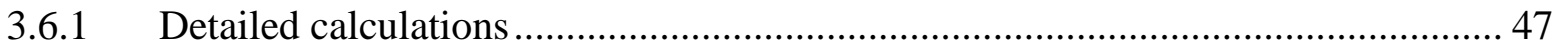

3.6.2 Savings and payback on investment ……………….............................................. 47

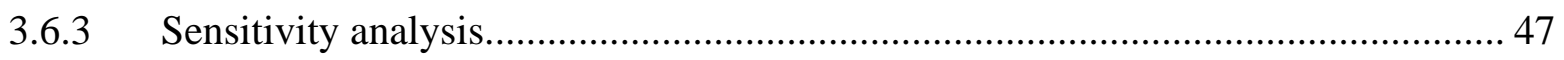

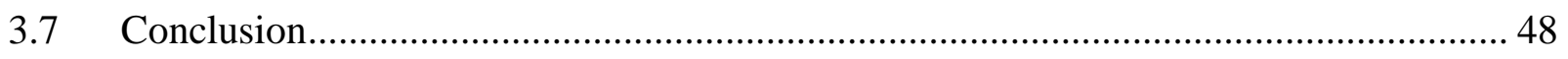

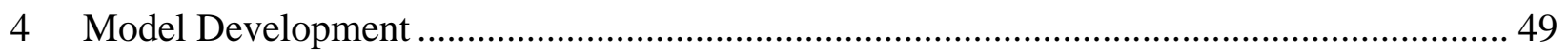

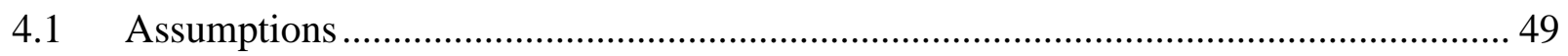

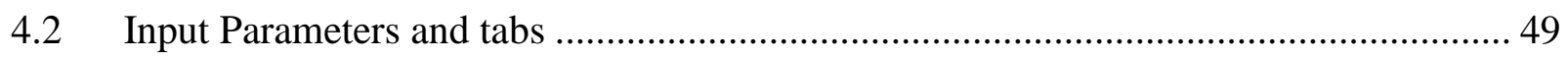

4.2.1 Boiler-based CHP system ............................................................................ 51

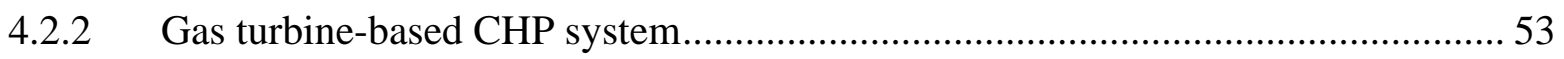

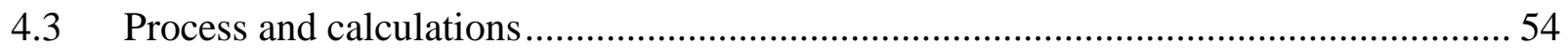

4.3.1 Boiler-based CHP system ……………………….............................................. 54

4.3.2 Gas-turbine based CHP system........................................................................ 58

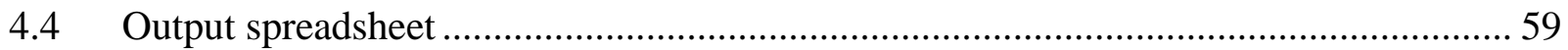

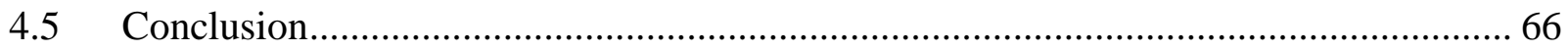

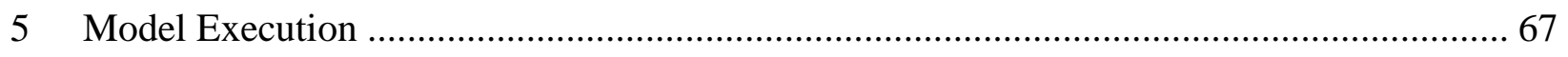

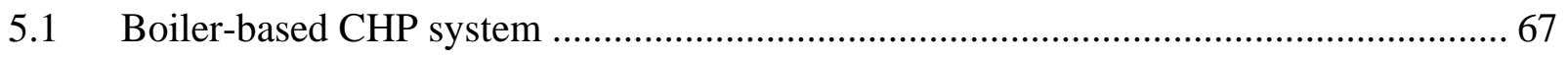




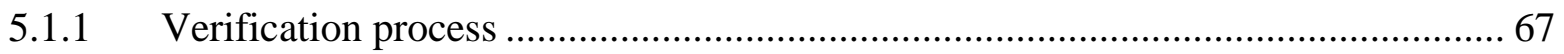

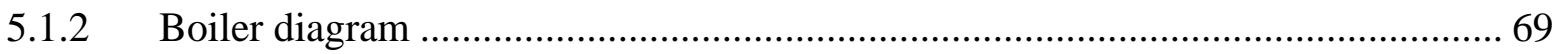

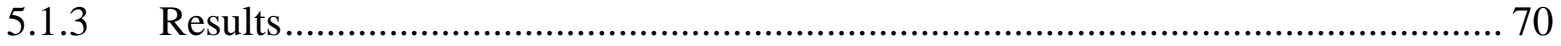

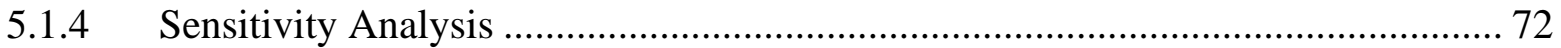

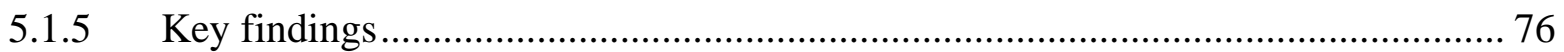

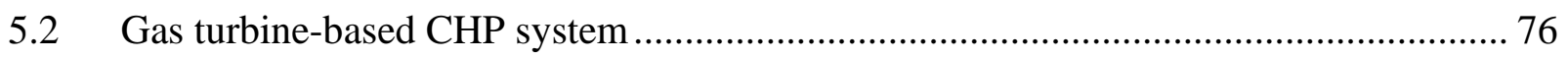

5.2.1 Verification process and block diagram ...................................................... 76

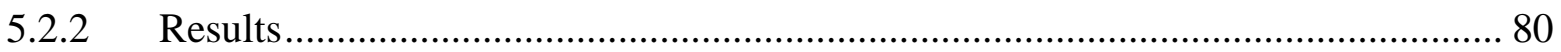

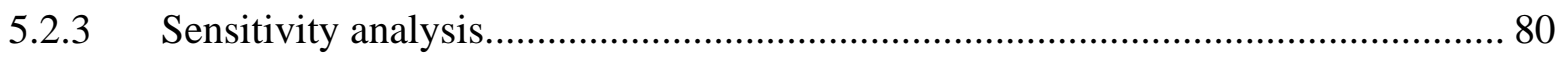

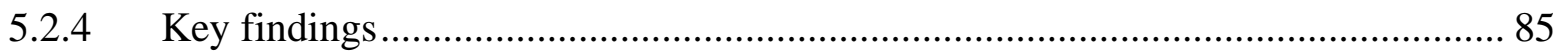

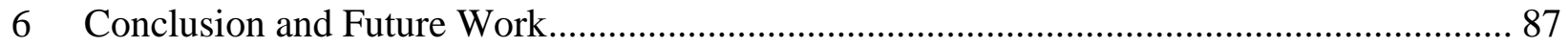

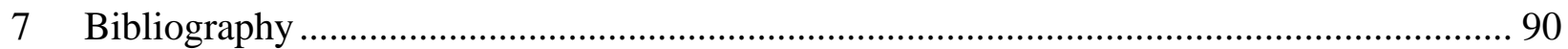




\section{List of Figures}

Figure 1-1: CHP as a Percentage of National Generating Capacity [3] ..................................... 3

Figure 1-2: Thermodynamic cycles arranged according to their stack temperature range [10] ... 10

Figure 1-3: Energy consumption breakdown in the United States, 2018 [24]......................... 20

Figure 2-1: Commercial Businesses with Topping Cycle CHP Systems, 2014 [46] .................. 35

Figure 2-2: Commercial Business Prime Mover in CHP Systems, 2014 [46] .......................... 35

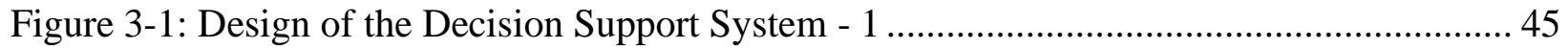

Figure 3-2: Design of the Decision Support System - 2 …................................................... 46

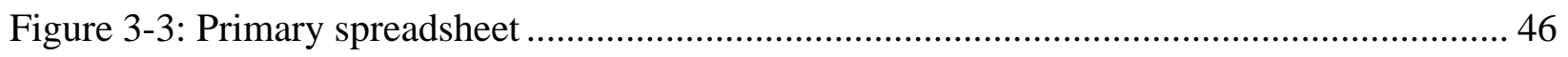

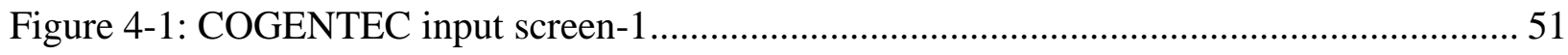

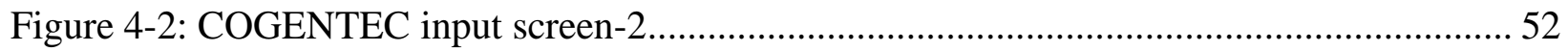

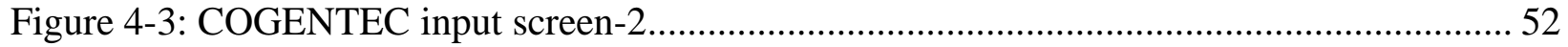

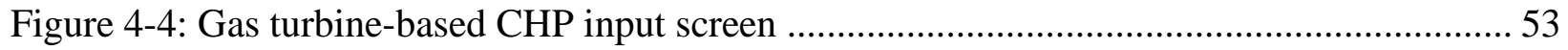

Figure 4-5: Computation of boiler-based CHP parameters-1 …........................................... 54

Figure 4-6: Computation of boiler-based CHP parameters-2 …......................................... 55

Figure 4-7: Computation of boiler-based CHP parameters-3 …......................................... 57

Figure 4-8: Computation of gas turbine-based CHP parameters-1 ........................................ 58

Figure 4-9: Computation of gas turbine-based CHP parameters-2 .......................................... 58

Figure 4-10: Buttons to move between spreadsheets ........................................................ 59

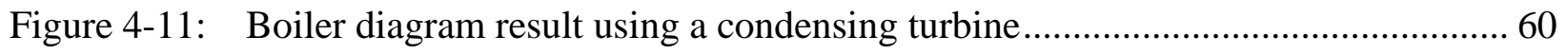

Figure 4-12: Payback on investment result and sensitivity analysis graphs ........................... 62

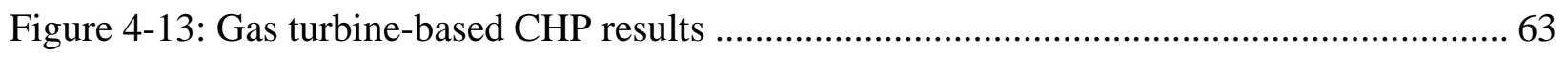

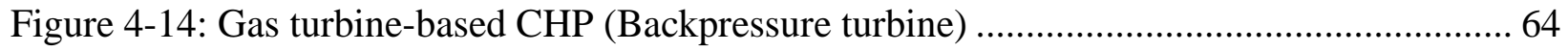

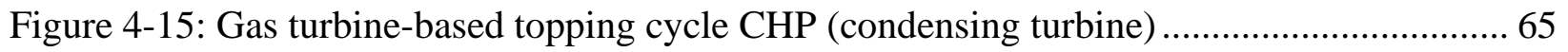

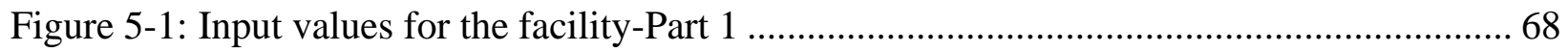

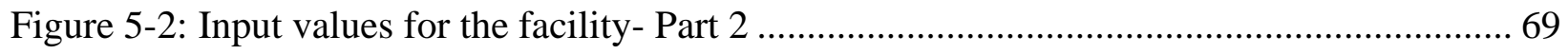

Figure 5-3: Results for the boiler-based CHP cycle ....................................................... 70

Figure 5-4: Boiler diagram using a condensing turbine................................................. 71

Figure 5-5: Pinch analysis between input and output parameters - Part 1 ............................... 72

Figure 5-6: Pinch analysis between input and output parameters - Part 2 .............................. 73

Figure 5-7: Sensitivity analysis on payback on investment period to NG and electricity usage cost 75 
Figure 5-8: Pinch analysis between the payback on investment period, natural gas cost and

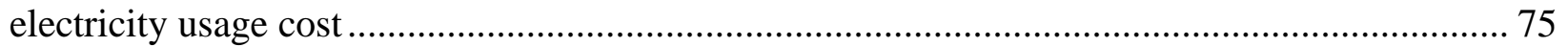

Figure 5-9: Input values with the UMass Amherst Case study [55].......................................... 77

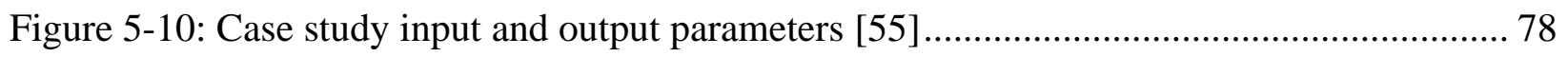

Figure 5-11: Gas-turbine based CHP system output............................................................... 79

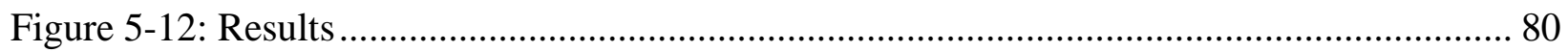

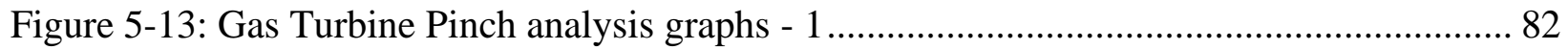

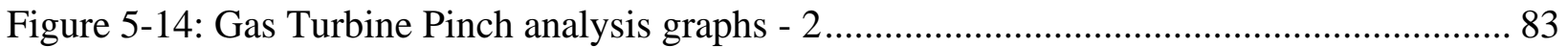

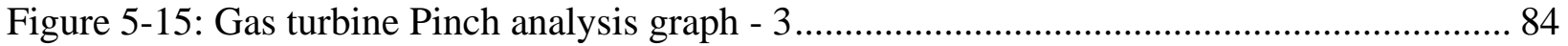

Figure 5-16: Impact of varying electricity and natural gas cost on payback on investment ........ 85 


\section{List of Tables}

Table 1-1: CHP Capacity by state (2012) [3] ........................................................................ 2

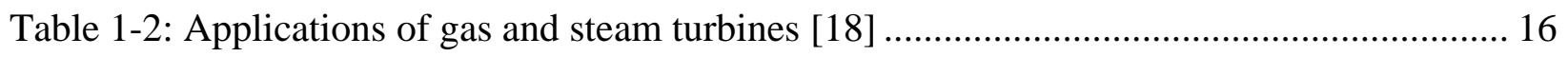

Table 3-1: Quantitative values of the parameters ............................................................. 40

Table 5-1: Key findings for the Boiler-based CHP system .................................................... 76

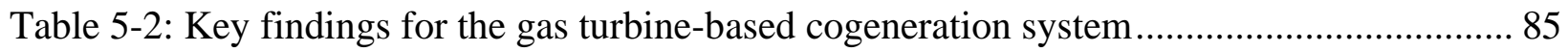




\section{Nomenclature}

\begin{tabular}{|c|c|}
\hline $\mathrm{CHP}$ & Combined Heat and Power \\
\hline COGENTEC & Cogeneration Topping Cycle Evaluation \\
\hline MW & Megawatt \\
\hline $\mathrm{kW}$ & Kilowatt \\
\hline $\mathrm{CO}_{2}$ & Carbon dioxide \\
\hline HVAC & Heating, Ventilation, and Air Conditioning \\
\hline $\mathrm{SRC}$ & Steam Rankine Cycle \\
\hline ORC & Organic Rankine Cycle \\
\hline MMBtu & Metric Million British Thermal Unit \\
\hline DSS & Decision Support System \\
\hline PRV & Pressure Reducing Valve \\
\hline B.P. & Backpressure Turbine \\
\hline DSIRE & Database of State Incentives for Renewables and Efficiency ${ }^{R}$ \\
\hline HRSG & Heat Recovery Steam Generator \\
\hline EPA & Environmental Protection Agency \\
\hline $\mathrm{kWh}$ & Kilowatt-hour \\
\hline MWh & Megawatt-hour \\
\hline PP & Pinch Point \\
\hline AP & Approach Point \\
\hline $\mathrm{dT}$ & Difference in Temperature \\
\hline SSMT & Steam System Modeler Tool \\
\hline TWh & Terawatt-hour \\
\hline PLC & Programmable Logic Controller \\
\hline EA & Excess air \% \\
\hline SR & Stoichiometric Ratio \\
\hline $\mathrm{Cp}_{\mathrm{g}}$ & Specific heat capacity of combustion gas \\
\hline PA & Pre-heated combustion air \\
\hline LHV & Lower heating value of fuel \\
\hline $\mathrm{HHV}$ & Higher heating value of fuel \\
\hline BS & Boiler savings with burner controls \\
\hline
\end{tabular}


TR

$\mathrm{h}_{\mathrm{s}}$

$\mathrm{h}_{\text {prv }}$

$\mathrm{h}_{\mathrm{mw}}$
Initial temperature rise during combustion

Specific enthalpy of inlet steam

Specific enthalpy of PRV outlet steam

Specific enthalpy of makeup water 


\section{Introduction}

Cogeneration (Combined Heat and Power, CHP) is the concurrent generation of mechanical power (electrical energy) and useful thermal energy from process heating systems such as furnaces, heaters, and kilns. It is prevalently used to retrieve the lost thermal energy, in the form of stack gases or steam, from those processes to generate electricity, thereby reducing the total energy usage (fuel consumption and electrical energy) and emissions of greenhouse gases. It delivers fuel and electrical energy services to industries in a single energy-efficient step. A typical CHP system consists of on-site electrical generators, prime movers, and fossil fuel-fired equipment (boilers/gas turbines). The exhaust from these machines is distributed, thereby producing energy, increasing efficiency, reliability and simultaneously reducing losses on the system. Reliability is reasonably increased by installing these systems as they increase the facility's resiliency by mitigating the adverse effects on the facility without affecting its runtime during power outages. The reliability and significantly higher efficiency as compared to the conventional generation of heat and power make CHP systems lucrative in industries and residential areas.

Properly designed CHP systems offer efficiencies greater than most other sources, including steam turbines. Similarly, CHP systems have higher efficiency and lower electricity and heat cost. They can often achieve total system efficiencies of $60 \%-80 \%$ compared to only about $45 \%-50 \%$ for conventional separate heat and power generation (total system efficiency is the sum of power and useful thermal energy divided by the fuel consumption to generate both energy services) by avoiding losses and capturing heat energy typically wasted in power generation to provide heating and cooling [1]. The most prevalent method of electricity generation conventional power plants that use fossil fuels for combustion. However, this system can also be operated by the utilization of renewable fuels such as biomass as the main source of fuel. Adequate availability of energy is significant for the economic development of a nation. Abuelnuor et al. [2] state that $80 \%$ of the electricity in the world is generated by thermal and natural gas power plants. Going forward with this scenario and existing energy policies around the world, this number is unlikely to decelerate. This can be attributed to the higher unit cost of renewable energy resources than that of

conventional energy resources. However, in recent years, renewable energy sources, CHP, waste 
heat recovery, and combined cycle power generation are emerging with positive impacts. An increase in methods of combined heat and power generation has brought forward numerous parameters that aid in the higher efficiency of the process. Therefore, discovering optimal working conditions based on different parameters can be a novel approach to achieve higher efficiencies in these plants. These analyses would pave the path for better plant efficiency, energy savings, economic benefits, and greenhouse gas emission reduction. However, manipulation of the parameters should not be done sporadically as the economic aspects of CHP plants are relatively more sensitive to change in input parameters than that of classical power plants.

Table 1-1: CHP Capacity by state (2012) [3]

\begin{tabular}{|c|c|}
\hline CHP Capacity & States in the U.S. \\
\hline \multirow{2}{*}{$2,000 \mathrm{MW}$} & $\begin{array}{c}\text { Alabama, California, Florida, Indiana, } \\
\text { Louisiana, Michigan, New Jersey, New York, } \\
\text { Oregon, Pennsylvania, Texas }\end{array}$ \\
\hline \multirow{2}{*}{$1,000-1,999 \mathrm{MW}$} & $\begin{array}{c}\text { Georgia, Illinois, Massachusetts, North } \\
\text { Carolina, South Carolina, Virginia, } \\
\text { Washington, Wisconsin }\end{array}$ \\
& $\begin{array}{c}\text { Arkansas, Colorado, Connecticut, Iowa, } \\
\text { Maine, Maryland, Minnesota, Mississippi, } \\
\text { Ohio, Oklahoma, Tennessee }\end{array}$ \\
\hline $100-999 \mathrm{MW}$ & $\begin{array}{c}\text { Arizona, Idaho, Kansas, Kentucky, Missouri, } \\
\text { Montana, Nebraska, Nevada, New Mexico, } \\
\text { Utah, West Virginia, Wyoming }\end{array}$ \\
\hline$<100 \mathrm{MW}$ & Alaska, New Hampshire, Hawaii, North \\
& Dakota, Rhode Island, South Dakota, \\
& Vermont \\
\hline
\end{tabular}

While CHP is a relatively older technology, its usage in the United States is minimal. On the other hand, European countries (Denmark, Finland, and Russia) are the global leaders in the implementation of CHP systems [4], [5]. They have performed excellent work in cutting back fossil fuel usage by notably increasing the culture of these systems in industries, government 
offices, and residential areas. They are performing exceptionally well in generating renewable energy resources from wind, water, and CHP, thereby bringing the country closer to their mission of zero-carbon emissions. A recent decline in wind energy and sea-water level in Denmark made the CHP system more popular, resulting in the Danish government turn more aggressive in embracing the CHP culture. Denmark uses bioenergy such as wood, straws, and other biodegradable waste products instead of coal and natural gas to generate heat and power. This novel solution decreases the usage of fossil fuels by a huge margin. Similarly, Italy also has a tremendous amount of power generation from CHP systems. However, their power generation is still attributed to the usage of natural gas. The industries are provided with lucrative incentives to invest and implement in CHP plants. This is a major obstacle in the United States. Many industries have huge potential to install CHP systems, which would generate more power than they use. However, the incentives and the price of electricity per unit are not sustainable if it is sent back to the grid, due to which industries are hesitant to implement it.

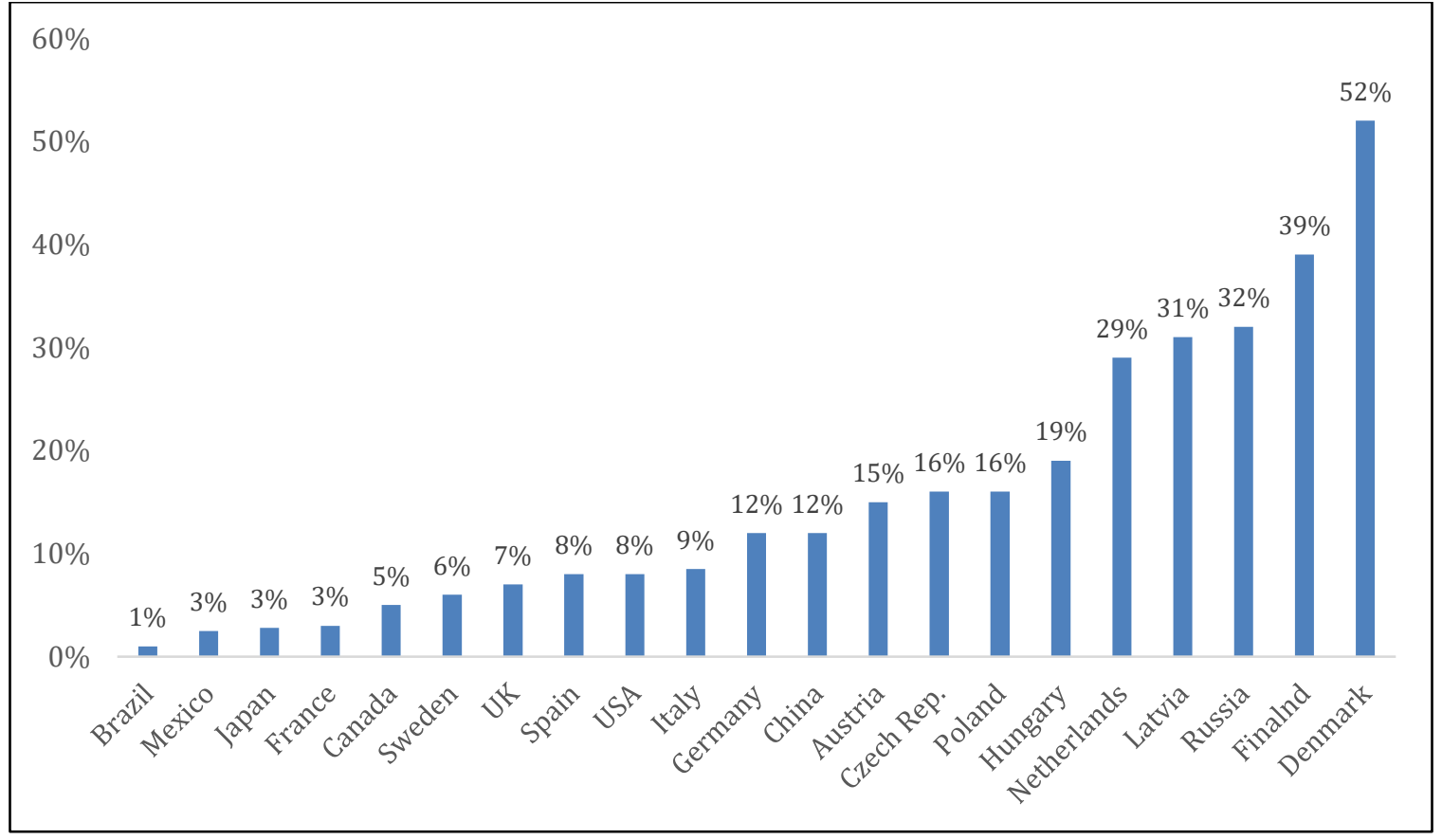

Figure 1-1: CHP as a Percentage of National Generating Capacity [3] 


\subsection{Fossil fuel usage and need for energy efficiency measures}

\subsubsection{Energy efficiency significance}

Most industrial and thermal power plants are highly energy-intensive. They use natural gas, coal, and fuel oils to operate their manufacturing processes. Similarly, power plants solely generate electricity by burning coal and natural gas in the presence of air as the primary fuel, thereby producing combustion gas to operate gas turbines. Gas turbines are connected to power generators that generate electricity by utilizing the mechanical energy produced by the turbines in the generators. However, in order to produce the required amount of electrical energy, a tremendous amount of energy must be supplied in the form of natural gas and coal. The usage of these forms of energy sources depletes the contents in the energy reservoirs accumulated on the planet during the span of millions of years. Similarly, the combustion of these fossil fuels aggravates the negative impact of greenhouse gases in the atmosphere by increasing it astronomically by greenhouse gases. It is identical in different industrial plants that specialize in the manufacturing of fiberglass, water and wastewater, metal fabrication, pulp and paper, and chemicals. These industries use fossil fuels directly as well as energy in the form of electricity. Irrespective of the method of energy consumption, it is evident that industries require a large amount of energy to operate.

The high usage of fossil fuels has adverse effects on the environment and the entire planet. The first negative effect is the depletion of energy resources that were formed meticulously in the span of millions of years. The human civilization has no method to mass-produce fossil fuels that can satisfy the needs of the planet. Shafiee et al. [6] derived a new formula using the Klass decision support system and estimated that the worldwide reservoir for oil, coal, and gas will be extinguished in approximately 35, 107, and 37 years respectively. The urgency of this depletion should not be neglected. Similarly, the second effect of a high amount of fossil fuel usage is the greenhouse gases that are produced due to their combustion. Fossil fuels produce a large amount of $\mathrm{CO}_{2}$ that is trapped in the atmosphere, thereby increasing the global temperature, leading to climate change. Moreover, the usage of fossil fuels contributes to water pollution and land degradation. Coal runoff, oil leaks, and fracking lead to pollution of water resources such as rivers, lakes, and oceans. Finally, mining and oil extraction involve large masses of lands in the form of extraction, transportation, and distribution. The extraction, transportation, and usage of fossil fuels 
have detrimental effects on all living beings on the planet. Therefore, it is of utmost importance to embrace clean energy with immediate effect, to decelerate climate change. One of the major ways of lessening the usage of fossil fuel for industries and power plants is to implement CHP systems. These systems can be used to produce onsite electricity and offset electrical and thermal energy usage and cost in the respective plants. Moreover, the industrial plants can also sell excess electrical energy back to the power grid, thereby reducing the load on the thermal power plants eventually.

\subsubsection{Exergy losses in the system}

Similarly, exergy losses should be accounted for in CHP plants to increase the overall efficiency. Exergy losses in a CHP system can be defined as the amount of reversible work that can be obtained at a maximum rate to achieve the system's equilibrium to that of the environment. The exergy analysis profusely includes the second law of thermodynamics, where a maximum entropy is achieved. In an irreversible process, decreasing exergy losses amount to an increase in the overall efficiency, thereby decreasing the amount of fossil fuel consumption and greenhouse gas emissions. The exergy losses can occur mostly in the heat exchangers, combustion chambers of a gas turbine system and boilers, and waste heat. These losses can be mitigated to achieve higher energy and cost savings in the facility. Similarly, the exergy production cost is an important factor that should be analyzed by the facilities in their processes. The exergy cost of steam, waste heat, and electricity should be considered and mitigated individually to minimize the cost of the operation of a CHP system. The second law of thermodynamics formula calculates the exergy losses in the system, that can be quantified and ranked among other exergy losses. The highest exergy losses in the system components should be dealt with first, followed by the remaining losses. By following these sequences of operations, exergy losses can be acknowledged and decreased in a CHP power plant. The research does not advertently address the exergy losses in the system; however, CHP plants have to include mitigation of exergy losses in system components such as boiler and gas turbine combustion chambers, heat exchangers, compressors and boiler walls to achieve higher power and minimal losses in the system. 


\subsubsection{Shale gas vs. conventional fuels in energy-efficient systems}

The discovery of adequate shale gas in the United States has made it simpler and effective to procure it for industrial, commercial, and residential usages [7]. Shale gas is a form of natural gas found within the shale formations. The impact of shale gas in the industrial sector has been tremendous, and the trend of this usage has rapidly spread throughout the world. One of the major advantages of shale gas is that it produces lesser $\mathrm{CO}_{2}$ than that of coal and oils. The marginal cost of shale gas in the United States is approximately \$4/MMBtu at the current time. Similarly, shale gas has been used instead of coals due to the amendments in the Clean Air Act, which is a sign of what is to come in terms of fuel consumption [7]. People constantly move to cheaper and better sources, which is why the shale gas boom is prevalent in this century. Researchers concur that due to the abundance availability of shale gas, it will be readily available for a cheap price in the long run. With such innovations, shale gas can be used as the fuel in CHP systems to get better energy savings at a reduced cost, while also acquiring energy efficiency incentives from the federal and state governments.

CHP systems have a great potential to offset the energy usage and cost in industrial and power plants. Steam can be generated by directly using fuel or by utilizing waste heat from the stack to generate steam. The process where steam is generated by utilizing fuel for combustion is called a topping cycle CHP. Similarly, the process where the steam is generated by utilizing the heat content in the boiler/furnace stack to generate steam and use a steam turbine to generate electricity is called a bottoming cycle CHP. Topping cycle requires additional fuel whereas the bottoming cycle does not require additional fuel to operate. Similarly, the topping cycle and bottoming cycle can be operated simultaneously to achieve higher efficiencies and yields, resulting in a combined cycle CHP system. In a typical industrial setting where boilers and furnaces are used for process heating, topping cycle is an ideal solution for offsetting energy costs. The plants can generate electricity and heat that can be used to offset their electricity usage cost and natural gas cost by utilizing the substitute heat generated from the cycle. Industrial plants that do not operate their boilers/furnaces at full load are a perfect candidate to embrace the topping cycle CHP for energy cost reduction. Similarly, thermal power plants are also applicable to the topping cycle CHP. The processes in thermal power plants generate flue gases with high-grade heat content. These flue 
gases can be used in gas turbines to generate electricity, and the medium grade heat exiting out of the gas turbines can be used to generate steam for power and heat generation.

CHP systems can increase the efficiency of fuel use: the combined production of electricity and heat, is apparently, more efficient than that of a separate production. These qualities are wellknown, but there has been difficulty in assessing the efficiency of combined heat and power since the inception of this technology in the past. However, in recent times, implementing combined heat and power in the industries to increase the plant overall efficiency is becoming easier and common. Wang et al. [8] enhanced different CHP plants' performance implemented in the cement industry to recover the available waste heat. The authors reviewed several industrial facilities, identifying the most appropriate CHP technology for each of them according to the facility size. For the topping cycle, CHP systems can satisfy the electric demand at full load. In these configurations, however, the heat demand might not be fully satisfied, and an auxiliary boiler might be needed to satisfy the remaining thermal load. This mode of operation is bound to make the plant self-sufficient in terms of electric loads, avoiding energy exchanges with the grid. CHP can be implemented using three different cycles (i) topping cycle, (ii) bottoming cycle, and (iii) combined cycles. In this section, the main goal is to study the workings and principles of the respective cycles.

\subsection{Type of CHP Systems}

\subsubsection{Topping Cycles}

U.S. DOE's Office of Efficiency and Renewable Energy (EERE) defines the topping cycle as "an approach where fuel is used first to generate electricity or mechanical power in a "prime mover" such as a gas turbine or reciprocating energy. Exhaust energy is captured and used for a secondary purpose, such as heating or cooling the facility [9].” As, the amount of heat required in a facility is proportional to the amount of fuel used, topping CHP systems are generally designed to satisfy a baseload thermal demand of a facility. The topping cycle is the most prevalent form of CHP, barring some industries where high-grade heat is required. Steam produced by the boilers is at the required pressure and temperature for the process. Therefore, if the boiler is operating at full load producing steam for the processes only, the topping cycle cannot be implemented. However, if the boiler is working at a partial-load, then it can be pushed to work at full-load, and the excess steam 
generated can be expanded in a steam turbine coupled to a generator to generate electricity. Similarly, the rejected heat from the boiler can also be used for manufacturing processes, domestic heating, and absorption chilling. As the efficiency of the system increases with CHP, there are higher fuel savings than that of separate thermodynamic cycles.

The topping cycle typically includes gas turbines or a steam boiler as the primary energy generating equipment. Gas turbines are an excellent candidate for a topping cycle CHP as they generate a significant amount of electricity as compared to the fuel energy provided to run the system. Similarly, steam boilers in a topping cycle CHP system generate steam and then, the electricity. The outlet steam from the steam turbine is used for heating and cooling the facility through HVAC systems and absorption chillers. This research studies the effects of various topping cycle parameters on the technical and economic aspects of implementing a topping cycle CHP system with a boiler or a gas turbine.

\subsubsection{Bottoming Cycles}

U.S. DOE's Office of Energy Efficiency and Renewable Energy (EERE) defines bottoming cycle as "an approach where the fuel is used to provide thermal input to a furnace or other hightemperature industrial processes, and a portion of the rejected heat is then recovered and used for power production, typically in a waste heat boiler/steam turbine system [9]." Waste heat from furnaces and other industrial processes can be classified as a high, moderate, and low grade in terms of the temperature range. However, only $25 \%$ to $30 \%$ of the input fuel energy is eventually converted to usable power, where the remaining energy is dispersed to the environment as waste heat. It is estimated that a substantial amount of energy can be recovered from waste heat in the industries and residential areas and utilized to produce additional heat and power. Prevalently, bottoming cycles are carried out using the Steam Rankine cycle (SRC), Organic Rankine Cycle (ORC), and Kalina cycle [10]. SRC uses waste heat to generate steam, which subsequently expands through a turbine, generating power. It can be operated to generate power in the range of 10-1,000 MW with maximum efficiency at the level of $47 \%$. Waste heat temperature of $1,800^{\circ} \mathrm{F}$ is optimal to achieve higher efficiency [10]. Korobitsyn, however, states that the performance of SRC decreases drastically with the reduction in waste heat temperature. In the Steam Rankine 
Bottoming cycle, electrical efficiencies of up to $58 \%$ can be achieved with the plant capacities within the range of 350 to $500 \mathrm{MW}$ of electrical power [11].

Industries and facilities that have medium and lower grade waste heat are suited for ORC and Kalina cycles as they have lower boiling points than that of steam at the same pressure. ORC operates on the same principle as SRC but uses pure, high-pressure organic fluids as well as organic mixtures that have a lower environmental impact. The working fluids in ORC have been recorded to have boiling points as low as $164^{\circ} \mathrm{F}$ [12]. ORC with biomass burner for combustion and thermal oil as the working fluid to achieve an overall efficiency of $88 \%$. However, more work must be done to increase the electrical efficiency of CHP which is limited (18\%) due to loss of residual heat. The major drawback of SRC and ORC is its constant temperature of vaporization. Kalina [13] proposed a novel cycle to substitute steam in an SRC, where a mixture of working fluids of varying concentration is used to account for the temperature of the hot and cold flows of the medium. In most Kalina cycles, a mixture of ammonia and water is used. At different points in the cycle, the fluid composition in the mixture changes as ammonia vaporizes first, thereby decreasing its concentration which results in the boiling temperature increment of the mixture. Therefore, the temperature differences between the waste heat and the working fluid result in efficiency rise in bottoming cycles.

\subsubsection{Combined Cycles}

Combined cycles corroborate a high-temperature topping cycle and low- or medium-temperature bottoming cycles. Different cycles such as Otto cycle, joule cycle, and high-temperature fuel cells operate at high temperatures but generate a lot of waste heat. Combining two cycles increases the overall efficiency as the heat rejected by one cycle can be utilized by the other cycle that operates in medium-grade temperature. Korobitsyn [10] ranked the most common cycles according to their working temperature range, as shown in Fig. 1-2. 


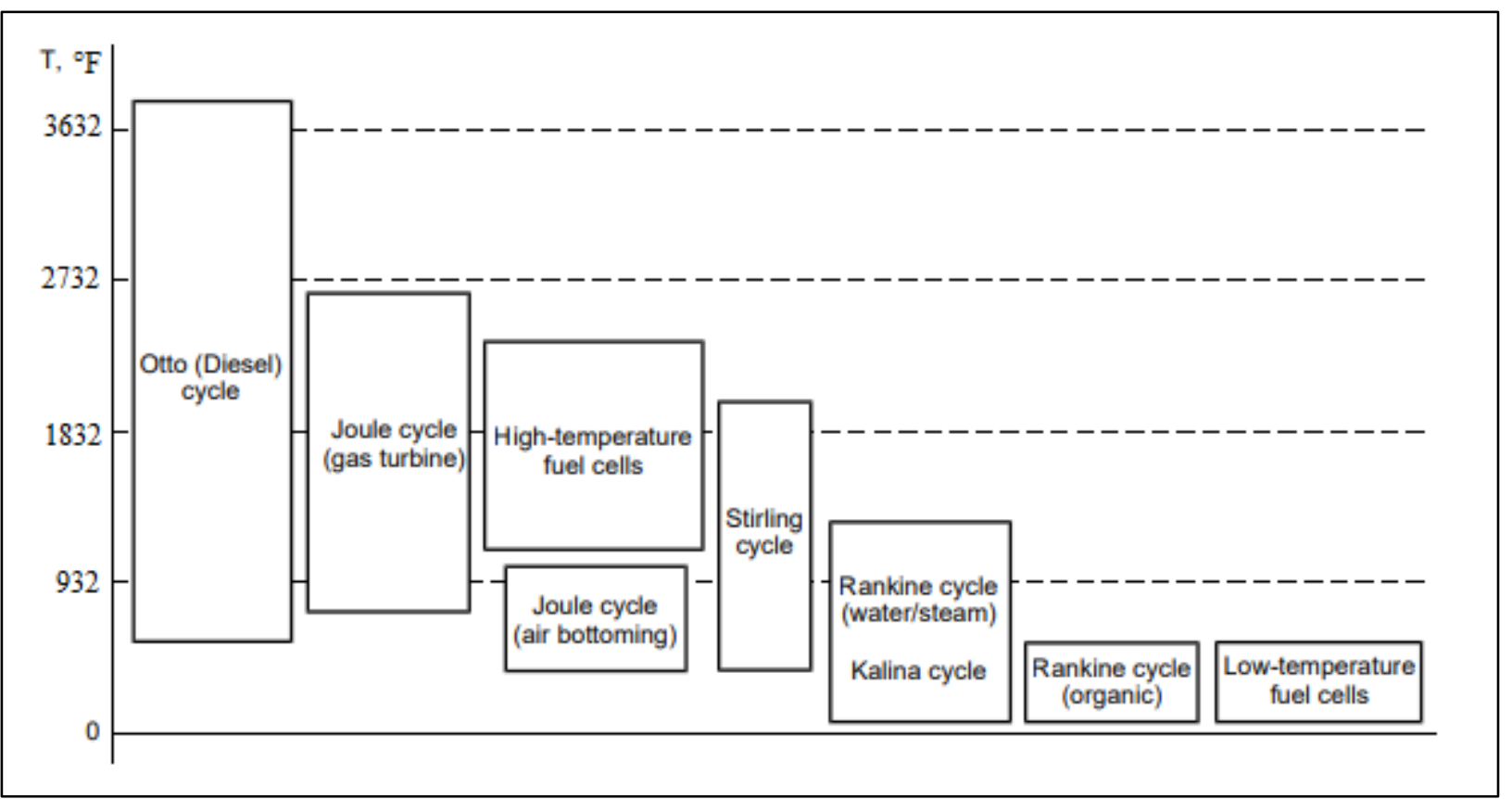

Figure 1-2: Thermodynamic cycles arranged according to their stack temperature range [10]

\subsection{Discussion on topping and bottoming cycles}

Topping and bottoming cycles have distinct differences. Topping cycles use primary fuel to generate steam and hence electricity whereas bottoming cycles use the exhaust from the fuel using equipment to generate steam and electricity. The main reason to implement one of these cycles is solely based on the working conditions of a facility. A facility whose processes require high-grade steam to operate is a prime candidate for a bottoming cycle. Bottoming cycle utilizes high-grade waste heat from industrial processes to generate steam at various pressure, which in turn generates electricity and heat. It does not require additional primary fuel in the furnace if the waste heat is maintained at the same temperature and mass flow rate. This property makes the bottoming cycle popular in industries as this cycle re-uses energy from a source that is supposedly transmitted out of the facility otherwise. However, topping cycle CHP is only possible when additional fuel is provided to the burner to produce excess steam. This cycle does not require an additional waste heat recovery boiler, as the primary furnace is used to produce steam. The topping cycle can be implemented by any facility which does not run its boilers at full load. If a boiler is working at full load and the process uses all the generated steam, then a topping cycle CHP cannot be implemented. Therefore, the main parameters required for a bottoming cycle and a topping cycle 
are the temperatures of the waste heat and the possibility of high enthalpy excess steam generation respectively. The intended purpose of these processes is the same; however, the processes are fundamentally different.

Another difference between these two cycles is that the topping cycle primarily focuses on the electrical power generation whereas the bottoming cycle prioritizes heat generation. This is further evident by the fact that bottoming cycles require high-grade heat to operate. Bottoming cycles can be of tremendous help in energy-intensive industries such as paper, refining, iron, and steel industries. From an economic standpoint, the topping cycle offers better effects in terms of energy savings. The enthalpy of steam can be changed as per the requirement of the cycle to increase the energy transfer between the steam and the steam turbines, thereby resulting in higher overall efficiency. In the bottoming cycle, the temperature of waste heat is not a parameter that can be suitably changed without interfering with the manufacturing process. Therefore, we will be at the mercy of the manufacturing process parameters in the bottoming cycle.

Topping cycle is a better alternative for a large proportion of industries that produce medium grade heat for their processes. Lower pressure and temperature of steam are easier to handle without doing a significant revamp on the process. Moreover, the number of industries that produce medium grade heat is considerably greater than that of the industries that produce high-grade heat. Therefore, the application of the topping cycle is very significant in energy savings and greenhouse gas emissions reduction. As a result, analysis of various operational parameters in the topping cycle CHP system for attaining favorable economics is studied in this research.

\subsection{Parameters to be studied}

CHP topping cycles can generate a wide range of power and heat based on the process and equipment parameters. The parameters can range from the type of equipment such as turbines and boilers to changes in weather. The study focuses on various parameters that aid the enhancement of a CHP topping cycle. The parameters studied in this study are described below in brief. 


\subsubsection{Boiler Parameters}

A traditional boiler is used to generate steam at required pressure and temperature by burning fuel such as natural gas, coal, and fuel oil. Topping cycle requires a boiler that can generate excess steam other than the required processes. The quality of steam can vary with the nature of the fuel used, controls on the burners, and different supplementary options on the boiler such as heat recovery, condensate return, and pre-heat using economizers. The nature of the boiler parameters that can be manipulated to obtain the necessary quality and quantity of steam is described in brief below.

\section{(a) Boiler Capacity}

The capacity of a boiler is typically defined as the amount of steam (in lbs.) produced by the boiler in an hour. Likewise, the boiler capacity, in some cases, can also be categorized as the amount of heat transferred from the fuel to the water (in MMBtu per hour). The size of a boiler is directly proportional to the amount of heat and power that can be recovered. In most facilities, the boilers are oversized to provide a substantial margin of capacity. It works competently in different industries; however, the efficiency is lower as most boilers used in typical facilities are conventional boilers. Higher capacity boilers can be pushed to full-load conditions to produce larger quantities of steam, thereby increasing the power generation to satisfy the plant's electrical demand and sell the remaining power back to the electricity grid. Boilers with different capacities can be set in the decision support system (DSS) produced from this study to determine the favorability of a topping cycle system in CHP plants.

\section{(b) Boiler efficiencies}

Boiler efficiencies are generally categorized into combustion efficiency and thermal efficiency. Thermal efficiency is the ratio of steam generated by the boiler to the fuel input. Similarly, combustion efficiency is the measure of the effectiveness of the transfer of heat content of the fuel into usable heat. The efficiencies of the boiler system in CHP systems can largely affect the heat and power generation. The rated input and output capacity differ because of combustion efficiency. Lower efficiencies would create a higher gap between the input and output capacity and vice versa. Therefore, the combustion efficiency of a boiler is a significant parameter for the amount of steam generation. It is largely dependent on steam energy, various losses in the boiler system, and the 
energy in input fuel. Combustion efficiency, for the most part, is steady. To improve it, the system must go significant changes and maintenance in the furnace and reduce the loss in flue gases. However, thermal efficiency depends only upon the energy in fuel and steam. It is also the ratio of output and input boiler capacity. Thermal efficiency accounts for the heat loss through the boiler jacket during boiler firing while combustion efficiency does not. The study includes the analysis of the topping cycle CHP in different combustion and thermal efficiencies.

\section{(c) System losses}

The boiler system has various losses that decrease its combustion and thermal efficiencies. Mainly, the losses are the stack losses and surface heat losses. These losses typically represent about $20 \%$ of the fuel input to the boiler [14]. The stack losses can be of significant importance in the CHP topping cycle because they can be used to preheat combustion air and boiler feed water using a heat exchanger and economizer respectively. The various temperatures of stack losses are used in this study to discern the efficiency of the CHP systems. Similarly, boiler losses are mainly comprised of surface losses such as radiation and convection. A reduction of surface losses through convection and radiation can reduce the fuel input, and consequently, increase the overall efficiency. Energy loss in stack gas is not considered as part of the boiler losses. They are independent of the amount and nature of fuel-fired in the boiler, but rather depend upon the size and piping surface area of the boiler system. Boiler losses are estimated to be around 1\%-3\% of total fuel energy [15]. Similarly, percentage loss in the process steam is the embodiment of energy losses due to steam traps, steal leaks, and inadequate surface insulation. This is typical to an individual facility; therefore, an effect of the percentage of loss in process steam is an important parameter to determine the CHP properties.

\section{(d) Burner controls and operation}

Burner controls in the boiler can significantly increase energy and cost savings. Parameters such as air-fuel ratio, excess air regulation, and burner modulation can provide better flexibility in the working of the boiler. These controls help the burner change its settings dynamically as per the requirements of the process. Fuel saved would result in higher heat and power generation in the CHP system. The United States has a significant amount of natural gas in its reserve. Therefore, most industries in the USA use natural gas for combustion. However, various industries throughout 
the world, where natural gas and other fuel are scarce, still use coal for combustion. Burner controls help increase the combustion efficiency of the primary heating equipment. The effect of an operative burner control is explored in this study.

\section{(e) Fuels}

The fuels that are considered in this study are coal, natural gas, and \#4 fuel oil. These fuels are widely used, and they produce various amounts of energy during combustion. Single fuel firing in considered for this study. Similarly, the cost of fuel also plays an important role in deciding the nature of fuel to be used. The cost of fuel and its combustion property determines the amount of heat generation and the efficiency of a CHP cycle. Therefore, it is imperative to include various fuel properties in the study.

(f) Steam and water end-uses

A boiler can generate high pressure and high-temperature steam, which can later be used for various end purposes. High-pressure steam is generally used in the steam turbines, whereas the low and medium pressure steams are used in the manufacturing process. Three types of steam are typically used for the processes (i) high-pressure steam (ii) low-pressure steam, and (iii) saturated steam. If the process requires low-pressure steam, a Pressure Reducing Valve (PRV), or a backpressure turbine (B.P.) is used. Backpressure turbines can be used instead of a PRV to generate electricity while also satisfying the process heating needs concurrently. In cases where saturated water/steam is needed by the process, PRV with desuperheater is utilized by the DSS. PRVs exhibit isenthalpic expansion whereas B.P. turbines exhibit isentropic expansion. Similarly, the saturated water coming out from the steam turbines can be used in comfort heating for the facility. The study will involve various end-uses requirements in different industries, hospitals, and residential areas where CHP systems are run.

\subsubsection{Heat Recovery Options}

a) Pre-heating options

Boiler feedwater and combustion air can often be pre-heated to reduce fuel usage in boilers. A heat exchanger is used to revert the flue gases (exhaust gas) with high temperatures into the heat exchanger, where it exchanges heat with the ambient air. An increase in the temperature of the 
ambient air reduces the energy required by the fuel to carry out combustion. Once the ambient/preheated combustion air is brought into contact with the fuel, there is a sudden rise in internal combustion temperature in the combustion chamber. The temperature rise is largely dependent upon the amount of excess air and the type of fuel. The temperature rise of the combustion gasses can be calculated by subtracting the combustion temperature with ambient/pre-heated combustion air. Similarly, economizers are used in industries to pre-heat the boiler feed water. The feed water is sensibly heated by the flue gases to a temperature below its boiling point. Likewise, the heat exchangers also have a wide range of efficiency. Higher efficiency will result in better heat transfer between the two fluids, thereby increasing the CHP system's efficiency. These parameters can be largely significant in CHP operations, by reducing energy usage and increasing overall system efficiency.

\section{b) Blowdown}

Boiler blowdown is significant for a continued boiler operation because it reduces the quantity of the chemical concentrations such as chemical solids and dissolved minerals. Without blowdown, the boiler and its piping could get damaged eventually. However, removing blowdown water means energy loss in the boiler system. Thermal energy from the blowdown stream can be recovered in the form of flash steam and pre-heating of makeup water [16]. These two options must be carried out with precision to remove all the chemical concentrations from the blowdown stream. As continuous blowdown must be monitored and carried out if the boiler runs, a significant amount of energy is wasted from this operation. The study accounts for a continuous blowdown system as most industrial boilers exhibit continuous blowdown. The blowdown recovery is a key element in energy savings in CHP operation, which would be studied in the DSS.

\section{c) Condensate return}

Condensate liquid retains the sensible energy that the steam possessed. Therefore, condensate liquid can be returned to the boiler to decrease fuel usages and increase boiler efficiency. Another advantage of using condensate is that it does not have to be treated again if the boiler feedwater is already treated. Similarly, makeup water cost can also be reduced by using a higher amount of condensate in the boiler. The amount of condensate return that a facility can achieve plays a 
significant role in energy cost savings as the condensate can have as much as $16 \%$ of the energy in steam.

\subsubsection{Process Support Equipment}

a) Steam Turbines

Steam turbines are the prime mover considered in the preliminary portion of this study. The steam turbines extract the thermal energy from the steam and transform it into mechanical work, and consequently electricity. The condensing steam turbines can emit significantly low-pressure steam, which is later condensed in a condenser. Similarly, backpressure steam turbines use up energy in steam and omit low or medium pressure steam, without condensing the steam. These turbines are mostly used in power plants where the sole purpose of the processes is to generate electricity. Steam turbines can be installed in the facility as per the end-uses requirements of steam and hot water. The cost of a steam turbine normally ranges from $\$ 1,136 / \mathrm{kW}$ for a $500 \mathrm{~kW}$ steam turbine to $\$ 666 / \mathrm{kW}$ for a $15,000 \mathrm{~kW}$ steam turbine, while $\$ 682 / \mathrm{kW}$ for a $3,000 \mathrm{~kW}$ steam turbine at the current time [17].

Table 1-2: Applications of gas and steam turbines [18]

\begin{tabular}{|c|l|l|l|c|}
\hline CHP System & \multicolumn{1}{|c|}{ Advantages } & \multicolumn{1}{c|}{ Disadvantages } & \multicolumn{1}{c|}{$\begin{array}{c}\text { Overall } \\
\text { Efficiency }\end{array}$} & Sizes \\
\hline Gas Turbine & $\begin{array}{l}\text {-High reliability } \\
\text {-Low emissions } \\
\text {-Less cooling } \\
\text { required }\end{array}$ & $\begin{array}{l}\text {-Requires a high-pressure } \\
\text { gas compressor } \\
\text {-Poor efficiency at low } \\
\text { loading } \\
\text {-Output falls as ambient } \\
\text { temperature rises }\end{array}$ & $66 \%$ to $71 \%$ & $\begin{array}{l}500 \mathrm{~kW} \text { to } \\
300 \mathrm{MW}\end{array}$ \\
\hline Steam Turbine & $\begin{array}{l}\text {-Higher efficiency } \\
\text {-Flexibility in fuel } \\
\text { type } \\
\text {-Long working life } \\
\text {-High reliability }\end{array}$ & $\begin{array}{l}\text {-Slow startup } \\
\text {-Low power to heat ratio }\end{array}$ & Up to $80 \%$ & $\begin{array}{l}50 \mathrm{~kW} \text { to } \\
300+\mathrm{MW}\end{array}$ \\
\hline
\end{tabular}

b) Gas Turbines

Gas turbines are fundamentally different from that of the steam turbines. Gas turbines are used while there is a significant need for power generation (typically $25 \mathrm{MW}$ to $300 \mathrm{MW}$ ). They utilize air as the working fluid and work on the principle of the Brayton cycle [10]. Atmospheric air is 
brought into the system and compressed by a compressor. Like most of the internal combustion engines, fuel is injected into the compressed air to actuate ignition, thereby creating combustion energy with high energy content. The gas, then, enters the turbine and expands by transferring its heat energy to the mechanical energy in the turbines and consequently, electrical energy in the turbine generator. Power plants can implement topping cycle CHP by generating steam from the exhaust gas coming out of the gas turbines. The usage of gas turbines to operate a topping cycle CHP cycle is studied in this research by keeping in mind about different power plants that might be releasing the medium grade heat gas into the atmosphere. The typical cost of a gas turbine system is $\$ 3,320 / \mathrm{kW}$ for a $3,300 \mathrm{~kW}$ gas turbine, $\$ 2,817 / \mathrm{kW}$ for a $4,324 \mathrm{~kW}$ gas turbine, $\$ 2,017 / \mathrm{kW}$ for a $7,487 \mathrm{~kW}$ gas turbine and $\$ 1,276 / \mathrm{kW}$ for a $40,485 \mathrm{~kW}$ gas turbine at the current time [19].

\section{c) Pressure Reduction Valves (PRV)}

The high-pressure steam generated by the boilers is not necessary for every industrial process. Most of the time, the generated steam is only used in the manufacturing processes. Therefore, pressure reduction valves are used in various sectors where steam at different pressures is required. Similarly, a facility might have more than one type of turbine based on its operation at different pressures. Low pressure, medium pressure, and high-pressure turbines can be run using steam at different pressures, which can be readily obtained using PRVs.

\section{d) Deaerators}

Boiler deaerators are commonly used to remove dissolved oxygen and $\mathrm{CO}_{2}$ from the boiler feedwater. The removal of these gases prevents corrosion due to oxidation and gas attachment in the boiler system. If the boiler feedwater is treated effectively, then the amount of blowdown water will be reduced, preventing energy and volumetric losses in the system.

\section{e) Condenser}

Condensers are significant when a facility uses steam turbines. The condensers cool the steam and achieve phase change from steam to water. However, if a backpressure steam turbine is used, the condensers are not implemented, as the steam coming out of these turbines are used in different 
operations. Condensate from the condenser can be cycled back to the boiler and mixed with boiler feed water to reduce fuel usage. Various condenser parameters will be analyzed in the DSS.

\section{f) Absorption Chillers}

Absorption chillers work based on separating and recombining working fluids with the help of low-pressure steam or hot water to produce cooling. Low-pressure steam from a backpressure turbine is a prime candidate for facilities to implement absorption chillers instead of mechanical chillers. The overall cost of an absorption chilling system is $\$ 1,800 /$ nominal ton at the current time [20]. Also, $15 \mathrm{psig}$ of low-pressure steam flowing at 5,400 lbs./hr would produce 300 nominal ton of cooling [21]. These values are integrated into this research for calculations.

\section{g) Piping}

The overall piping in the CHP system changes the efficiency and output of the CHP system. Various sizes of pipes would change the flow rate and the pressure of the steam. Similarly, there will be a significant amount of losses if the piping is not insulated. This study will involve the insulation of pipes at various levels to calculate the overall heat loss and power generation due to its effect.

\subsubsection{Miscellaneous}

\section{a) Weather}

Various ambient air conditions throughout the air induce certain changes in the combustion in the boiler. When the ambient air temperature is lower, the pre-heater has to transfer more heat to raise the temperature, which in turn, would require more fuel consumption for combustion. Therefore, the fuel consumption would be different for the same amount of ambient air during a different time of the year.

\section{b) Grid Interconnection cost}

One of the most difficult challenges in operating a successful CHP system is a favorable grid interconnection cost for the facilities and the utilities. The inevitable increase in different renewable sources of energy would lead to the revision of interconnection requirements and processes. Numerous states in the US have various grid interconnection costs, but the similarity 
among all the states and the utilities is that the grid interconnection cost is high. Bird et al. [22] listed out three major interconnection challenges (i) scarce information about the grid (ii) unnecessary equipment requirements (iii) lack of consistent equipment requirements. The development in grid interconnection has a long way to go. The main scope of the grid interconnection cost is to incorporate it with the CHP system to calculate the actual payback on investment of the system.

Similarly, CHP systems are also an example of a distributed generation. It paves the way for an industry or a commercial facility to connect to the grid and supply clean and reliable electricity. One of the other major advantages of distributed generation is the changes in electricity prices based on time of day (spot trading). Major energy-efficient states in the U.S. have distributed generation where the electricity price changes at on-peak and off-peak periods. Applying engineering analysis to the distributed generation would result in higher cost savings and cleaner energy.

\section{c) Cost of electricity sold}

The cost of the electricity sold is significantly dependent on the grid interconnection cost and its integration. As of now, the cost of integrating a facility to a grid and the price of electricity sold to the grid are contrary to what the facility pays for purchasing the electricity. The study will involve various selling prices of electricity in the calculations so that the DSS can be used in most of the US.

\section{d) Clean energy incentives}

There are wide ranges of incentives available in the United States when there is an adequate amount of renewable energy generation. DSIRE is one of the most inclusive sources in the United States to explore different energy efficiency and renewable energy incentives [23]. The incentives can be filtered as per the states and utility providers. It is an initiative run by North Carolina State Clean Energy Technology. They synthesize several DSSs to help search federal and state-level energy efficiency incentives which are up to date. Similarly, they also manage archives of the older policies for reference. The site mostly brings forth renewable energy incentives including wind, solar, geothermal, and hydropower energy; however, there are various energy efficiency incentives 
by reducing energy usage and cost in the plant. Facilities throughout the United States can explore in detail the DSIRE incentives before and after implementing the CHP systems to offset their implementation cost.

\subsection{Need for Research}

With modernization and industrialization of facilities still on a growing trend to stand out in the global avenue, most industries must increase their production on all fronts. An increase in production is often accompanied by an increase in energy usage. Fossil fuels are the most consumed form of energy on the planet. The overall percentage of fuel consumption in the United States in 2018 is shown in Figure 1-3. About 80\% of energy consumption is directly related to fossil fuels.

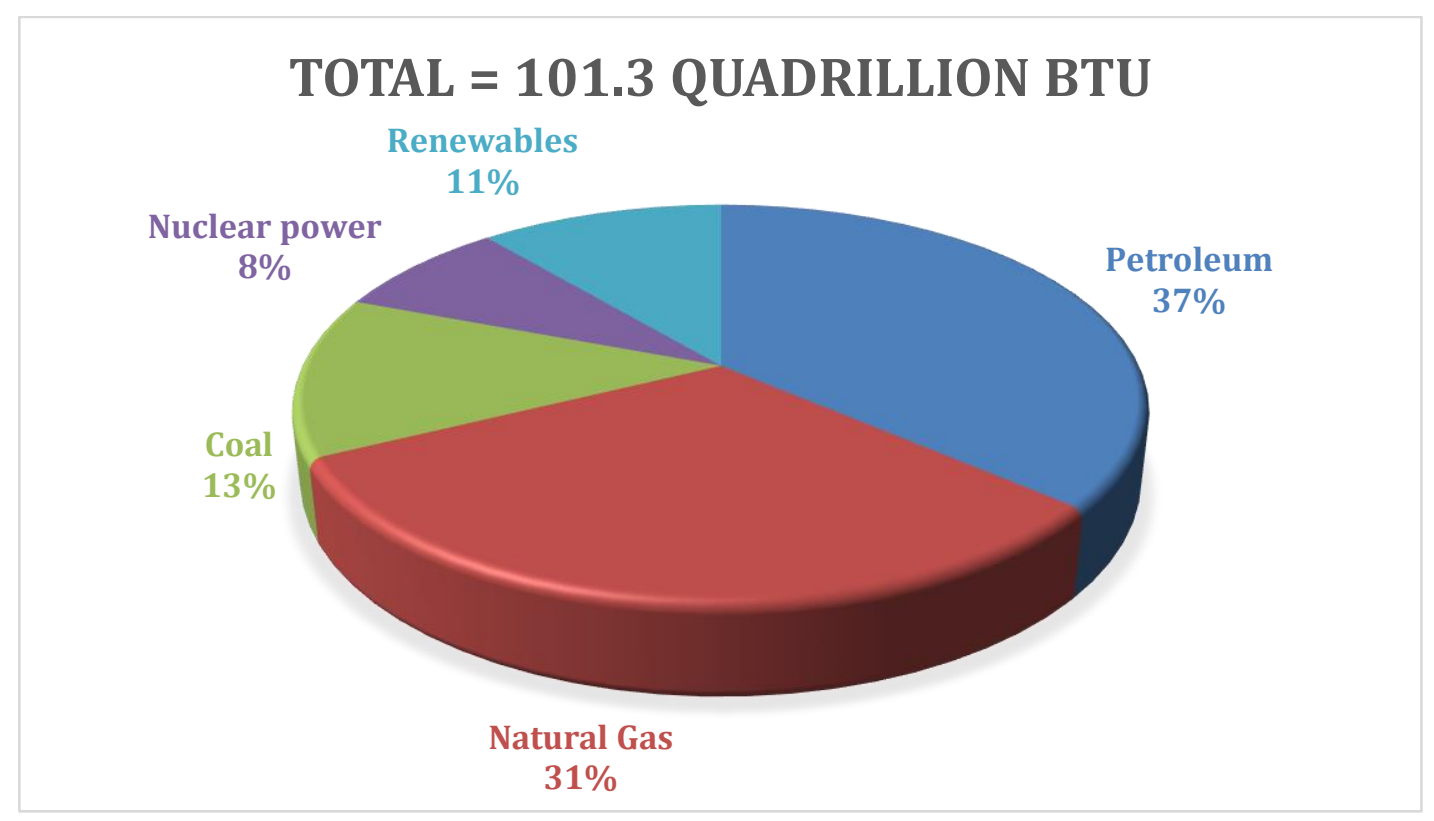

Figure 1-3: Energy consumption breakdown in the United States, 2018 [24]

Most industries require high and medium grade heat for their process. The heat requirements are satisfied by a boiler, that generates steam for direct and indirect heating in paper industries, food processing industries, chemical plants, and refineries. More so than often, the boilers are not operated at full load. In such instances, the topping cycle of CHP can be established where the excess steam generated can be used for combined heat and power generation. The benefit of a CHP system is enormous, provided the variables line up in a perfect storm. However, if the combinations 
of variables are not optimal, the system is not technically and economically feasible. Much literature has been focusing on the bottoming cycle of the CHP, where the flue gases are used to generate steam in a Heat Recovery Steam Generator (HRSG) to drive the prime mover and generate electricity and heat. The existing research findings in the bottoming cycle (mostly with gas turbines and their parameters) pertaining to their energy and exergy analysis do not help comprehensively in the analysis of the technical and economic feasibility for a topping cycle CHP in industries.

Therefore, the industrial plants can make extensive use of a Decision Support System (DSS) that can help them evaluate the feasibility of a topping cycle CHP for their existing processes. It can help them to devise the advantages and the disadvantages of monetary, power, and energy considerations based upon the demand side over time. These results can be found out by using a DSS where a user can enter the input variables, vary the values of the variables based on the ranges that do not affect the existing system and obtain, for each case, the changes in technological and economic feasibility. A contradictory situation with the absence of a DSS would lead to a facility follow the path set up by a vendor, without realizing whether it is economically viable or not. Similarly, it is a complicated task to commence a plan for a system as big as CHP in industries. Convincing the upper management to implement new processes can be a daunting task for the employees. For a topping cycle, there are minimally available programs that would evaluate the feasibility of the system based on the equipment and operating parameters in their processes. This study further aids the industries to procure the economic benefits or loss pertained by incorporating a CHP system. A DSS will bridge the gap between an idea and its implementation by incorporating mathematical values and measurements.

\subsection{Research Objectives}

The main objectives of this study are listed below:

1. Design and develop a spreadsheet-based DSS to analyze and study the process and economic feasibility of the topping cycle CHP system.

2. Pinch analysis of energy, process heat, cost parameters related to the technical and economic feasibility of a topping cycle CHP system. 


\section{Verification of the DSS.}

The primary objective of this research is to study the topping cycle of CHP using a boiler, various end uses and the dominant variables, and their effect on desirable economic benefits. Implementing CHP is a necessary step towards energy usage reduction and clean energy. However, the challenges of recognizing a successful system before implementing it are still scarce and research has not been carried out in this regard. The study will collect ample parameters which can be modified as per the requirements and characteristics of a facility and get the decision on the topping cycle CHP system.

Secondly, the research also reflects upon the pinch analysis of energy, electricity generated, cost savings, energy savings, and payback on investment of investment with respect to the changes in the abovementioned parameters. A typical pinch analysis include site survey where process heat and other equipment data. A heat balance is carried out to validate the data analysis. Realistic targets are set for the DSS by including constraints if any. Finally, the DSS is created for the analysis. The analysis would let the user know the effect of different parameters on the selected output and devise methods to generate better output modifying the parameters as per the facility's needs. The study will produce outcomes based on the best, medium, and worst scenarios while setting up CHP systems in a facility with a certain pressure, temperature, and quantity requirements of steam to payback on investment and power generation.

Finally, the study is aimed to design and develop a DSS that enhances the decision-making capability in a topping cycle CHP (using backpressure or condensing turbine) where the boiler(s) are not working at full load. The DSS aims to determine whether a topping cycle CHP can be implemented for economic benefits in different industries. The ranges of values of different input parameters that will devise the lowest payback on investment from the DSS can be implemented in the facility.

\subsection{Limitations}

This research study does not consider the impacts of parameters in the heat and power generation on a dynamic scale. The study only involves the relationship of different parameters for boilers of 
any given capacity to generate a decision. There are no continuous recordings of data which would record the steam energy and power output uninterruptedly. The study also does not comprise of bottoming as research in these fields has been abundantly done. Finally, the research does not consider vapor recompression cycle as a method for generating pressurized steam for end uses.

\subsection{Conclusion}

The growing need for fossil fuel and its effects on the environment has been on a growing trend since its discovery. The development of CHP systems in industries, residential and commercial areas will be of tremendous help to reduce fossil fuel usage to satisfy energy demands. The use of the topping cycle CHP would change the way industries utilize energy and pay for the usage. This will also result in lesser greenhouse gas emissions. This research study aims to develop a DSS that can be consistently used by facilities to get hindsight on the economic benefits of installing a topping cycle CHP system. 


\section{Literature Review}

\subsection{Applications and workings of CHP systems}

Singh et al. [25] performed a detailed study of the advantages of CHP plants that can operate by using prime movers such as reciprocating engines, steam turbines, gas turbines, microturbines, and fuel cells. Reciprocating engines, steam turbines, and gas turbines have been in use for a while, whereas microturbines and fuel cells are the technologies that are still in their infancy. Steam turbines (0.1-250 MW) and gas turbines (0.5-250 MW) have the maximum power generation capability while reciprocating engines (0.02-6 MW), microturbines (0.025-0.25 MW) and fuel cells (0.003-1.2 MW) have the lowest. Similarly, fuel cells have the lowest emissions because they do not require fuel for combustion. Instead, they generate heat and power through electrochemical processes. Likewise, heat recovery steam generators (HRSG), instead of a boiler, are used to generate steam from the exhaust gas thermal energy and absorption chillers, instead of electric chillers, are used to generate thermally activated cooling. The authors state that CHP plants eliminate transmission and distribution losses. Moreover, through increase reliability and power quality, the plant equipment is always online, resulting in an uninterrupted revenue generation. Based on the Northeast Blackout of 2003, the authors present the fact that 10 out of 12 CHP sites performed without any interruption. CHP plants also minimize greenhouse gas emissions. The U.S. EPA reported that CHP plants have avoided 11.8 million metric tons of $\mathrm{CO}_{2}$ by initiating 410 CHP projects. Similarly, 20\% of the CHP systems have payback on investment of fewer than 2 years, $40 \%$ offer a payback on investment of 2 to 4 years, and the remaining $40 \%$ offer a payback on investment of 4 to 6 years. Apart from the industries, CHP systems can be used in hospitals, residential, universities, supermarkets, and restaurants. Finally, the authors theorize that CHPs have the potential to produce significant economic and environmental benefits, however, the collaborative efforts between the customers and utility partners should overcome cost-related barriers for effective implementation.

Khan et al. [26] investigated gas and steam bottoming cycles with heat exchanger and HRSG respectively. The effects of turbine inlet temperature, pressure ratio, and exhaust gas flow rate are studied concerning the thermal efficiency and exergy loss of exhaust gas. The topping cycle embraced for this research is the gas turbine cycle which receives combustion air from the 
compressor. There are two bottoming cycles: (i) air bottoming cycle using a heat exchanger to heat the ambient air and generate power from a second gas turbine (ii) steam bottoming cycle which utilizes an HRSG to generate steam and rotate a steam turbine. Ambient temperature, the mass flow rate of air and steam, isentropic efficiency of pump compressors and turbines were kept constant in this study. The new work that is done by the combined cycle, topping cycle and bottoming cycles are calculated. The net-work of the gas turbine cycle increases with the turbine inlet temperature and mass fraction of exhaust gas but decreases with pressure ratio. Similarly, the higher the turbine inlet temperature, the higher power is recovered through the bottoming cycles. The authors conclude that higher turbine inlet temperature is significant to utilize the heat exchangers and HRSG in the bottoming cycle to increase power generation and combined cycle efficiency.

Waste heat recovery is a major part of any combined cycle. The heat recovery equipment recovers the waste heat by generating steam in a heat exchanger or an HRSG. Butcher et al. [27] conducted a study on the performance of waste heat recovery systems based on a second law analysis. The parameters considered for this study are temperature, net-work output, and entropy generation under various operating conditions. The HRSG consists of an economizer, an evaporator and a superheater. The system is assumed to be in a steady-state with no pressure drop on the steam side. The authors found that higher pinch points resulted in higher gas temperature in the economizer, thereby reducing heat exchanger efficiency and steam generation. Similarly, the second law efficiency increases when the exhaust gas inlet temperature is increased. Moreover, exhaust gas temperature with different composition of oxygen percentage affects the efficiency differently.

Higher oxygen percentage decreased the second law efficiency of HRSG. The authors state that the parameters to increase the second low efficiency can help us to efficiently convert energy input into work output and realize how well the thermodynamic means are utilized.

\subsection{Feasibility Study of CHP systems}

Frigo et al. [28] conducted a feasibility study of a CHP system comprising of steam turbine and biomass gasification for tissue paper production. The primary objective of this study is to evaluate whether a CHP plant based on biomass as fuel can be operated, technically and economically, or not. The plant operates on the bottoming cycle. The combustion chamber produces high pressure 
superheated steam which is used to drive the steam turbine for electricity generation. A wood gasification process is used to furnish the syngas applied in high-temperature hoods. Similarly, steam required for drying is bled from the steam turbine. Steam turbine outlet has a condenser, deaerator, and a preheater to warm up boiler feed water. Likewise, the combustion air is preheated using exhaust gas. For a paper production of 80 tons/day, the steam powerplant achieved a net electrical efficiency of $23.9 \%$. It proves that different fuels can be used as an alternative at places where natural gas is not readily available to run CHP plants.

Ahmadi et al. [29] studied the thermodynamic and economic performance of thermal power plants (coal-fired power plant, natural gas-fired power plant, combined cycle power plant, and CHP and trigeneration power plants) to understand the inherent energy and exergy losses. The authors found that the highest exergy loss occurs in the combustion chamber and boilers. Energy and exergy efficiencies can be improved by using equipment such as fuel cells and desalination units because they prevent heat losses. Combined cycle power plants have maximum exergy destruction in the combustion chamber as the materials cannot withstand the critically high temperature and pressure. The authors conclude that the plants can be more efficient if they work in supercritical conditions with optimal working conditions.

Bilgen [30] studied the exergy and engineering of two gas turbine-based CHP plants. The first plant comprised of a gas turbine system (gas turbine, compressor, combustion chamber, and expander), HRSG, and a steam turbine, and the second plant comprised of just a gas turbine system. The author studied the exergy based on the first and second laws of thermodynamics and the engineering analysis based on the levelized cost and payback on the investment period. Gibbs function and Lagrangian multipliers were used to find the equilibrium composition temperature and pressure, and the combustion chamber feed. Similarly, for the engineering evaluation, a modular cost estimating DSS is used. The DSS is used to calculate the economic parameters, levelized cost, and payback on the investment period for CHP. For the gas turbine-based system, a CHP system achieved fuel utilization efficiency improvement of $105 \%$ and an exergy efficiency improvement of $40 \%$. Likewise, for the gas turbine-steam turbine system, the fuel utilization efficiency and the exergy efficiency were lower than that of the gas turbine system. Finally, the 
author agrees with the reported data that the standalone gas turbine CHP plants have better efficiency than that of the gas turbine system integrated with steam turbines.

Holmberg et al. [31] researched the fuel-costs allocation and $\mathrm{CO}_{2}$ emissions in a CHP plant generating heat for paper drying and electricity for the plant and selling back to the grid. The plant uses black liquor and bark from the mill as partial fuel, and oil from the market to satisfy the remaining fuel demand. Fuel costs and $\mathrm{CO}_{2}$ emissions allocation to generate heat and power in this study is done by (i) energy method, (ii) exergy method, and (iii) market-based method. The market-based method is when the electricity price is based on the market price. The authors aimed to uncover the cost allocation differences between the earnings of the CHP plant (energy producer) and the energy procurement cost of the paper mill (energy purchaser). The study concluded that varying fuel and electricity costs influence the revenue of the plant and the energy procurement cost of the mill. Therefore, the most profitable method for the plant was the energy method because it assigns the fuel costs equally to power and heat, resulting in the price of heat becoming higher. However, for the paper mill, the exergy method resulted in the lowest procurement cost. The exergy method accounts for the earnings made by selling back the bark and black liquor to the CHP plant, which might lead to lower energy procurement costs for the mill. Similarly, the energy method generates the highest $\mathrm{CO}_{2}$ emissions for heat, whereas the market-based method allocated lower emissions.

Ozkan et al. [32] studied the exergy analysis to determine the exergy losses in a two gas turbinesbased bottoming cycle CHP plant to decrease the exergy losses, thereby increasing the efficiency of the plant. The author utilizes the second law of thermodynamics for the analysis. The analysis involves exergy losses in the heat exchanger, combustion chamber, steam boiler, gas turbine, and compressor. The CHP system has a total capacity of 55,000 $\mathrm{MW}_{\mathrm{e}} / \mathrm{yr}$. The physical and chemical exergy of the CHP plant is taken into consideration. Exergy losses in the parameters are calculated using the physical and the chemical exergy losses formula. The sources of irreversibility are accounted for and reduced to mitigate exergy losses and increase efficiency. The author infers to increase the efficiency of the combustion chamber, heat exchanger, and the steam boiler to decrease maximum possible exergy losses without significantly changing the process. Exergy losses are at its peak in the heat exchanger at around 44.44\%, Therefore, the author concludes that 
implementing energy efficiency measures in the heat exchanger at first would result in a higher efficiency increase.

\subsection{Energy Efficiency Study in CHP systems}

Beyene [33] brought out a concept of eco-park, a cluster of different injuries in proximity, where the input and output of the CHP systems of those plants can be utilized by the others to generate better economic and environmental benefits. The study aimed to reveal the energy efficiency benefits from CHP. The author explains how the existing electricity distribution system, mostly reliable, can malfunction during power outages. Commencement of decentralized CHP systems can be a legitimate alternative to the less efficient grid systems of today. Topping cycle parameters can be altered to generate energy for electricity production and heat recovery at the scale required by the plant's end uses. The review of the two cycles concludes that the topping cycles are more flexible and have higher efficiencies than their counterparts. The author studied five topping cycles and five bottoming cycles with various power and heat requirements for this research. It is found that the power distribution in CHP systems is less challenging than the thermal distribution. This is explained by the nature of thermal distribution in terms of steam, hot water, chilled water, and district heating. The author concludes that CHP, especially topping cycles, can be beneficial in economic and environmental issues improvements. Their installation can pave the way for other parameters that reduce waste, consequently increasing performance by these added benefits. However, more parameters can be defined to gain a significant leap in the field of CHP plant optimization.

Murugan et al. [34] studied the effect on cycle efficiency with a reduction in energy loss and irreversibility at different points of a combined cycle such as heat input point work output point, and heat rejection part. The outcomes of the combined cycle are compared with a stand-alone Rankine steam cycle. The combined cycle consists of water as the working fluid in the topping cycle and ammonia-water mixture in the bottoming cycle. The authors found that combined cycles are, indeed, better in terms of efficiency by $2.1 \%$ than a stand-alone Rankine steam cycle at the same inlet conditions. Similarly, there is a $20 \%$ reduction in energy loss in the condenser of the compared cycle than that of the stand-alone Rankine cycle. Therefore, different working fluids can 
be used to better the efficiency of the cycle and the power generation. In this study, the ammoniawater mixture was concluded as the best working fluid in the combined bottoming cycle.

One of the major objectives of this study is to determine a sweet spot in the topping cycle CHP based on different operating parameters. Ferreira et al. [35] studied the method to increase the efficiency and annual savings of high-grade temperature furnaces through the topping cycle. Two production lines that consist of a furnace (average setpoint $1,652^{\circ} \mathrm{F}$ ) each as the main source of heat for quenching. Propane gas is used to heat the furnaces (approximately 30\% energy usage in the plant/year). Gas microturbines are used in the topping cycle, as they are cost-effective and have more savings. Similarly, turbines exhaust gas is best matched to the heat required by other processes in the plant such as pre-heater, baths/air dryers, and annealing furnaces. The method laid out by the authors are: (i) no efficiency measure (ii) Replacement of fuel from propane to natural gas (iii) Reuse of flue gas in secondary furnaces (iv) Reuse of flue gas in microturbine (15 $\left.\mathrm{kW}_{\mathrm{e}}\right)$ (v) Reuse of flue gas in microturbine $\left(30 \mathrm{~kW}_{\mathrm{e}}\right)$ (vi) Reuse of flue gas in microturbine $\left(65 \mathrm{~kW}_{\mathrm{e}}\right)$. The experiments showed that the fifth scenario $\left(30 \mathrm{~kW}_{\mathrm{e}}\right.$ output) was the best match between energy output and energy requirements. However, maximum savings can be achieved in the existing plant by installing a $45 \mathrm{~kW}_{\mathrm{e}}$ microturbine, as the rated microturbine would utilize all the exhaust gas resulting in optimal efficiency. Scenario (v) produced annual cost savings increase by $40 \%$, energy usage reduction by $17.2 \%$, and $\mathrm{CO}_{2}$ emissions reduction by $7.8 \%$.

Maheshwari et al. [36] evaluated steam turbines, gas turbines, and ammonia-water turbines to achieve improvements in their performance by varying their thermodynamic settings. In a combined cycle, the energy generated from the bottoming cycle is hugely dependent on the effective energy utilization by the topping cycle. The three turbines system are arranged in different combinations to carry out thermodynamic analysis of various parameters. For the systems with ammonia-water turbines and gas turbines, at constant cycle pressure ratio, ammonia mass fraction is varied, thereby resulting in a reduction of work output. This is aided by the reduction in mass of water, while the mass of ammonia increases; since enthalpy of water is more than that of ammonia, the net enthalpy of the mixture decreases when ammonia mass fraction is increased. Similarly, for a simple gas turbine-based combined cycle system, the efficiency of the cycle 
increases when the cycle pressure ratio increases because lesser input fuel is required for combustion due to an increase in the ambient air temperature.

Carpenter et al. [37] quantified energy savings by improving the boiler controls with automodulation on the firing rate and decrement in excess air percentage during combustion. These parameters greatly influence the boiler combustion efficiency and the energy loss in stack gases. A decrease in energy content in the stack gas ultimately increases the combustion efficiency and the amount of fuel that is burnt during the combustion resulting in cleaner combustion. The author attained an $11 \%$ increase in the combustion efficiency by implementing automatic modulation of firing rate. Similarly, with calculations, the excess air percentage can be kept at $10 \%$ for better combustion and higher energy efficiency.

\subsection{Design and operational parameters studies}

Nag et al. [38] researched the design and operation of a heat recovery steam generator to achieve minimum irreversibility. Gas turbines operate in conjunction with HRSG and steam turbines, which create a significant link between the topping and bottoming cycles. The authors have provided a method to minimize entropy generation due to the loss of energy during the steam generation in HRSG. The parameters considered for this study are gas pressure, exhaust gas temperature, steam temperature, heat capacity ratio, and the number of transfer units of the economizer and evaporator. Nag et al. found that the entropy increased with an increase in gas pressure and temperature. The lesser temperature would decrease the irreversibility in the process; however, the steam temperature would also be lowered. Similarly, entropy generation decreases for higher heat capacity ratio. Besides, for exhaust gas with temperature from the gas turbine of the topping cycle, the steam generated would be higher for the respective heat capacity. Finally, the authors conclude that the HRSG should work in its maximum capacity to achieve minimum exergy loss.

Somcharoenwattana et al. [39] carried out a study to improve the operational parameters of two natural-gas CHP plants, working on the principle of the bottoming cycle, by changing the system design and operational schedule during on-peak and off-peak period for more flexible operation. The CHP operation (52.5 MW) includes two individual $20 \mathrm{MW}$ gas turbines, two HRSGs, one 
steam turbine with the power of 12.5 electrical output, four auxiliary boilers, and three absorption chillers. In the first case, the author replaces the existing gas turbines, thereby increasing the overall efficiency from $48 \%$ to $61 \%$, natural gas savings of $24 \%$, and $\mathrm{CO}_{2}$ emission reduction of 27\%. The existing gas turbines were old and exhibited numerous breakdowns and unstable conditions. They were replaced by newer gas turbines with half the heat rate (rate of fuel consumed for electricity production $(\mathrm{kWh})$ ) and gross electrical efficiency of $41.7 \%$ (a $17 \%$ increase). The author states that the higher the ambient air temperature, the lower the electricity generation. Therefore, the temperature of the inlet air for the gas turbine was reduced from $91.4^{\circ} \mathrm{F}$ to $55.4^{\circ} \mathrm{F}$ by using the chilled water from the absorption chiller. This change in the inlet gas temperature parameter increased the overall efficiency to $61 \%$ and power output (MWh/year) by $91 \%$ (from 389,294 MWh/year to 744,775 MWh/year). Similarly, in the second case, a CHP plant (9.9 MW) which supplies electricity and cooling for the building was chosen. There was a vivid difference between the cooling load profiles during the day and night. The author introduced two chilled water storage tanks that are used to charge the chilled water at night and discharge into the building during the day, resulting in a reduction in chiller size and gas turbine system. The chilled water requirements during the night, albeit lower requirement, were satisfied by two mechanical chillers, while the absorption chiller generated chilled water and stored them in the water storage tanks. The author concludes that longer operating hours of absorption chillers and gas turbines would generate higher revenue. Therefore, changes in parameters such as decrement in inlet gas temperature in gas turbines and increment in operational hours would result in higher electricity and cooling generation.

Valdes et al. [40] studied the influence of different parameters such as ambient temperature and pressure, isentropic efficiency of the gas turbine, superheaters and reheaters temperature, evaporators, and economizers on the thermo-economic performances of combined cycled gas turbine power plants on full-load and partial-load. The authors use the cash flow DSS and energy generation cost as the two thermo-economic DSS. The single pressure combined cycle gas turbine power plant results (for cost generation and cash flow) were used as the reference points in the study. For the full-load study, a decrease in pressure (P), pinch points (PP), approach points (AP), and gas to steam temperature difference (dT) at the superheater increased efficiency whereas an increase in the total heat transfer area resulted in efficiency increase. For partial load, however, 
when the load on the gas turbine was decreased, the efficiency and gross power decreased too. When the load is under $55 \%$, the cash flow starts to be negative which means that the cost of generation is higher than the selling price to the grid. The authors concluded that the results are significantly dependent on the type of turbine selected and the initial design parameters. The document also inferred that modification in design parameters defines the generating cost or cash flow series better than that of efficiency. Finally, it showed that a generating cost optimization should be done for a liberalized electricity market and cash flow optimization in a regulated market.

Similarly, there have been studies on individual equipment in a combined cycle. Franco et al. [41] devised an experiment for the optimum design of heat recovery steam generators (HRSG), a significant component of a combined cycle, for maximum performance. The authors carried out the study in two steps: (i) changes in the main parameters such as the pressure, temperature, and mass flow rate of the gas, water, and steam (ii) changes in the HRSG design for better heat transfer in the bottoming cycle. In the first step, the minimization of the exergy loss due to the difference in temperature and pressure of the exhaust gas and water was considered whereas in the second step, the geometry of HRSG, that includes volume minimization or compactness maximization while maintaining performances related to heat flow and pressure drop, is considered. The authors achieved an exergy loss reduction of $25 \%$ by increasing the surface length ratio of the HRSG tubes by $5-6 \%$, the volume of the HRSG by $8 \%$, and the compactness of HRSG from 120 to $140 \mathrm{~m}^{2} / \mathrm{m}^{3}$.

Arrieta et al. [42] performed a study on the effects of ambient temperature in a natural gas run combined-cycle thermal power plant consisting of two gas turbines, two HRSGs (with supplementary firing) and steam-turbine. The power generated by the plant is inversely proportional to the ambient air temperature, which means that a minute change in the ambient temperature influences the power generated and revenues drastically. Similarly, lower ambient air pressure shows a similar trend in power generation as that of temperature. Finally, a decrease in air's relative humidity increases the plant's efficiency. Out of the three parameters discussed above, the temperature is the most pre-dominant parameter, therefore the other parameters such as pressure, relative humidity, electric frequency, power factor, and fuel characteristics were kept constant in this study. The study was carried with simulation using Gate Cycle software, where 
data from the gas turbines, HRSGs, steam turbines, condensers, and other equipment were set up. The gas temperature increase after supplementary firing in the HRSG is also considered for the overall power generation. The results indicated that the maximum ambient air temperature $\left(95^{\circ} \mathrm{F}\right)$ and minimum gas temperature after supplementary firing $\left(977^{\circ} \mathrm{F}\right)$ generated $468 \mathrm{MW}$ power, whereas the minimum ambient temperature $\left(32^{\circ} \mathrm{F}\right)$ and maximum gas temperature after supplementary firing $\left(1,247^{\circ} \mathrm{F}\right)$ generated $642 \mathrm{MW}$. The simulation also showed a variation of overall cycle efficiency of $3.4 \%$. This inferred that the use of supplementary firing in the HRSG would increase the power generated in the gas cycles, however decreasing the thermal efficiency. Thermal efficiency decrement is associate with higher fuel usage by the supplementary firing in HRSG.

Similarly, Şen et al. [43] also performed a study about the influence of ambient temperature on the power generation of a natural gas-run combined cycle power plant. Ambient air temperature between $46.4^{\circ} \mathrm{F}$ and $73.4^{\circ} \mathrm{F}$ was used to study its effects. The authors recorded the power at different temperatures with the help of transmitters and transformers and analyzed the respective data using data acquisition card (DAQ) and supervisory control and data acquisition (SCADA). The loggers were used to measure the energy from the gas turbines and steam turbines at different ambient air temperature range. The results were a power generation of $227.7 \mathrm{MW}$ at $46.4^{\circ} \mathrm{F}$ ambient temperature and 197.3 $\mathrm{MW}$ at $73.4^{\circ} \mathrm{F}$. The authors concluded that the higher temperature ambient air has lesser oxygen in the air entering the combustion chamber, thereby affecting the combustion process and the energy it produces.

Oh et al. [44] evaluated the economic feasibility of a gas turbine-based CHP to a hotel or an office building in Seoul, South Korea. The study considered the annual energy demand for electricity, heating, and cooling along with operational parameters, equipment, and industrial policy. The author utilizes a mixed-integer linear programming method to obtain the most optimal solution of parameters used for a hotel or an office building. The optimization planning process includes the assumption of annual electricity, heating, and cooling demands based on a priori. Similarly, the study does not consider the grid interconnection cost, and the fac the overall electricity generated by the CHP system. Based on the linear programming method, the author presents formula to calculate the energy supply-demand, annual cooling demand, and the annual variable cost. Finally, 
the total annual cost for the investment is calculated by generating the sum of the annual variable and the annual fixed cost. Data related to the maximum and the minimum electricity, heat, and cooling demands were collected from the hotel and an office building of similar sizes. The author found out the implementation of a gas turbine based cogeneration system did not generate a desirable payback on investment. However, the implementation of a gas turbine based CHP was economically feasible for a hotel. The payback on investment for the hotel was 6 years, and the payback on investment for the office building was 9 years.

CHP systems have the versatility to be implemented in the power plants, industrial facilities, commercial and institutional facilities such as colleges, universities, hospitals, hotels, offices, K12 schools, and nursing homes. Unsurprisingly, according to a report produced by the U.S Department of Energy, the CHP systems in the commercial facilities account for $50 \%$ of the total CHP systems in the United States [45]. The report highlights successful CHP installations in industrial and commercial facilities. The report highlights a group of office buildings that has a $4.3 \mathrm{MW}_{\mathrm{e}}$ topping cycle CHP plant which provides $100 \%$ of the electricity needs to the buildings. Similarly, the CHP system also integrates a 1,050-ton absorption chiller for cooling needs during summer. Another example is a data center that implemented a microturbine topping cycle CHP system to generate enough energy to operate a 300-ton absorption chiller for its cooling needs. Figures 2-1 and 2-2 show the commercial and industrial facilities that use the CHP system and their prime mover respectively. 


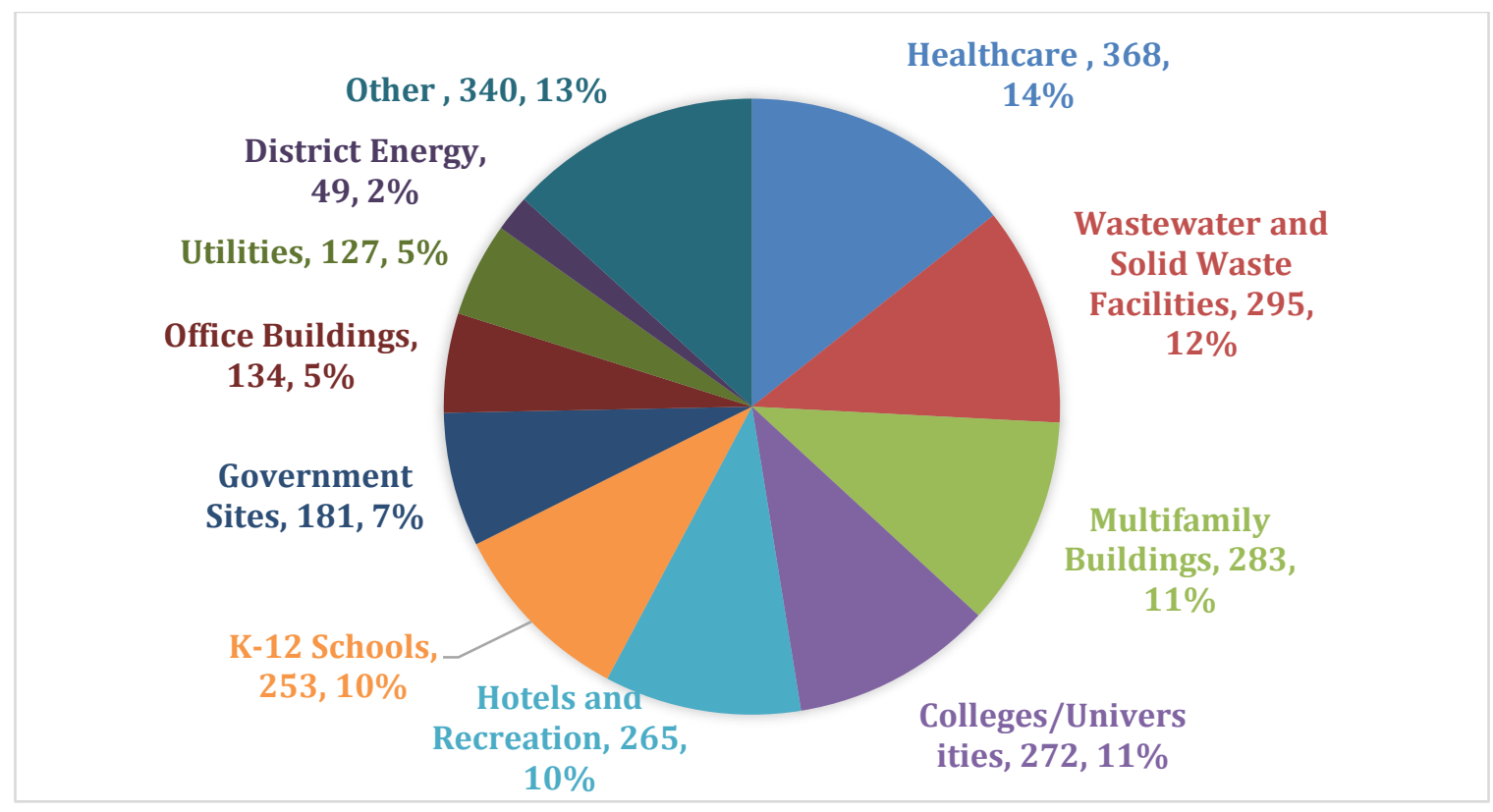

Figure 2-1: Commercial Businesses with Topping Cycle CHP Systems, 2014 [46]

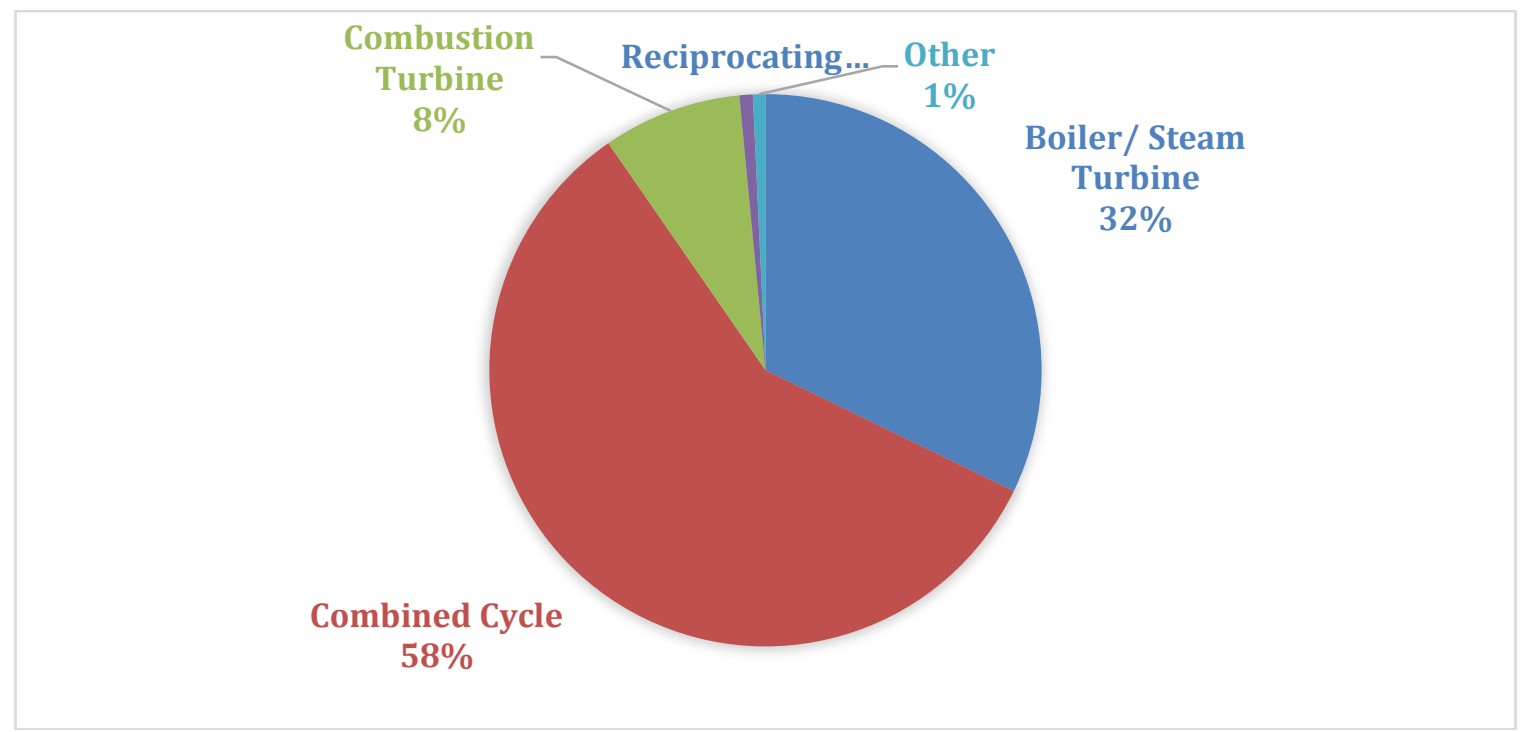

Figure 2-2: Commercial Business Prime Mover in CHP Systems, 2014 [46]

Arzbaecher et al. [47] conducted a study on a waste heat recovery in industries and how it can be utilized for other industrial applications using pinch analysis. The author consults several literature and industries to identify high-grade waste heat utilization opportunities from equipment such as furnaces, boilers, and kilns. The opportunities are identified and associated with the recent energy savings and advancement methods. To satisfy the research target, the author uses pinch analysis. The analysis identifies the most promising waste heat recovery opportunities without influencing 
the process integration and energy efficiency of the facility negatively. The author processes a site survey to gather data from the heat, sets the target to achieve the maximum heat recovery, design the DSS and optimize in terms of cost-effectiveness, and the optimized trade-off between the efficiency of the plant and total energy and fuel cost. The pinch analysis is extremely useful to continuously track record of energy cost and savings. The author concludes that the potential for the waste heat recovery is tremendous as only $5 \%$ of the industries in the United States implement waste heat recovery. Similarly, waste heat recovery by a significant number of industries would result in a reduction in greenhouse gas emissions.

McBrien et al. [48] studied the energy savings from heat recovery in an integrated steel supply chain through pinch analysis. The author uses pinch analysis to compare a standard heat recovery process and an integrated heat recovery process in the research. The author found out that an integrated heat recovery process could save up to 2.37 MMBtu/ton of hot rolled steel, instead of a 1.42 MMBtu/ton of hot rolled steel savings by using a conventional heat recovery process. The author also provided methods to extend the heat recovery methods and data collection to all the primary steel industries. The work is conducted by creating a mass and energy balance of the steel supply chain at first. Later, a pinch analysis is introduced to deduce possible energy savings by recovering the waste heat from the processes. The materials that already have heat or are heated to a certain process temperature are identified as the prime candidate for waste heat recovery.

Steam System Modeler Tool (SSMT) is used to carry out calculations related to the steam turbines, deaerators, and PRVs [49]. SSMT is extremely useful to chart out a boiler system with up to three steam headers and compare it with a second DSS to track the changes in the output systems when an input parameter is changed. The overall goal of SSMT is to increase the steam system efficiency in industrial facilities. Various boiler parameters such as the pressure, temperature, specific enthalpy, specific entropy, combustion efficiency, and isentropic efficiency of the turbines are used as a determining factor for the changes in output quality such as power generation and overall system efficiency. 


\subsection{Power generation and its integration to the grid}

Asmar et al. [50] carried out a study to develop a decision-making policy to quantify the most optimal CHP system that can be integrated into the electricity grid. Setting up CHP plants decentralizes the electricity sector. The CHP plants can be linked to the electricity grid without major expenses, resulting in the control of losses and assaults. The study is based on gas turbine CHP systems. A decision-making strategy named "Multi-objective optimization" is used for the study. The main aim of the simulation is to find a CHP power that is favorable to the economy and the environment. It corresponds to ten years of CHP integration to the power grid with an average operational hour of 8000 hours/year. The simulation is carried out 1000 times, generating around 15,000 solutions. The solutions discover the objective function of the total cost and pollutant emissions to be minimized by setting up CHP. The dependent variables (cost and pollutant emissions) are displayed in a linear regression DSS. The equations are also dependent on the energy demand and the nature of the system. Therefore, the multilinear equation is the relationship between power, total cost, and polluting emissions in a span of ten years. So, the power corresponding to the smallest residue is termed as the best option to be integrated into the grid. This process is the selection of best CHP to be adapted to the level of integration required and encouraging subsidies are introduced to motivate the customers to pursue CHP. The authors conclude that the choice of pursuing CHP is also largely dependent on the wish of the customer (public or private).

The total energy consumption in the Italian paper industry is estimated to be $7.01 \mathrm{TWh} / \mathrm{yr}$, out of which $5.54 \mathrm{TW} / \mathrm{yr}$ of energy is generated for the production. It provides a unique opportunity to implement CHP systems. Therefore, Gambini et al. [4] made a case study on high-efficiency CHP systems for the paper industry in Italy where the incentive scheme for selling electricity back to the grid has been modified with better rates for the unit selling price of electricity in the recent years. Gatecycle software is used for the detailed design of the CHP systems. It can be used to manipulate pressure, temperature, and enthalpy conditions of the working fluid (mainly water), therefore, obtaining different efficiency and output power. The authors study internal combustion engines (ICE), gas turbine (GT), backpressure turbine steam power plant (BPT-SPP), condensing turbine steam power plant (CT-SPP), and combined cycle power plants (CCPP). There were two conditions for selecting the best CHP systems; (i) the electricity generated should be equal to the 
electricity demand of the plant (electricity cannot be sent to the national grid) (ii) Consequently, the remaining energy should be used to maximize heat generation to achieve maximum Heat ${ }_{C H P}$ /Energy ratio, resulting in high-efficiency CHP (HEC). The results of the study were enumerated through energy, economic and environmental parameters, that were later added to get a total key performance indicator to compare the studied CHP systems. The study indicated that gas turbines (GT) were the best CHP system for the selected paper industry. For the reference, the gas turbine CHP system primarily consists of a gas turbine to generate electricity and an HRSG to generate steam for heating.

\subsection{Conclusion}

This literature review reveals the prominence of the research work done in the field of CHP. It is shown that significant research work has been carried out in the field of bottoming and combinedcycle CHP systems. The work done by various authors for the bottoming and combined cycles has been studied and implemented by various governmental, industrial, and commercial facilities around the world. However, the literature survey iterates that there is no such DSS to enable an industrial practitioner to evaluate the technical and economic aspects of a topping cycle CHP system. The DSS developed in this study will address this need. 


\section{Research Approach}

This research aims to develop a system to analyze the economic and technical feasibility of a topping cycle CHP system and pinch analysis of variables and parameters to obtain higher power generation and lower payback on the investment. It is most commonly applied to an industrial facility where a boiler at a partial-load is utilized for process heating requirements and the remaining capacity of the boiler is utilized to operate the CHP system by using a steam turbine. Similarly, the research also involves a CHP opportunity with a gas turbine system instead of a steam boiler. The gas turbine system is operated to generate electricity for the topping cycle, and the turbine exhaust is utilized by a waste heat recovery boiler to generate steam for a steam turbine and respective end uses.

\subsection{Data Collection}

In order to successfully carry out the research, extensive studies were performed on CHP systems that use boilers and gas turbines. Facilities that utilize boilers had to be studied for implementing CHP. As the topping cycle is only possible where there is an excess generation of steam from a boiler, data collection, and facility selection was critical. Several discussions had to be carried out with the plant personnel to convey the message about CHP's significance related to energy and cost savings. The energy consumption and cost incurred to the facility also had to be considered. The data collection activity was significant because of the amount of equipment that had to be considered. The list of equipment and parameters that had to be considered for the study are, while not limited to, listed below:
a. Boiler (its parameters) - Steam properties and losses
b. Steam piping - Steam flow and losses
c. PRVs-Steam pressure reduction
d. Comfort heating
e. Fuel usages
f. Deaerator
g. Economizer
h. Air pre-heater 
The plant personnel was interviewed for the data procurement related to the abovementioned equipment and parameters. Data was collected from a paper industry that uses high-pressure steam to dry their products before shipping them out. A significant amount of heat energy was required by the process to fulfill the product specification and demand. The facility also fitted quite well to the scope of a topping cycle CHP as the boiler used natural gas as the fuel and was being operated to about $30 \%$ of its total capacity. The stack temperature of the boiler was measured with a combustion analyzer which calculated the combustion efficiency of the boiler furnace. In addition to this, it also calculated the temperature of the flue gas, the temperature of the ambient air, and the percentage of excess air during combustion. Boiler parameters such as boiler pressure and temperature were recorded from the boiler display screen. The facility had a centralized computer that dynamically recorded most of the parameters in the boiler system. The data were later run through the spreadsheet-based DSS to validate its accuracy in an industrial setup. The recorded parameters are shown in Table 3-1.

Table 3-1: Quantitative values of the parameters

\begin{tabular}{|c|c|}
\hline Boiler Parameter & Values \\
\hline Boiler rated capacity & $204 \mathrm{MMBtu} / \mathrm{hr}$ \\
\hline Boiler maximum steam generation & $150,000 \mathrm{lbs} / \mathrm{hr}$ \\
\hline Boiler combustion efficiency & $56.96 \%$ \\
\hline Excess air \% during combustion & $18.52 \%$ \\
\hline Present steam generation & $46,500 \mathrm{lbs} / \mathrm{hr}$ \\
\hline Steam pressure & $186 \mathrm{psig}$ \\
\hline Steam temperature & $664^{0} \mathrm{~F}$ \\
\hline Boiler blowdown \% & $3.26 \%$ \\
\hline Process 1 steam requirement & $33,500 \mathrm{lbs} / \mathrm{hr}$ \\
\hline Process 1 steam pressure & $176 \mathrm{psig}$ \\
\hline Process 1 steam temperature & $374^{0} \mathrm{~F}$ \\
\hline Process 2 steam requirement & $10,000 \mathrm{lbs} / \mathrm{hr}$ \\
\hline Process 2 steam pressure & $60 \mathrm{psig}$ \\
\hline Process 2 steam temperature & $325^{\circ} \mathrm{F}$ \\
\hline Process steam loss & $100 \%(\mathrm{sent}$ to sewer $)$ \\
\hline Does the facility implement blowdown heat recovery? & No \\
\hline Does the facility have burner controls? & No \\
\hline Does the facility preheat combustion air? & No \\
\hline
\end{tabular}




\subsection{Variable determination}

Variables have been selected for the DSS as per the requirements in a boiler/turbine-based CHP system. A literature survey has been carried out on topping cycle CHP systems, and are mentioned in chapter 2 . These parameters, as defined in chapter 2, were also found to be an integral part of a boiler operating system in the facility. Therefore, these variables had to be considered during the development of the DSS. Finally, after collecting the values of these parameters from the facility, they are entered into the DSS for data analysis and result generation.

\subsection{Generation of DSS}

After the procurement of the data from the paper facility, the DSS was generated by referencing the reviewed literature and the parameters during the data collection. A hypothetical DSS was also developed for a gas turbine-based CHP system. The calculations and feasibility of the gas turbines in CHP systems were verified by consulting numerous research papers related to them. As a result, it was possible to integrate a gas turbine and a waste heat recovery boiler for a combined topping cycle in the DSS. The DSS has two different input sheets (i) boiler (ii) gas turbine. The values have to be entered into the respective parameter cells to successfully operate the DSS. Once a user inputs all the necessary parameters, the DSS calculates the variables such as total cost and energy savings, the flow of steam throughout the system, and payback on investment, among other variables. Similarly, the DSS also generates a spreadsheet with a block diagram for the entire CHP system (technical aspects) and also has values of important steam and energy parameters displayed. Finally, the DSS generates a result page that has all the economic aspects of the respective system for the facility. The result sheet displays total savings, cost incurred, and payback on investment on the investment. Finally, the result page also generates graphs related to the pinch point analysis for the change in output variables at different ranges of the input variables.

\subsection{Data analysis using the DSS}

As mentioned in Section 3.3, the data collected from the facility (as shown in 3.1) were entered through the DSS. The user enters the values of input parameters as requested in the input questionnaire in the boiler/gas turbine screen. Some buttons help a user to navigate between the input sheet, the block diagram sheet, and the result sheet. The navigation buttons are carefully programmed to move through different sheets corresponding to the usage of backpressure or a 
condensing turbine for power generation. As the implementation of either of the two turbines significantly changes the design of the CHP system, two spreadsheets have been developed for each of the turbine usages. The user can enter the values of various parameters repeatedly to operate the DSS several times. The DSS will procure the results based on the changes in variables. There are various options of energy efficiency measures that a user can change such as pre-heating the combustion air, burner controls using automatic modulation and excess air control, blowdown heat recovery, and type of turbine used. Based on the data entered by the user, the DSS will generate results commensurate with the energy, fuel, and water cost.

\subsection{Results}

\subsubsection{Block diagram of the CHP system}

Once the user enters all the data and clicks on the "go-to boiler/gas turbine diagram" button in the input spreadsheet, the DSS navigates the DSS to the block diagram spreadsheet. It is a comprehensive block diagram that consists of equipment such as boiler, economizer, deaerator, steam turbines, PRVs, process steam usage, and make-up water inflow. Similarly, the block diagram also has numerical values related to the steam/water flow rate at different points of the cycle, their pressure and temperature. For the gas turbine system, there are two block diagrams; one is when the user chooses a backpressure turbine and absorption cooling and the other one is when the user chooses a condensing turbine. The diagram makes it easier for a user (experienced or a layman) to understand the CHP system that they want to set up in the facility.

\subsection{Model}

Like previously described, the main purpose of this research is to identify opportunities in the topping cycle CHP system in industries that utilize boilers and gas turbines as their primary heat generator. The idea is to identify a range of values in the independent variables for which the payback on investment is the lowest by implementing sensitivity analysis between the respective variables. An excel-based DSS is developed to identify opportunities for the same. Sensitivity analyses are carried out with respect to output variables such as power generation and payback on investment. Different input variables that incur a substantial impact on the output variables are selected for the sensitivity analyses. Input variables are selected as per their severity of impact on 
the output. Users will be able to enter variables related to the input side of boilers and gas turbines. The DSS will finally provide the block diagram of the CHP system and the results, primarily focused on the payback on the investment period of the investment. The DSS has set boundaries regarding the operational pressure and temperature of the steam. They are as follows:

1. The operating temperature of the superheated steam should be between $32^{\circ} \mathrm{F}$ and $1,500^{\circ} \mathrm{F}$.

2. The operating pressure of the superheated steam should be between -14.5949 psig and 1,085 psig.

3. The operating temperature of the saturated liquid/steam should be between $32^{0} \mathrm{~F}$ and $705^{\circ} \mathrm{F}$.

4. The operating pressure of the saturated liquid/steam should be between $-14.61 \mathrm{psig}$ and 3,185 psig.

The DSS is further strengthened by the addition of superheated and saturated steam tables [51] based on the IAMWS Industrial formulation 1997 for the thermodynamics properties of water and steam (IAPWS-IF97). The DSS interpolates the pressure and temperature of the steam that the user provides and returns the accurate values of specific enthalpy and specific entropy, by consulting the steam tables. The DSS also returns the values of steam temperature for the corresponding pressure and specific entropy. Other than these values, the DSS performs algebraic calculations to generate the results and the payback on investment in implementing the opportunity, ultimately.

Figure 3-1 shows the fundamental design of the DSS in MS Excel ${ }^{\mathrm{R}}$. The primary box mentions the first choice that a user will have while using the DSS. The DSS computes the total energy savings, cost savings, and payback on investment. The user can tabulate between the CHP diagram sheet (boiler and gas turbine, separately), input parameter sheet, and the result sheet. In this section, the DSS for a topping cycle CHP with a boiler/gas turbine is presented. The power generated by the steam turbines is directly proportional to the amount of steam that is provided to them. Therefore, a significant amount of steam has to be utilized by the steam turbines to generate electricity that would result in a desirable payback on investment. The DSS has options to input up to four different processes and corroborate them with pressure-reducing valves (PRV) or a backpressure turbine, solely depending upon the profit. Similarly, the excess steam is run through the steam 
turbines (condensing or backpressure turbine) to generate power, while returning the condensate in the CHP system. Input parameters include, and are not limited to, steam quantity, steam pressure, steam temperature, excess air percentage, and boiler stack gas temperature. These parameters compute the output values of the boiler such as combustion efficiency, thermal efficiency, energy in the steam, and losses in steam and boiler system. The CHP systems only account for superheated steam and generate the specific enthalpy of steam as per the pressure and the temperature of steam. The DSS is equipped with saturated and superheated steam tables that automatically calculates the specific enthalpy and specific entropy of the steam at corresponding pressure and temperature. Based on the specific enthalpy of the steam at the turbine inlet and outlet, the total energy transfer from the steam to the turbine blades is calculated. The energy transfer, while considering the turbine's isentropic efficiency and the generator efficiency, is used to calculate the total power generation in kilowatt $(\mathrm{kW})$. 


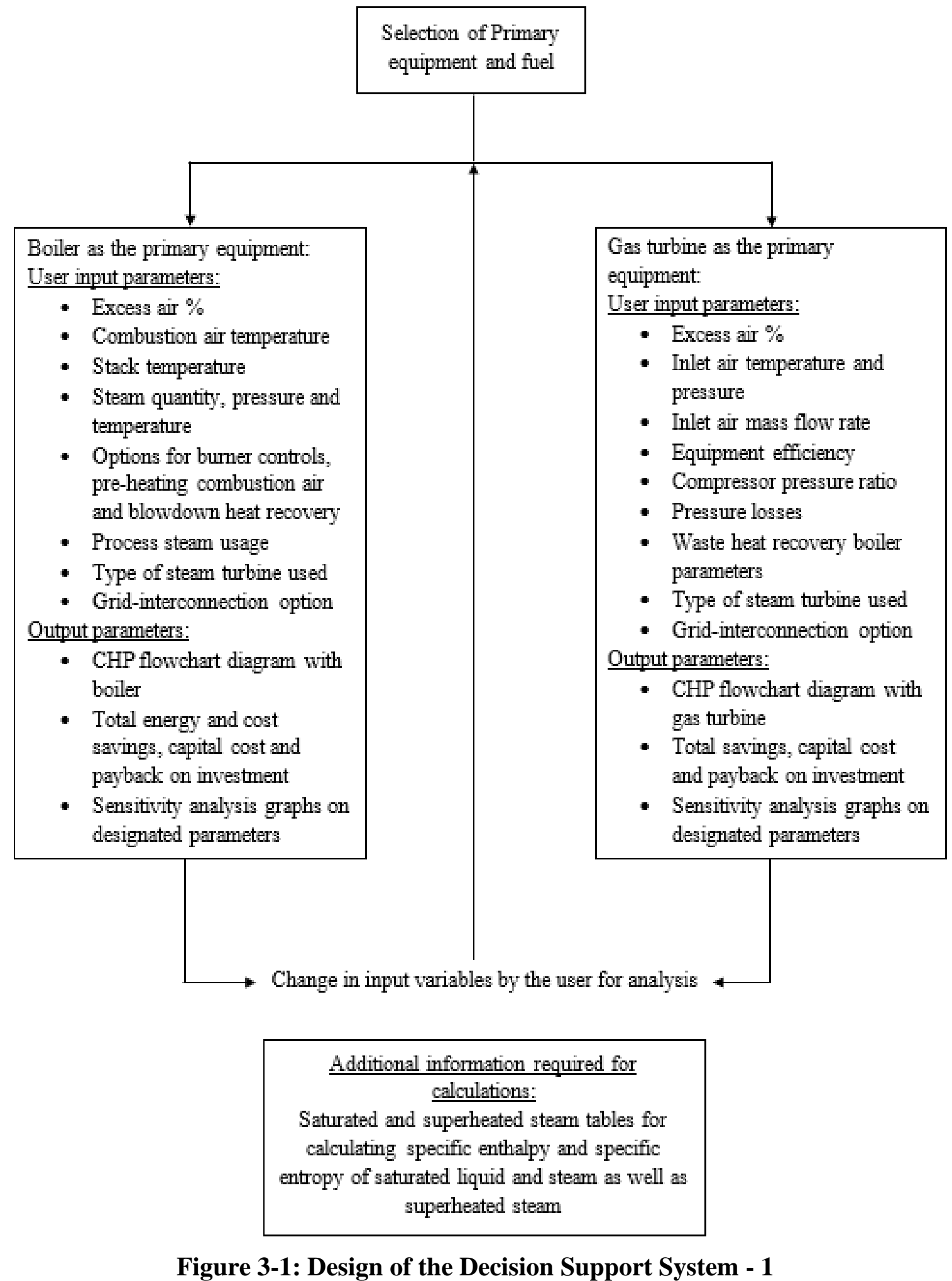




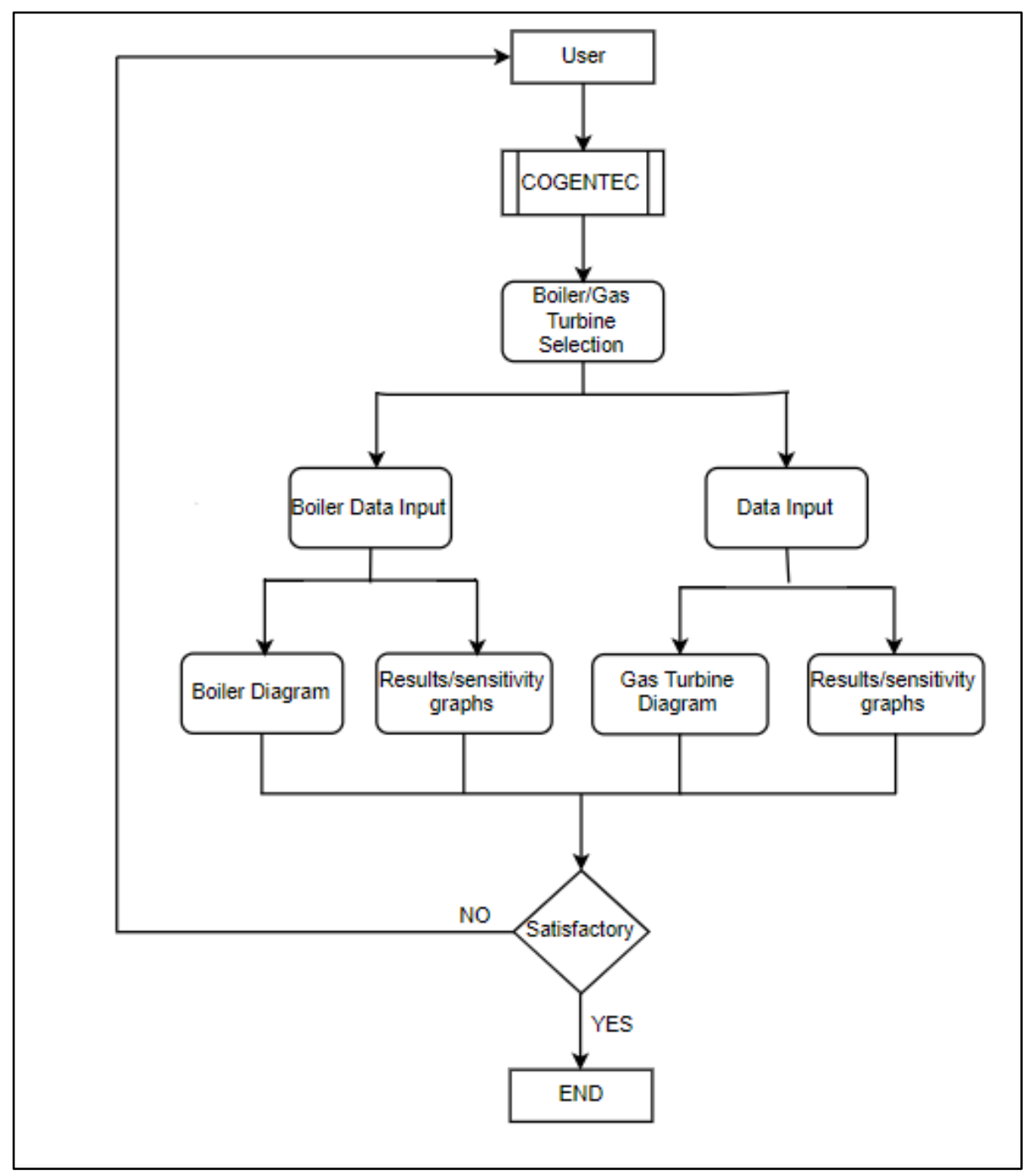

Figure 3-2: Design of the Decision Support System - 2

\begin{tabular}{|c|c|c|c|c|c|c|}
\hline 2 & \multicolumn{2}{|l|}{ A } & \multicolumn{3}{|c|}{ B } & C \\
\hline 1 & Primary Equipment & 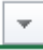 & & Iary Fuel & 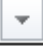 & \\
\hline 2 & Boiler & & 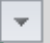 & Natural Gas & & \\
\hline 3 & GasTurbine & & & & & \\
\hline 4 & Boiler & & & & & \\
\hline 5 & & & & Continue & & \\
\hline 6 & & & & & & \\
\hline
\end{tabular}

Figure 3-3: Primary spreadsheet

Figure 3-3 lets the user choose the primary equipment among the gas turbine and boiler. Based on the requirement of the facility, a CHP system with a boiler or a gas turbine can be selected. The boiler system is integrated with fuels such as natural gas, coal, and \#4 fuel oil whereas the gas 
turbine system is integrated with natural gas only because natural gas is widely used as the reference fuel for gas turbines all over the world [52]. After the selection of the desired primary equipment, the user is guided to the input section of the spreadsheet, where input parameters as stated should be entered.

\subsubsection{Detailed calculations}

The DSS does meticulously detailed calculations to compute results on the summary and the block diagram sheet. These calculations cannot be brought into the display using the navigation buttons. However, they can be viewed on the parameter input sheet. These calculations are a fundamental part of this DSS. They are a comprehensive display of numerous values that are not shown in the result and the block diagram sheet. These values include specific enthalpy and entropy at every stage of the cycle. Similarly, the calculated values also include information regarding boiler feedwater, combustion, steam, steam turbines, HVAC, absorption chilling, deaerator, and economizer.

\subsubsection{Savings and payback on investment}

The "go-to result" button on every spreadsheet navigates the user to the "result" spreadsheet where the total cost savings and payback on investment is tabulated. The table also includes costs incurred by fuel and water consumption. The savings are generated from natural gas savings through comfort heating, electricity, and demand savings. Finally, the payback on investment period on investment is calculated by utilizing the cash inflow and outflow for the CHP process.

\subsubsection{Sensitivity analysis}

The DSS has an integrated sensitivity analysis graph creator that automatically creates graphs for pinch analysis of different output variables based on the changes occurring on the input variables. Effect of the steam and boiler properties on the power generation and the payback on investment is shown by the analysis. The analysis is dynamically created, and any change in the input variables changes the graph as per the relationship between the input and the output parameters. It means that the user can change the input parameters anytime during its usage, and the graph will let the user know about the most favorable numbers for a topping cycle CHP. The analysis can be done 
by the facilities themselves by referring the graphs to correctly devise a procedure to implement a CHP system with desirable payback on investment.

\subsection{Conclusion}

The proposed model is a decision management system designed in an MS Excel ${ }^{\mathrm{R}}$ with multiple tabs that calculates the economic and technical feasibility of a topping cycle CHP system with a steam boiler or a gas-turbine as the primary heat generator. Once the data is entered into the DSS, the program calculates and displays the results. The results include a CHP system block diagram with boiler/gas-turbine, detailed calculations, results on total savings and payback on investment, and pinch analysis. 


\section{Model Development}

\subsection{Assumptions}

1. Inlet mass flow rate is equal to the outlet mass flow rate in the steam turbines.

2. Steam passing through the steam turbines exhibit the isentropic process.

3. Steam flowing through the PRVs exhibits the isenthalpic process.

4. The boiler feed water leaves the deaerator and the economizer as the saturated liquid at the respective pressure.

\subsection{Input Parameters and tabs}

Values of parameters that dictate the output values such as power generation and payback on the investment of a boiler/gas-turbine based CHP systems are shown in the input screen. The name of the decision support system is termed as Cogeneration Topping Cycle Evaluation (COGENTEC) in this study.

Similarly, COGENTEC has 8 main tabs where a user can navigate using macro buttons that are designed for each tab. These tabs have unique functions that are exclusive to either a steam boiler or a gas turbine-based CHP system. Basic description of each tab is listed below:

\section{Main tab}

The "Main" tab is opened automatically every time the user opens COGENTEC. In this tab, the user can select the type of primary equipment (Gas turbine/Boiler) and the choice of fuel for their operation. Once selected, the user presses the "continue" button to load a corresponding tab of selection. The "continue" tab is coded to recognize the selection of one of the primary equipment and its fuel type.

\section{Boiler tab}

If the user selected "Boiler" in the "Main" tab, then COGENTEC directs to the "Boiler" tab where the user is required to enter the input parameters for a boiler-based cogeneration system. The input parameters are related to the boiler operations, turbine operations, water and steam quantity, 
energy, fuel, and water cost. After the user enters the required values for the parameters as shown in Figures 4-1, 4-2, and 4-3, COGENTEC computes the diagram and the result. Consequently, the user can select the "Boiler diagram" or the "Results" button to navigate to the respective tabs.

\section{Boiler Diagram}

The "Boiler Diagram" tab consists of an elaborated block diagram of a typical CHP system with the values based on the input parameters entered by the user for their analysis. The tab has comprehensive data related to the mass flow rate of water/steam in different parts of the CHP system. The user can go to either of the "Boiler" tab or the "Results" tab from this tab.

\section{Result - Boiler}

The "Result - Boiler" tab is generated by COGENTEC when the user selects the "Results" button in the "Boiler" tab or the "Boiler Diagram" tab. This tab includes the total energy cost and expenditure for the proposed CHP system. It also shows the overall payback on the investment for the CHP system. Similarly, the tab also has pinch analysis data corresponding to several input and output variables for a more comprehensive analysis of the system and data.

\section{Gas turbine}

The tab "Gas turbine" is opened when the user selects the gas turbine as the primary equipment. The input section can be used by the user to enter variables related to a gas-turbine-based CHP system. Similar to the "Boiler" tab, the user can select on the "Gas turbine diagram" button or the "Results" button.

\section{Diagram - GT BPT}

When the user selects a backpressure turbine as the choice of steam turbine, the user is directed to the "Diagram - GT BPT" tab which has the comprehensive CHP system block diagram that includes a backpressure turbine. The tab also has the "Results" button and the "Go back to input page" for navigation.

\section{Diagram - GT CT}


When the user selects a condensing turbine as the choice of the steam turbine, the user is directed to the "Diagram - GT CT" tab which has the CHP system block diagram that includes a condensing turbine. The user can open the results tab by clicking on the "Results" button within this tab.

\section{Result-GT}

The results of the gas turbine-based CHP system displays the energy cost and expenses of the proposed system. Similarly, the tab also has pinch analysis graphs to analyze the data and the variable correlation. The user can go back to the "gas turbine diagram" tab or the "input" tab if more analysis or modifications are required.

COGENTEC also has five more tabs (i) Constants (ii) Steam tables (iii) Saturated table (iv) Entropy (v) P-S. The constant tab has values of the thermodynamic and operational constant that are required for the study. The steam tables tab has the superheated properties of steam. Similarly, the saturated table tab has the saturated properties of steam and water. Entropy and the P-S tabs have specific entropy values of saturated and superheated steam.

\subsubsection{Boiler-based CHP system}

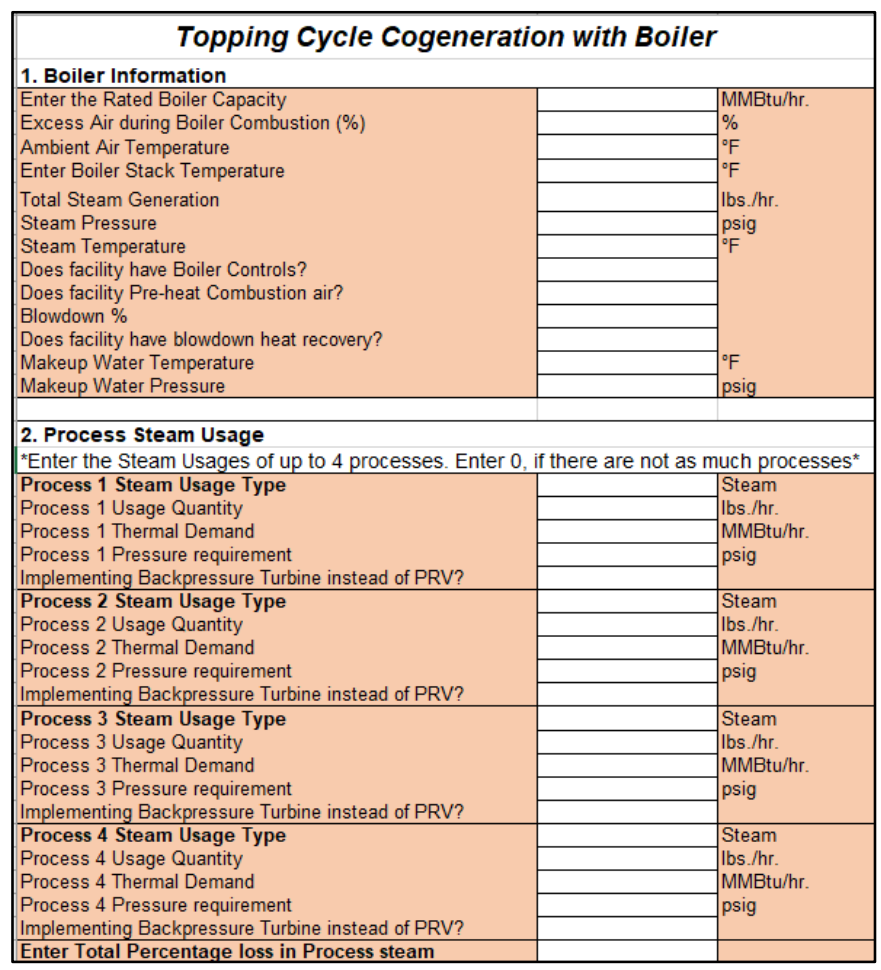

Figure 4-1: COGENTEC input screen-1 
cooling is required all the time) and heating during winter months. As the primary objective of a topping cycle is power generation, excess heat can only be used by the HVAC and chiller units in this study. Facilities are suggested to do an in-depth study to develop a situation for using the heat in outlet steam for district heating. Figure 4-3 lets the user input their utility, fuel, and water cost. The utility and the fuel costs are a constant price that the facilities pay to the utility companies. COGENTEC does not address or include the "time of day" costs that can vary constantly and arbitrarily within the same facility. The spot trading at various times of the day is prevalent in states such as California, Massachusetts, and Ohio. However, in states such as West Virginia and Vermont, distributed generation is not practiced. The user will have to enter the constant price of electricity that they owe to the facility for electricity usage every month. These values are utilized by COGENTEC to calculate expenditure and savings incurred by implementing the project.

\subsubsection{Gas turbine-based CHP system}

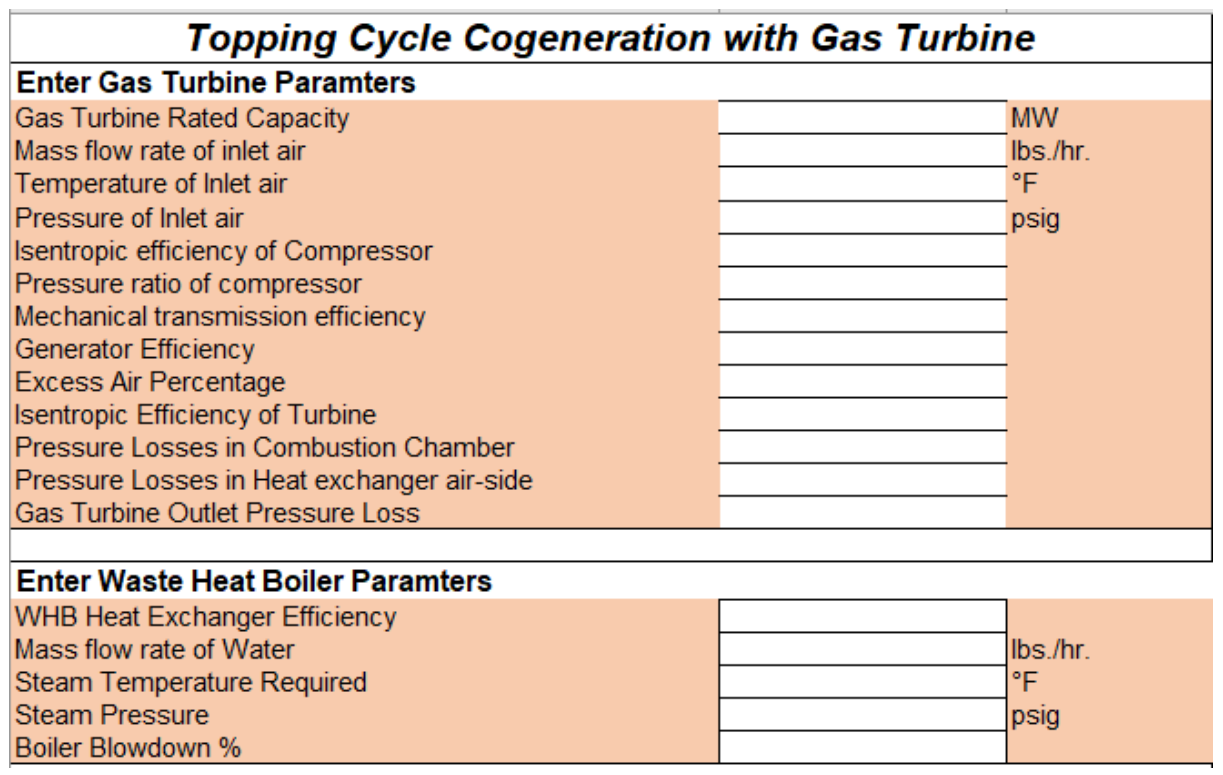

Figure 4-4: Gas turbine-based CHP input screen

In Figure 3-3, if the user selects the gas turbine, then COGENTEC redirects to the gas turbine input spreadsheet. The gas turbine CHP system is fundamentally different from the boiler-based CHP system. In the input section of the gas turbine system, the user has to enter the mass flow rate, pressure, and temperature of the inlet air, efficiency of the compressor, generator and the turbine, the pressure ratio of the compressor and pressure losses in the gas turbine system. Similarly, gas 
turbines exhaust gas is considered to be a high-grade heat source, therefore, the user has the option to install a waste heat recovery boiler to generate steam for using it in steam turbines. The user can enter the waste heat boiler's parameters such as its efficiency, mass flow rate of water, steam pressure, temperature, and boiler blowdown percentage.

\subsection{Process and calculations}

Once the user enters the input parameters in the gas turbine or boiler input sheet, COGENTEC computes the output parameters within the spreadsheet and displays them in the boiler/gas turbine block diagram spreadsheet and the resulting spreadsheet.

\subsubsection{Boiler-based CHP system}

\begin{tabular}{|c|c|c|c|}
\hline \multirow{6}{*}{ Boiler Feed Water Info } & Boiler feed water required & 151,244 & lbs./hr. \\
\hline & Boiler Feed Water Pressure & 192 & psig \\
\hline & Boiler Feedwater Temperature & 250 & ${ }^{\circ} \mathrm{F}$ \\
\hline & Boiler Combustion Chamber Inlet Temperature & 70 & ${ }^{\circ} \mathrm{F}$ \\
\hline & Boiler Feed Water Energy & 33.08 & MMBtu/hr. \\
\hline & Specific enthalpy of feed water & 218.70 & Btu/lb. \\
\hline \multirow{7}{*}{$\begin{array}{l}\text { Boiler Combustion } \\
\text { Properties }\end{array}$} & Initial Combustion Temperature rise & 3,715 & ${ }^{\circ} \mathrm{F}$ \\
\hline & Boiler Thermal Efficiency & $58 \%$ & \\
\hline & Boiler Combustion Efficiency & $51 \%$ & \\
\hline & Fuel Quantity & 336.83 & MMBtu/hr. \\
\hline & Fuel Consumption Rate in lbs./hr. & 15,002 & Ibs./hr. \\
\hline & Combustion air flow rate & 305,817 & $\mathrm{lbs} . / \mathrm{hr}$. \\
\hline & Flue Gas Flow Rate & 320,818 & lbs./hr. \\
\hline \multirow{4}{*}{$\begin{array}{l}\text { Inflow and Outflow of } \\
\text { energy in Boiler }\end{array}$} & Energy in Steam & 196.69 & MMBtu/hr. \\
\hline & Boiler Losses & 5.90 & MMBtu/hr. \\
\hline & Stack Losses & 166.25 & MMBtu/hr. \\
\hline & Blowdown losses & 1.07 & MMBtu/hr. \\
\hline \multirow[b]{2}{*}{ Steam Properties } & Specific enthalpy of Steam & $1,355.44$ & Btu/lb. \\
\hline & Total Steam Quantity & 145,110 & Ibs./hr. \\
\hline \multirow{3}{*}{ Process Steam } & Temperature of Outlet Water From Process & 356 & ${ }^{\circ} \mathrm{F}$ \\
\hline & Pressure of Outlet Water From Process & 137 & psig \\
\hline & Process Outlet Steam Quantity & 0 & lbs./hr. \\
\hline \multirow{10}{*}{ Turbine Properties } & Mass flow rate of steam to the turbines & 101,610 & Ibs./hr. \\
\hline & Specific entropy at Turbine Inlet/Outlet & 1.707 & Btu/lb.-R \\
\hline & Ideal Enthalpy at Turbine Outlet & $1,039.21$ & Btu/lb. \\
\hline & Actual Enthalpy at Turbine Outlet & $1,118.26$ & Btu/lb. \\
\hline & Temperature of Outlet steam/water & 166 & ${ }^{\circ} \mathrm{F}$ \\
\hline & Energy Transfer from Steam to Turbines & 24.10 & MMBtu/hr. \\
\hline & Power Generation & 6,708 & $\mathrm{~kW}$ \\
\hline & Energy content in the outlet steam & 172.588 & MMBtu/hr. \\
\hline & Turbine Condenser Outlet Pressure & 0.000 & psig \\
\hline & Turbine Condenser Outlet Temperature & 165.0 & ${ }^{\circ} \mathrm{F}$ \\
\hline \multirow{5}{*}{ HVAC } & Total Steam used by absorption chiller & 0 & lbs./hr. \\
\hline & Temperature outlet from Absorption Chiller & 0 & ${ }^{\circ} \mathrm{F}$ \\
\hline & Total Savings from Absorption Chiller & 0 & $\mathrm{kWh} / \mathrm{yr}$. \\
\hline & Outlet Temperature water/steam from HVAC heat $\epsilon$ & 160 & ${ }^{\circ} \mathrm{F}$ \\
\hline & Natural Gas Savings in HVAC & 0.81 & MMBtu/hr. \\
\hline
\end{tabular}

Figure 4-5: Computation of boiler-based CHP parameters-1 


\begin{tabular}{|c|c|c|c|c|}
\hline \multirow{4}{*}{ Condenser } & Comfort Heating Outlet Water Temperature & & 160 & $\begin{array}{l}{ }^{\circ} \mathrm{F} \\
\end{array}$ \\
\hline & Comfort Heating Outlet Water Pressure & & 0.0 & psig \\
\hline & Condenser Outlet Temperature & & 159.7 & ${ }^{\circ} \mathrm{F}$ \\
\hline & Condenser Outlet Quantity & & 101,610 & $\mathrm{lbs} / \mathrm{hr}$ \\
\hline \multirow{12}{*}{ Deaerator and Feedwater } & Makeup water Quantity & & 49,890 & $\mathrm{lbs} . / \mathrm{hr}$. \\
\hline & Temperature of water at Deaerator inlet/Outlet & & 114 & ${ }^{\circ} \mathrm{F}$ \\
\hline & Pressure of water at Deaerator inlet/Outlet & & 15.0 & psig \\
\hline & Mass flow rate of water going to Deaerator & & 151,500 & lbs./hr. \\
\hline & Specific enthalpy of saturated liquid deaerator feed & & 218.34 & $\mathrm{Btu} / \mathrm{lb}$. \\
\hline & Specific enthalpy of Vented Steam & & $1,163.90$ & Btu/lb. \\
\hline & Vent rate & & $1,500.00$ & $\mathrm{lbs} / \mathrm{hr}$ \\
\hline & Flash Steam from blowdown heat recovery & & 0.00 & $\mathrm{lbs} . / \mathrm{hr}$. \\
\hline & Flash Steam Heat Content at 5 psig & & $1,155.89$ & Btu/lb. \\
\hline & Total heat content in Flash Steam & & 0.80 & MMBtu/hr \\
\hline & Inlet steam to the deaerator & & 1,244 & Ibs./hr. \\
\hline & Deaerator Outlet Water & & 151,244 & $\mathrm{lbs} / \mathrm{hr}$ \\
\hline \multirow{8}{*}{ Economic aspects } & Fuel Cost & $\$$ & $8,851,989.34$ & lyr. \\
\hline & Water usage cost & $\$$ & $524,205.81$ & lyr. \\
\hline & Turbine Capital and Installation Cost & $\$$ & $3,450,339.88$ & \\
\hline & Electricity usage savings & $\$$ & $5,288,616.33$ & /yr. \\
\hline & Demand Savings & $\$$ & $1,287,943.10$ & /yr. \\
\hline & Chiller Savings & $\$$ & - & \\
\hline & NG savings in winter & $\$$ & $10,654.06$ & /yr. \\
\hline & Absorption Chiller Cost & $\$$ & - & \\
\hline Net Metering & Cost Savings from Selling Electricity & $\$$ & - & \\
\hline
\end{tabular}

Figure 4-6: Computation of boiler-based CHP parameters-2

Figures 4-5 and 4-6 displays the calculations carried out in the spreadsheet for properties related to boiler feedwater, boiler combustion and losses, process and turbine steam, steam turbine, comfort heating, and absorption cooling. For example, the boiler thermal efficiency utilizes the heating value of the fuel, excess air percentage, and stoichiometric ratio of the fuel. There are two different ways the spreadsheet calculates the thermal efficiency. They are explained below.

\subsubsection{Thermal Efficiency without burner controls}

Burner controls include automatic modulation and reduction in excess air utilization for increasing energy efficiency. Burner modulation mode changes the burner firing rate periodically between the preset limits to maintain the boiler pressure and temperature at a desirable operation range. Similarly, it also reduces boiler purge and draft losses, thereby letting the boiler to work in low firing mode frequently. The optimal amount of excess air percentage for complete combustion of fuel is about $10 \%$ [37]. However, the majority of burners operate with excess air higher than $10 \%$. Burner controls automatically operate boiler with excess air as low as $10 \%$ for higher fuel efficiency, while overseeing complete combustion. Similarly, Carpenter et. al [37] also estimated typical savings up to $11 \%$ while using boiler modulation with PLCs. The calculation for calculating thermal efficiency (TE) with boiler controls is shown below: 


$$
\mathrm{TE}=\left[\left\{(1+(1+\mathbf{E A}) \mathbf{x R}) \times \mathbf{C} \mathbf{p}_{\mathrm{g}}\right\} \mathbf{x}\left\{\frac{\mathrm{PA}+\frac{\mathrm{LHV}}{(1+(1+\mathrm{EA}) \times \mathbf{S R}) \mathbf{x C p _ { \mathrm { g } }}}}{\mathrm{HHV}}\right\}\right] \mathbf{x}(1+\mathrm{BS})
$$

Where,

EA $=$ Excess air with boiler modulation, $10 \%$

SR = Stoichiometric Ratio, no units

$\mathrm{Cp}_{\mathrm{g}}=$ Specific heat capacity of combustion gas, Btu/lb- ${ }^{0} \mathrm{~F}$

$\mathrm{PA}=$ Pre-heated combustion air, ${ }^{0} \mathrm{~F}$

LHV = Lower heating value of fuel, Btu/lb

$\mathrm{HHV}=$ Higher heating value of fuel, Btu/lb

BS = Boiler savings with burner controls, $11 \%$

\subsubsection{Thermal Efficiency without burner controls}

Thermal efficiency without boiler controls can be simply calculated by using the actual excess air in the system and stoichiometric ratio of the corresponding fuel. The thermal efficiency without taking burner controls into account can be calculated as:

$$
\mathrm{TE}=\left[\frac{\left\{(1+(1+\mathrm{EA})+\mathrm{SR}) \mathbf{x} \mathbf{C p}_{\mathrm{g}} \mathbf{x}(\mathrm{TR}-\text { Stack Temperature })\right\}}{\text { HHV }}\right]
$$

Where,

EA = Excess air percentage during combustion, \%

SR = Stoichiometric Ratio, no units

$\mathrm{Cp}_{\mathrm{g}} \quad=$ Specific heat capacity of combustion gas, $\mathrm{Btu} / \mathrm{lb}-{ }^{0} \mathrm{~F}$

TR = Initial temperature rise during combustion, ${ }^{0} \mathrm{~F}$

$\mathrm{HHV}=$ Higher heating value of fuel, Btu/lb 


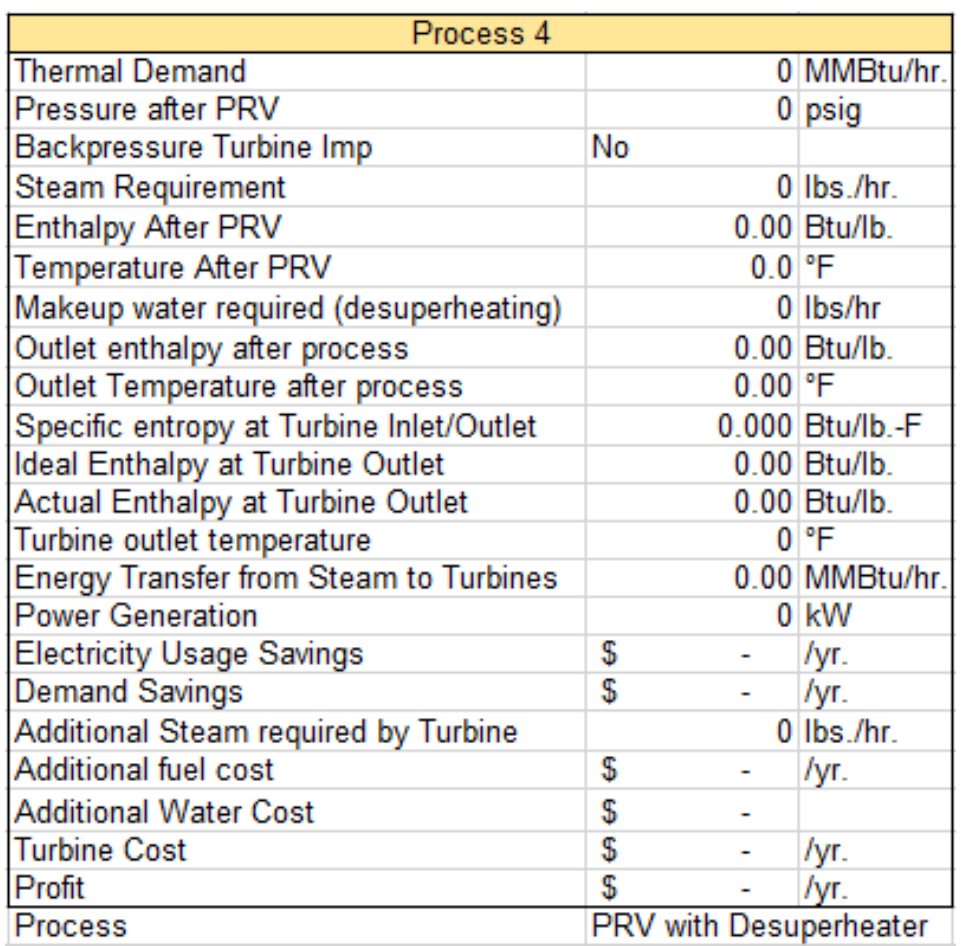

Figure 4-7: Computation of boiler-based CHP parameters-3

Similarly, in Figure 4-7, the calculated parameters for one of the four processes are shown. The process thermal demand, PRV outlet pressure, backpressure turbine implementation, and steam requirement are entered by the user in the input section. When a process requires saturated steam at a lower pressure, a PRV with desuperheating is selected by COGENTEC. It calculates additional makeup water required by the PRV to reduce the pressure to the desired state. PRV with desuperheater utilizes makeup water to expand the superheated steam into saturated steam/water. Outlet enthalpy from the PRV (with desuperheating) is assumed to be the specific enthalpy of saturated steam at the outlet pressure. Similarly, the outlet steam temperature after the desuperheating process in the PRV is also assumed to be the saturated steam temperature at the set pressure. The calculations for PRV with a desuperheater is shown below:

Where,

$$
\text { Makeup water for PRV }=\frac{\text { Steam flow rate } \mathrm{x}\left(\mathrm{h}_{\mathrm{s}}-\mathrm{h}_{\mathrm{prv}}\right)}{\mathrm{h}_{\mathrm{prv}}-\mathrm{h}_{\mathrm{mw}}}
$$

$$
\begin{array}{ll}
\mathrm{h}_{\mathrm{s}} & =\text { Specific enthalpy of inlet steam, Btu/lb } \\
\mathrm{h}_{\text {prv }} & =\text { Specific enthalpy of PRV outlet steam, Btu/lb } \\
\mathrm{h}_{\mathrm{mw}} & =\text { Specific enthalpy of makeup water, Btu/lb }
\end{array}
$$




\subsubsection{Gas-turbine based CHP system}

\begin{tabular}{|c|c|}
\hline Compressor Outlet Temperature & $128^{\circ} \mathrm{F}$ \\
\hline Compressor work required & $2,930 \mathrm{~kW}$ \\
\hline Pressure of compressed air & 267 psia \\
\hline Initial Temperature at Combustion Chamber & $3,831^{\circ} \mathrm{F}$ \\
\hline Mas flow rate of fuel & $7,650 \mathrm{lbs} . / \mathrm{hr}$ \\
\hline Fuel Energy & $155 \mathrm{MMBtu} / \mathrm{hr}$. \\
\hline Combustion efficiency & $92 \%$ \\
\hline Turbine Inlet Temperature & $1,533^{\circ} \mathrm{F}$ \\
\hline Turbine Inlet Pressure & 253 psia \\
\hline Turbine Outlet Temperature & $987^{\circ} \mathrm{F}$ \\
\hline Power Generated by Turbine & $16,752 \mathrm{~kW}$ \\
\hline Net Power & $13,822 \mathrm{~kW}$ \\
\hline Flue Gas Outlet Temperature from WRSG & $225^{\circ} \mathrm{F}$ \\
\hline Steam Specific Enthalpy & $1,379.01 \mathrm{Btu} / \mathrm{lb}$ \\
\hline Mass flow rate of steam to the turbines & $98,000 \mathrm{lbs} . / \mathrm{hr}$ \\
\hline Steam Specific Entropy & $1.609 \mathrm{Btu} / \mathrm{lb}-\mathrm{F}$ \\
\hline Ideal Enthalpy at Turbine Outlet & 1,094.86 Btu/lb. \\
\hline Actual Enthalpy at Turbine Outlet & 1,165.89 Btu/lb. \\
\hline Temperature of Outlet steam/water & $260^{\circ} \mathrm{F}$ \\
\hline Energy Transfer from Steam to Turbines & $20.88 \mathrm{MMBtu} / \mathrm{hr}$. \\
\hline Power Generation & $5,813 \mathrm{~kW}$ \\
\hline Energy content in the outlet steam & $133 \mathrm{MMBtu} / \mathrm{hr}$. \\
\hline Steam Pressure after Condensing Turbine conde & 15 psig \\
\hline Steam Temperature after Condensing Turbine co & 212 \\
\hline Total Steam used by absorption chiller & $7,200 \mathrm{lbs} . / \mathrm{hr}$. \\
\hline Temperature outlet from Absorption Chiller & $250^{\circ} \mathrm{F}$ \\
\hline Total Savings from Absorption Chiller & $1,536,225 \mathrm{kWh} / \mathrm{yr}$. \\
\hline Outlet Temperature from HVAC heat exchanger & $254{ }^{\circ} \mathrm{F}$ \\
\hline Outlet after reaching saturation point & 250 \\
\hline Natural Gas Savings in HVAC & $0.54 \mathrm{MMBtu} / \mathrm{hr}$. \\
\hline Hot water For Kalina Cycle & $98,000 \mathrm{lbs} / \mathrm{hr}$ \\
\hline Hot water Pressure & 15 psig \\
\hline Hot Water Temperature & $250{ }^{\circ} \mathrm{F}$ \\
\hline Hot Water Temperature Out & $176^{\circ} \mathrm{F}$ \\
\hline Energy Transfer from Hot water to $\mathrm{NH} 3$ & 7.22 MMBtu/hr. \\
\hline Power generation from Kalina Cycle & $260 \mathrm{~kW}$ \\
\hline
\end{tabular}

Figure 4-8: Computation of gas turbine-based CHP parameters-1

\begin{tabular}{|c|c|c|}
\hline Temperature before mixing with makeup water & 176 & ${ }^{\circ} \mathrm{F}$ \\
\hline Makeup Water Quantity & 2,000 & $\mathrm{lbs} / \mathrm{hr}$ \\
\hline Makeup Water Temperature & 60 & ${ }^{\circ} \mathrm{F}$ \\
\hline Temperature at Deaerator Inlet & 174 & ${ }^{\circ} \mathrm{F}$ \\
\hline Pressure of water at Deaerator inlet/Outlet & 10.0 & psig \\
\hline Mass flow rate of water going to Deaerator & 100,000 & lbs./hr. \\
\hline Specific enthalpy of saturated liquid deaerator fe & 207.82 & $\mathrm{Btu} / \mathrm{lb}$. \\
\hline Specific enthalpy of Vented Steam & $1,160.28$ & Btu/lb. \\
\hline Vent rate & $1,000.00$ & Ibs/hr \\
\hline Inlet steam to the deaerator & 813 & lbs./hr. \\
\hline Boiler feedwater Quantity & 99,813 & lbs./hr. \\
\hline Boiler Feed Water Pressure & 10 & psig \\
\hline Boiler Feedwater Temperature & 239 & ${ }^{\circ} \mathrm{F}$ \\
\hline Boiler Feed Water Energy & 20.74 & MMBtu/hr. \\
\hline Specific enthalpy of feed water & 207.82 & $\mathrm{Btu} / \mathrm{lb}$ \\
\hline Total Power generation & 19,895 & $\mathrm{~kW}$ \\
\hline NG Cost Savings from HVAC Boiler & $7,762.52$ & /yr. \\
\hline Electricty Savings from Absorption Chiller & $\$ 153,622.51$ & /yr. \\
\hline Total Electricity Savings from turbines & $\$ 17,428,232.95$ & /yr. \\
\hline Total Demand Savings & $\$ 3,581,143.76$ & /yr. \\
\hline Natural Gas Cost & $-\$ 4,074,445.96$ & /yr. \\
\hline Water Usage Cost & $-\$ 176,200.00$ & /yr. \\
\hline Gas Turbine Cost & $-\$ 24,382,742.14$ & \\
\hline Steam Turbine Cost & $-\$ 3,126,715.74$ & \\
\hline ORC cost & $-\$ 390,137.14$ & \\
\hline HRSG cost & $-\$ 300,000.00$ & \\
\hline Absorption Chiller Cost & $720,000.00$ & \\
\hline Net metering capital cost & - & \\
\hline \multirow[t]{2}{*}{ Cost savings by selling Electricity } & 0 & \\
\hline & 21.00 & months \\
\hline
\end{tabular}

Figure 4-9: Computation of gas turbine-based CHP parameters-2 
Figures 4-8 and 4-9 illustrate the calculated parameters in a gas turbine-based CHP system. COGENTEC computes the power generated by the gas turbine, a steam turbine in the Rankine cycle, and the Organic Rankine cycle (ORC). The user selects an option to implement a condensing turbine or a backpressure turbine to generate electricity from the steam coming out of the waste heat recovery boiler. COGENTEC automatically integrates an ORC based on the working fluid of ammonia and water mixture. While it does not do calculations of an ORC in detail, the research assumes that for a $1 \mathrm{MMBtu} / \mathrm{hr}$ of energy transferred from the hot water to the working fluid in the ORC, $36 \mathrm{~kW}$ of electrical energy is generated [53], [54]. Similarly, with a backpressure turbine, COGENTEC calculates savings and investment costs for an absorption chilling system as well.

\subsection{Output spreadsheet}

COGENTEC has five output screens for the boiler and gas turbine-based CHP system. They are shown below:

1. Boiler diagram

2. Result - Boiler

3. Diagram - Gas turbine (Backpressure turbine)

4. Diagram - Gas turbine (Condensing turbine)

5. Result - Gas turbine

There are specific buttons in each spreadsheet to move between them. These buttons simplify the user interface and let a user switch to different sheets as per their needs. Figure 4-10 shows the switching buttons. The gas turbine diagram (either with a backpressure turbine or a condensing turbine) sheet is opened when the user clicks on the first button shown below. COGENTEC decides which spreadsheet to open depending upon the utilization of the steam turbine for the bottoming cycle. Similarly, clicking on the "results" button would lead the user to the results page where total cost savings, investment cost, the payback on investment period on investment, and the sensitivity graphs are located.

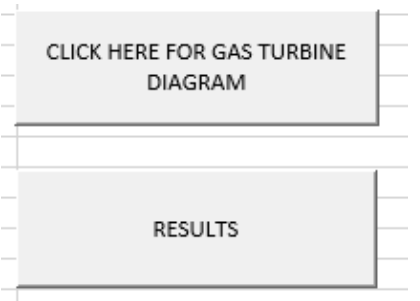

Figure 4-10: Buttons to move between spreadsheets 


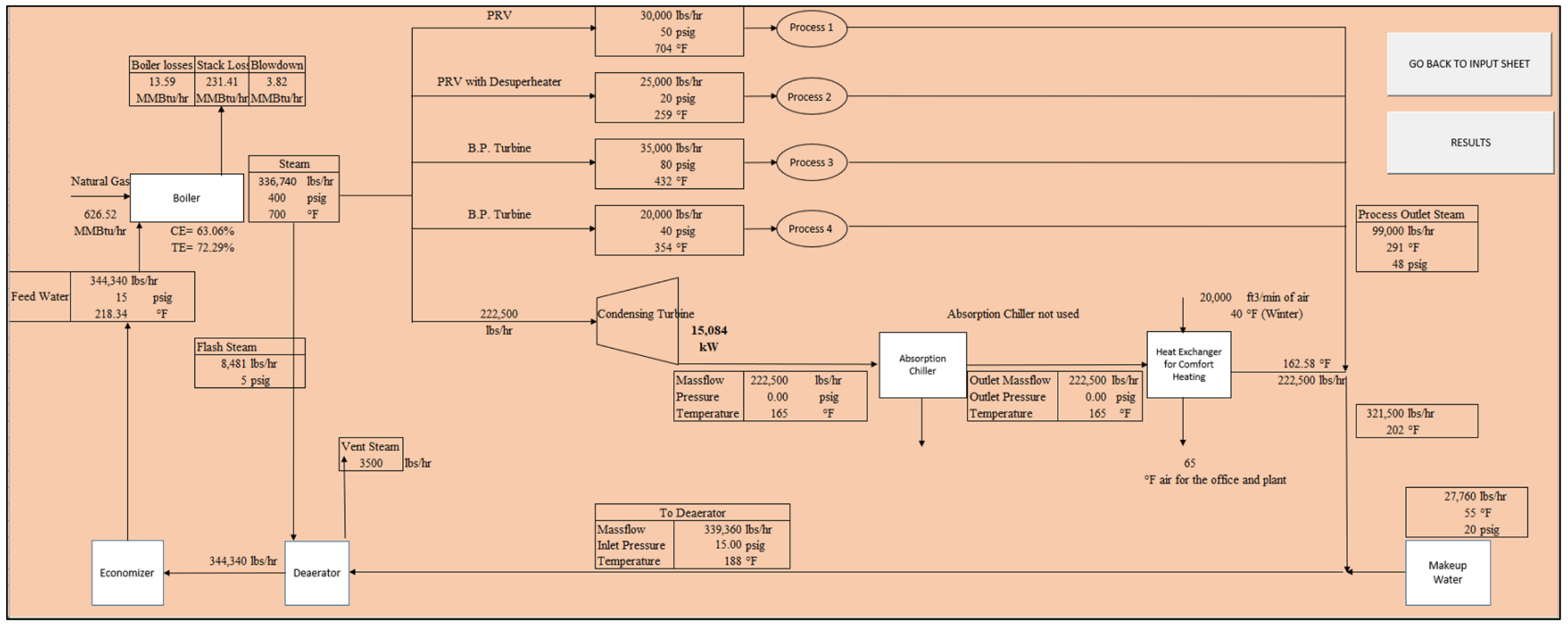

Figure 4-11: Boiler diagram result using a condensing turbine 
The boiler based-CHP diagram is an inclusive diagram that corporates the major processes and equipment in a topping cycle CHP system. Figure 4-11 presents a flowchart of the CHP process which starts with boiler feed water going into the boiler. The boiler heats the water to change its phase to superheated steam as per the requirement of the facility's processes. COGENTEC allows up to four different industrial processes that utilize superheated steam, low-pressure steam, and saturated water. Similarly, the excess steam is directed into a backpressure turbine or a condensing steam turbine, that generates electricity. In cases that utilize a backpressure turbine, the outlet steam still has a substantial amount of energy that is transferred to the working fluid in absorption chilling and comfort heating. However, if a condensing turbine is used, the turbine outlet is saturated water which cannot be used for absorption chilling. Therefore, in cases where a condensing turbine is used, the facility can utilize the turbine outlet water for comfort heating during the winter season.

The user can enter the percentage loss in steam during the process. The makeup water is then mixed with the turbine outlet water in a condenser, and later with makeup water. Condensate is then returned to the boiler through a deaerator and an economizer. The deaerator uses a portion of steam from the boiler. The amount of steam consumed by the deaerator is depended upon the temperature and amount of the condensate. The deaerator loses a percentage of steam which contains dissolved oxygen and $\mathrm{CO}_{2}$. The flash steam removes dissolved oxygen and impurities from the condensate and sends it to the boiler economizer where it is heated up to its saturated temperature.

The boiler diagram also has boiler losses, stack losses, blowdown losses, the total power generated embedded in it. The diagram is aimed to help the user to carefully gauge the process and its parameters. 


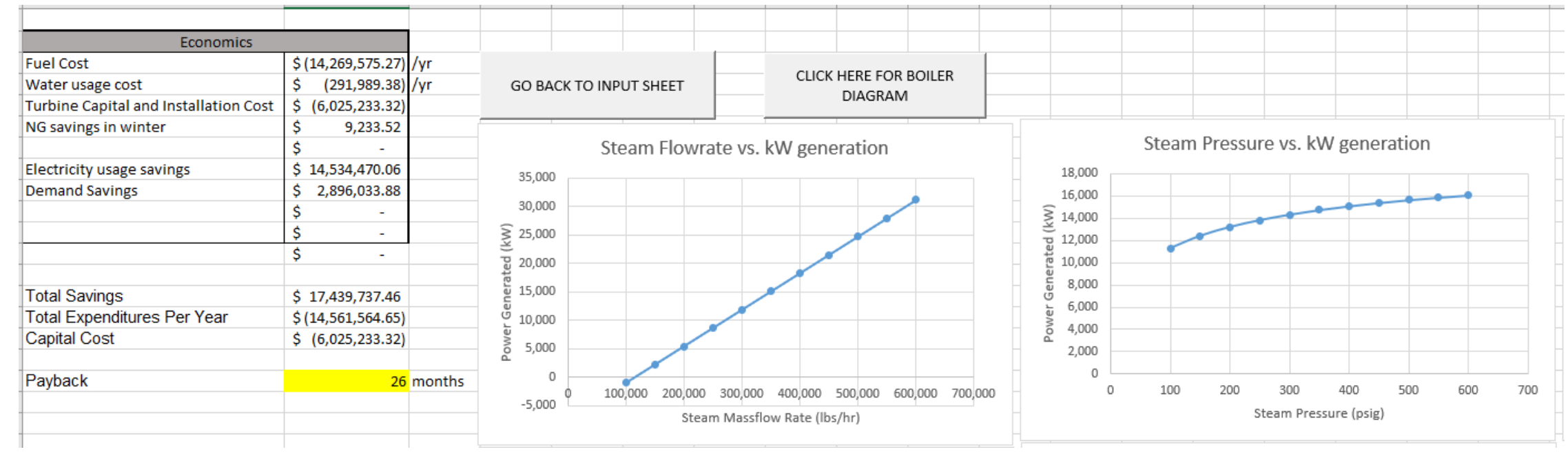

Figure 4-12: Payback on investment result and sensitivity analysis graphs 
Figure 4-12 shows the results of the boiler-based CHP system that constitutes the capital cost, annual cost, annual savings, and the payback on investment. If the total cost incurred on fuel and water is more than that of the cost savings, then COGENTEC will calculate the payback on investment is extremely high and not feasible. The capital cost includes the cost of the steam turbine, absorption chiller, and grid interconnection costs (if applicable). The table processes the total savings, capital cost, and annual cost to calculate the payback on investment on the investment.

Similarly, the spreadsheet also has numerous graphs for pinch analysis which lets the user know about the what-if scenarios for different variable values. The graphs are generated by plotting the major input variables against the output variables. Some examples include steam flowrate vs. kW generation, steam pressure vs. kW generation, and turbine exit pressure vs. payback on investment. The result sheet has different sensitivity graphs that analyze the impact of change in the independent variable on the dependent variable. Figure 4-13, 4-14, and 4-15 show the results of a gas turbine-based CHP.

\begin{tabular}{|c|c|c|}
\hline \multicolumn{3}{|l|}{ Economics } \\
\hline NG Cost Savings from HVAC Boiler & $6,468.77$ & /yr \\
\hline ( & - & /yr \\
\hline Total Electricity Savings from Turbines & $\$ 22,434,546.77$ & /yr \\
\hline Total Demand Savings & $\$ 3,841,531.98$ & $/ \mathrm{yr}$ \\
\hline & $\$$ & \\
\hline Natural Gas Cost & $\$(3,225,634.45)$ & $/ \mathrm{yr}$ \\
\hline Water Usage Cost & $\$ \quad(351,400.00)$ & $/ \mathrm{yr}$ \\
\hline Gas Turbine Cost & $\$(25,161,451.91)$ & \\
\hline Steam Turbine Cost & $\$(3,483,202.35)$ & \\
\hline ORC cost & $\$ \quad-$ & \\
\hline HRSG cost & $\$ \quad(300,000.00)$ & \\
\hline 0 & - & \\
\hline & $\$$ & \\
\hline Total Savings & $\$ 26,282,547.52$ & /yr \\
\hline Total Expenditures Per Year & $\$(3,577,034.45)$ & $/ \mathrm{yr}$ \\
\hline Capital Cost & $\$(28,944,654.26)$ & \\
\hline Payback & 16 & months \\
\hline
\end{tabular}

Figure 4-13: Gas turbine-based CHP results 


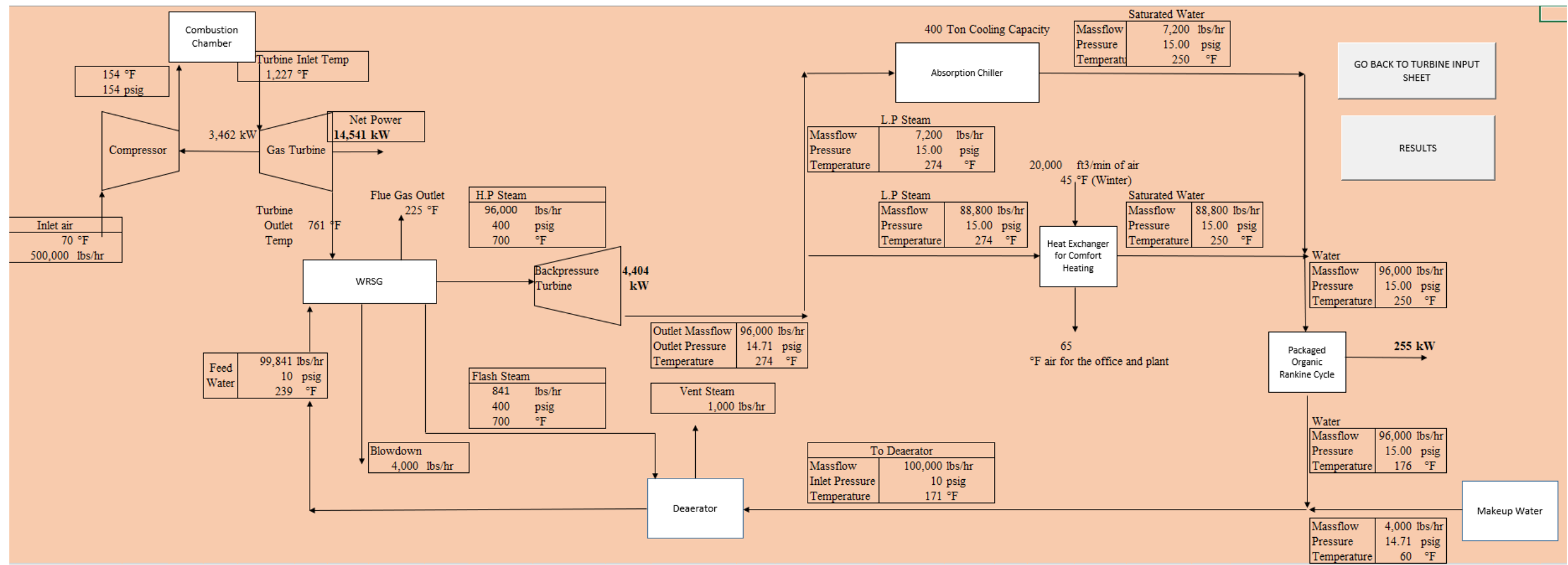

Figure 4-14: Gas turbine-based CHP (Backpressure turbine) 


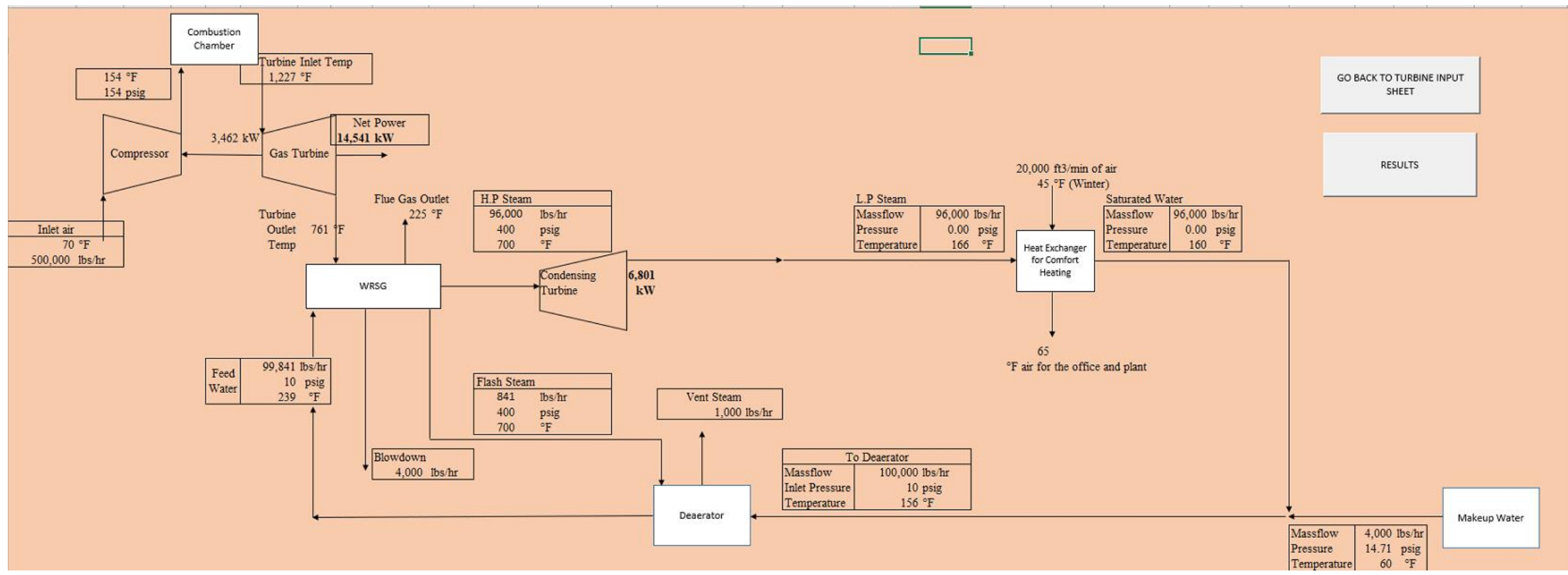

Figure 4-15: Gas turbine-based topping cycle CHP (condensing turbine) 
Finally, COGENTEC performs sensitivity analysis using different input variables that have a substantial impact on output parameters such as power generation and payback on investment period. The simple payback on investment period includes the cost of steam turbines, gas turbines, absorption chillers, energy, and water cost. The sensitivity charts help users picture the range of independent variables that result in corresponding savings.

\subsection{Conclusion}

Microsoft Excel ${ }^{\mathrm{R}}$-based decision support system "COGENTEC" was designed to evaluate the technical and economic feasibility of a topping cycle based CHP system. COGENTEC has the technical capability of incorporating two types of CHP topping cycle systems (i) boiler-based CHP system (ii) gas turbine-based CHP system. The boiler-based CHP system utilizes a steam boiler whose excess steam is used to generate electricity aided by a steam turbine. Similarly, Gas-turbine based CHP system utilizes a gas turbine unit and a waste heat recovery boiler to generate steam from the turbine exhaust to generate electricity. COGENTEC computes the results such as the power generation, payback on the investment, a block diagram of the CHP system, and graphs on the sensitivity analysis is various operating parameters. The user can analyze the results and the ranges of values calculated by the sensitivity analysis graphs to decide whether or not to implement a topping cycle CHP system in their facility. 


\section{Model Execution}

\subsection{Boiler-based CHP system}

As mentioned in Section 4.2.1, the data collected from the facility are entered in the input screen of the COGENTEC. The information is then processed in COGENTEC and displayed in the result and boiler diagram tab. The process that COGENTEC utilizes is described in the sections below.

\subsubsection{Verification process}

The input parameters from Table 3.1 are selected as per the requirements of the plant which has an opportunity for the topping cycle. The plant has a natural gas boiler of rated capacity 204.8 $\mathrm{MMBtu} / \mathrm{hr}$ that can generate a maximum $150,000 \mathrm{lbs} / \mathrm{hr}$ of steam consistently. However, only $43,500 \mathrm{lbs} / \mathrm{hr}$ of steam is generated in the current scenario to satisfy the heat requirements for two plant processes. The validation process will have the boiler run at its maximum capacity and generate steam at the required pressure and temperature as per its capability. The output power using a condensing steam turbine will be generated at the designated steam flow rate, pressure, temperature, specific enthalpy, and specific entropy. The fuel used in the boiler is natural gas and its price is $\$ 3.0 / \mathrm{MMBtu}$ and the cost of electricity is $\$ 0.09 / \mathrm{kWh}$. The measurements of power will help to get the data on the economic benefits of power generation by varying several major parameters. The change in steam quantity would also change the amount of electricity and supplemental heat generation in the pinch analysis. The study is carried out under the current pressure and temperature condition of steam that the facility has been working with. The analysis provides us the respective amount of heat and power generation. Similarly, a sensitivity analysis chart is developed for the relationship between the output parameters and the change in input parameters to identify a point of breakeven in terms of cost savings and natural gas usage cost.

The boiler system in the facility has an economizer which utilizes the heat content from the flue gas to pre-heat the feed water going to the boiler furnace. The stack temperature is $1,357^{0}$ and it heats the boiler feed water to a temperature of $226^{\circ} \mathrm{F}$ and a pressure of $192 \mathrm{psig}$. Pre-heating the boiler feedwater reduces the load on the burners and saves natural gas usage. Similarly, the stack gas can also be used to pre-heat the combustion air going to the burners, thereby reducing natural gas usage. However, this energy efficiency method is not implemented by the facility. The boiler 
is set at a steam flow rate of $150,000 \mathrm{lbs} / \mathrm{hr}$, out of which $43,500 \mathrm{lbs} / \mathrm{hr}$ is used for the process, and the remaining steam is used to rotate the prime mover for power generation. A condensing steam turbine is used for the validation process because it generates more power than a backpressure turbine. The steam that enters the turbine is at $186 \mathrm{psig}$ and $664^{\circ} \mathrm{F}$ and comes out of the turbine at -10 psig and $166^{\circ} \mathrm{F}$, generating power by moving the blades of the turbine. The steam at a negative pressure is immediately condensed by a condenser that is attached to the turbine, thereby losing its latent heat of vaporization. Finally, the saturated water can be used to heat the air for comfort heating during the winter season. In a case where a backpressure turbine is used, the outlet steam can also be used conveniently for an absorption chiller system. After utilizing the heat content from the turbine water, makeup water is introduced to the system to fill in the void created by the usage of all the steam by the process. The mixture of water is then sent to the deaerator for water treatment, after which it enters the economizer gaining sensible heat by exchanging heat with the stack air. Finally, the water is sent back to the boiler to complete the loop. Figures 5-1 and 5-2 show the input parameters and input values for the facility.

\begin{tabular}{|c|c|c|}
\hline \multirow{4}{*}{$\begin{array}{l}\text { Turbine Type } \\
\text { Enter Turbine Outlet Pressure } \\
\text { Enter Deaerator Inlet Pressure } \\
\text { Enter Deaerator Vent Rate }\end{array}$} & Condensing Turbine & \multirow{4}{*}{$\begin{array}{l}\text { psig } \\
\text { psig } \\
\%\end{array}$} \\
\hline & -10 & \\
\hline & 15 & \\
\hline & $1.00 \%$ & \\
\hline \multicolumn{3}{|l|}{ 4. HVAC } \\
\hline \multirow{4}{*}{$\begin{array}{l}\text { HVAC Rated CFM } \\
\text { Average Winter Temperature } \\
\text { HVAC Coefficient Of Performance } \\
\text { HVAC Total Capacity }\end{array}$} & 20,000 & \multirow{3}{*}{${ }^{\circ} \mathrm{F}$} \\
\hline & 45 & \\
\hline & 4 & \\
\hline & 400 & Ton \\
\hline \multicolumn{3}{|l|}{ 5. Net Metering } \\
\hline \multirow{4}{*}{$\begin{array}{l}\text { Scope for Net Metering } \\
\text { Capital Cost } \\
\text { Cost of Electricity Sold } \\
\% \text { of Generated Electricity Sold }\end{array}$} & No & \multirow{4}{*}{$/ \mathrm{kWh}$} \\
\hline & & \\
\hline & & \\
\hline & & \\
\hline
\end{tabular}

Figure 5-1: Input values for the facility-Part 1 


\section{Topping Cycle Cogeneration with Boiler}

\begin{tabular}{|c|c|c|}
\hline \multicolumn{3}{|l|}{ 1. Boiler Information } \\
\hline \multirow{2}{*}{$\begin{array}{l}\text { Enter the Rated Boiler Capacity } \\
\text { Excess Air during Boiler Combustion (\%) }\end{array}$} & 204 & MMBtu/hr. \\
\hline & $19 \%$ & $\%$ \\
\hline \multirow{2}{*}{$\begin{array}{l}\text { Ambient Air Temperature } \\
\text { Enter Boiler Stack Temperature }\end{array}$} & 70 & ${ }^{\circ} \mathrm{F}$ \\
\hline & 1,357 & ${ }^{\circ} \mathrm{F}$ \\
\hline Total Steam Generation & 150,000 & Ibs./hr. \\
\hline Steam Pressure & 186 & psig \\
\hline Steam Temperature & 664 & ${ }^{\circ} \mathrm{F}$ \\
\hline Does facility have Burner Controls? & No & \\
\hline Does facility Pre-heat Combustion air? & No & \\
\hline Blowdown \% & $3.26 \%$ & \\
\hline Does facility have blowdown heat recovery? & No & \\
\hline Boiler feedwater pressure & 192 & psig \\
\hline \multirow{2}{*}{$\begin{array}{l}\text { Makeup Water Temperature } \\
\text { Makeup Water Pressure }\end{array}$} & 60 & ${ }^{\circ} \mathrm{F}$ \\
\hline & 20 & psig \\
\hline \multicolumn{3}{|c|}{ 2. Process Steam Usage } \\
\hline \multicolumn{3}{|c|}{${ }^{*}$ Enter the Steam Usages of up to 4 processes. Enter 0 , if there are not as much processes ${ }^{*}$} \\
\hline \multirow{5}{*}{$\begin{array}{l}\text { Process } 1 \text { Steam Usage Type } \\
\text { Process } 1 \text { Usage Quantity } \\
\text { Process } 1 \text { Thermal Demand } \\
\text { Process } 1 \text { Pressure requirement } \\
\text { Implementing Backpressure Turbine instead of PRV? }\end{array}$} & Superheated & Steam \\
\hline & 10,000 & Ibs./hr. \\
\hline & 8 & MMBtu/hr. \\
\hline & 60 & psig \\
\hline & No & \\
\hline \multirow{5}{*}{$\begin{array}{l}\text { Process } 2 \text { Steam Usage Type } \\
\text { Process } 2 \text { Usage Quantity } \\
\text { Process } 2 \text { Thermal Demand } \\
\text { Process } 2 \text { Pressure requirement } \\
\text { Implementing Backpressure Turbine instead of PRV? }\end{array}$} & Saturated & Steam \\
\hline & 33,500 & Ibs./hr. \\
\hline & 30 & MMBtu/hr. \\
\hline & 176 & psig \\
\hline & $\mathrm{No}$ & \\
\hline \multirow{5}{*}{$\begin{array}{l}\text { Process } 3 \text { Steam Usage Type } \\
\text { Process } 3 \text { Usage Quantity } \\
\text { Process } 3 \text { Thermal Demand } \\
\text { Process } 3 \text { Pressure requirement } \\
\text { Implementing Backpressure Turbine instead of PRV? }\end{array}$} & Superheated & Steam \\
\hline & 0 & Ibs./hr. \\
\hline & 0 & MMBtu/hr. \\
\hline & 0 & psig \\
\hline & No & \\
\hline \multirow{5}{*}{$\begin{array}{l}\text { Process } 4 \text { Steam Usage Type } \\
\text { Process } 4 \text { Usage Quantity } \\
\text { Process } 4 \text { Thermal Demand } \\
\text { Process } 4 \text { Pressure requirement } \\
\text { Implementing Backpressure Turbine instead of PRV? }\end{array}$} & Saturated & Steam \\
\hline & 0 & Ibs./hr. \\
\hline & 0 & MMBtu/hr. \\
\hline & 0 & \\
\hline & Yes & \\
\hline Enter Total Percentage loss in Process steam & $100 \%$ & \\
\hline
\end{tabular}

Figure 5-2: Input values for the facility- Part 2

\subsubsection{Boiler diagram}

Figure 5-3 shows the boiler diagram for the facility during the validation process. While generating the maximum amount of steam $\left(150,000 \mathrm{lbs} / \mathrm{hr}, 186 \mathrm{psig}, 664^{\circ} \mathrm{F}\right)$ for this boiler, the energy content in the steam is calculated to be $203.32 \mathrm{MMBtu} / \mathrm{hr}$. The maximum capacity of the boiler is 204 MMBtu/hr, so the generation of the steam is mathematically accurate. This process would establish the boiler at full-load, and the electricity generation would be maximum. It shows the total power generated as $6,708 \mathrm{~kW}$ when the steam at the mass flow rate of 101,610 lbs/hr passes through a condensing steam turbine and exits as saturated water by losing its latent heat of vaporization in the turbine condenser. The steam headed to the industrial process is used without any recovery. Therefore, 49,890 $\mathrm{lbs} / \mathrm{hr}$ of water is pumped into the cycle as make-up water. The usage of a 
condensing turbine made it impossible to implement an absorption chilling system as the turbine outlet water does not have enough energy to support trigeneration. However, the water can be used for comfort heating through HVAC systems during winter as shown in the diagram. The mixture of turbine outlet water and makeup water $(151,500 \mathrm{lbs} / \mathrm{hr})$ goes to the deaerator where it is treated using steam from the boiler. 1,500 lbs/hr steam that contains impurities and dissolved oxygen is vented out of the deaerator. The water, then, passes through an economizer where it gains sensible heat, after which, it is sent to the boiler to repeat the process. A tremendous amount of energy is wasted through stack gas (166.25 MMBtu/hr). It is suggested to use the stack gas to preheat the combustion air and implement burner controls to reduce losses in the stack gases.

\subsubsection{Results}

Figure 5-3 shows the results obtained from this CHP cycle. The payback on investment comes out to be a negative value. It means that the annual savings after implementing the CHP cycle are lesser than the annual expenditure. Thus, the CHP cycle at this facility with its respective energy, fuel, and water cost will not result in savings. COGENTEC shows negative payback as infinite, and the sensitivity analysis graphs show the negative, infeasible payback as " 0 " months. Similarly, the size of the boiler is also an important factor. However, the most important factor for this calculation is the energy and fuel cost. With a lower fuel cost, the project could have had desirable payback on investment. Moreover, the combustion efficiency of the boiler furnace is around 50\% only. It means that half of the fuel is wasted in stack gases. The facility can implement automatic burner controls and pre-heat combustion air to ultimately increase the combustion efficiency and produce a desirable payback on investment.

\begin{tabular}{|c|c|c|}
\hline \multicolumn{3}{|c|}{ Economics } \\
\hline Fuel Cost & $\$(8,851,989.34)$ & $/ \mathrm{yr}$ \\
\hline Water usage cost & $\$ \quad(524,205.81)$ & $/ \mathrm{yr}$ \\
\hline Turbine Capital and Installation Cos & $\$(3,450,339.88)$ & \\
\hline & $\$$ & \\
\hline & $\$ \quad-$ & \\
\hline Electricity usage savings & $\$ 5,288,616.33$ & $/ \mathrm{yr}$ \\
\hline Demand Savings & $\$ 1,287,943.10$ & $/ \mathrm{yr}$ \\
\hline & $\$-$ & $/ \mathrm{yr}$ \\
\hline NG savings in winter & $10,654.06$ & $/ \mathrm{yr}$ \\
\hline & - & $/ \mathrm{yr}$ \\
\hline Total Savings & $\$ 6,587,213.49$ & $/ \mathrm{yr}$ \\
\hline Total Expenditures Per Year & $\$(9,376,195.15)$ & $/ \mathrm{yr}$ \\
\hline Capital Cost & $\$(3,450,339.88)$ & \\
\hline Payback & Infinite & months \\
\hline
\end{tabular}

Figure 5-3: Results for the boiler-based CHP cycle 


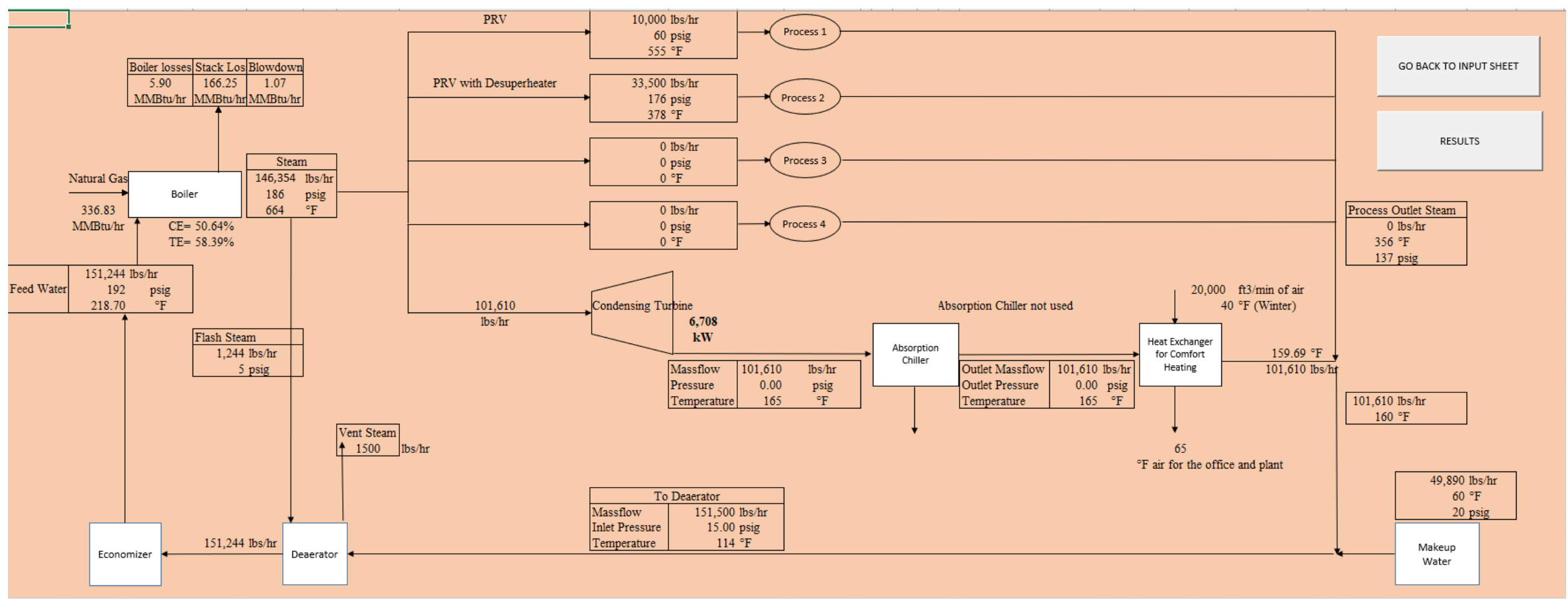

Figure 5-4: Boiler diagram using a condensing turbine 


\subsubsection{Sensitivity Analysis}

The sensitivity analysis is integrated into COGENTEC, thereby making it easier for the user to change the input values to produce as many graphs as they require. Figure 5-5 shows the relationship between the changes in the input variables to the power generation in $(\mathrm{kW})$ and the payback on investment period on investment (months).
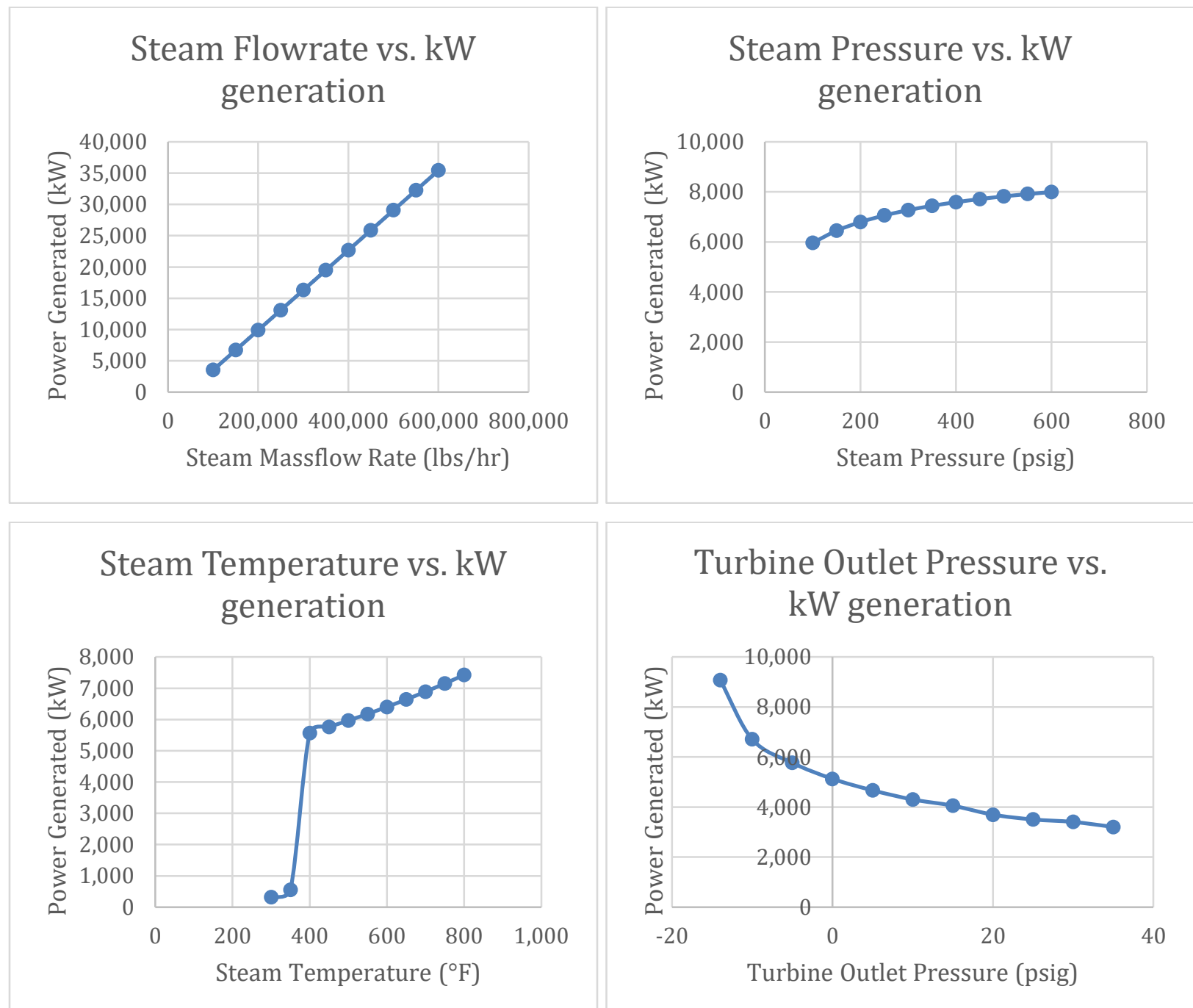

Figure 5-5: Pinch analysis between input and output parameters - Part 1 

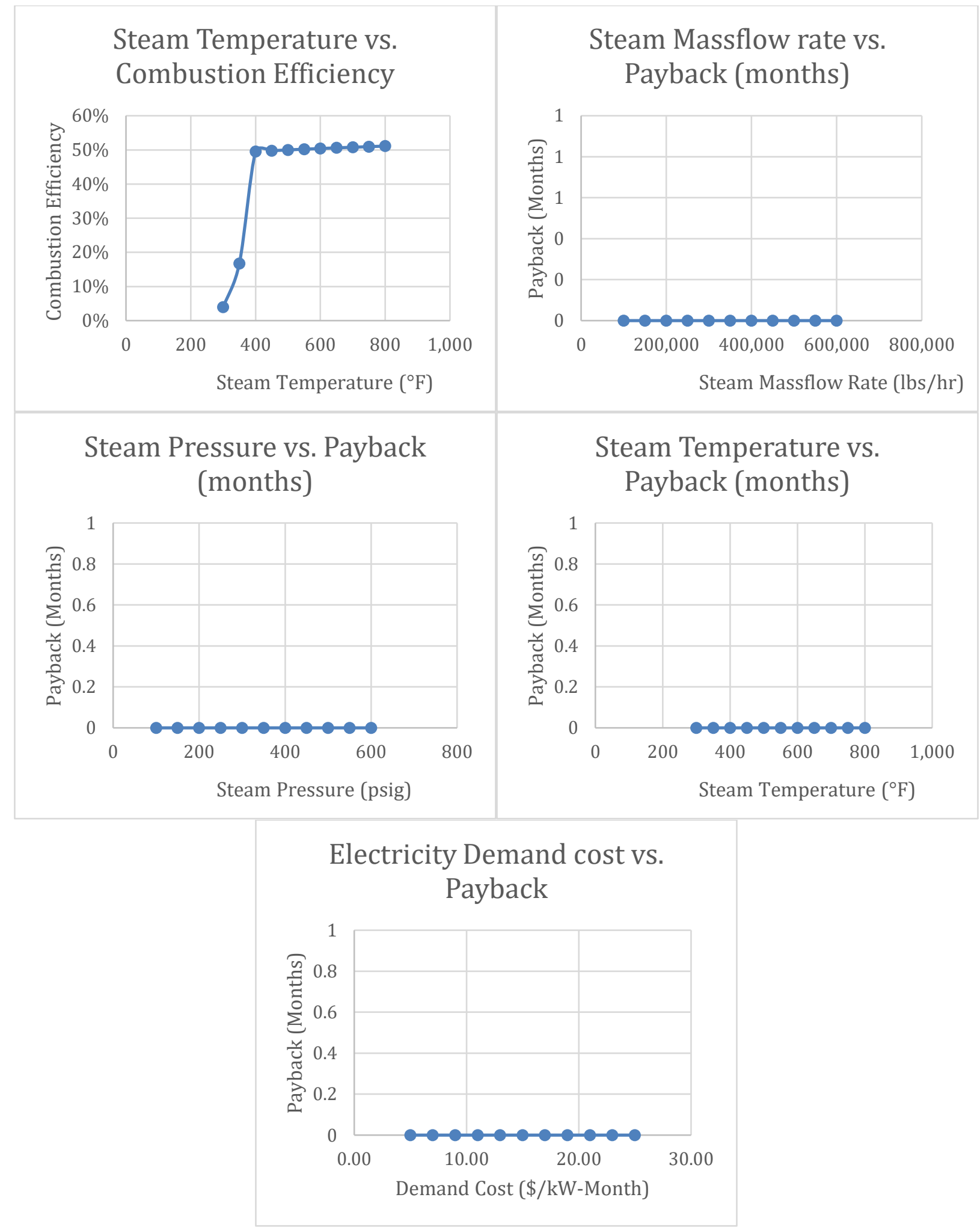

Figure 5-6: Pinch analysis between input and output parameters - Part $2^{1}$

\footnotetext{
${ }^{1}$ Zero months payback in the graphs suggest infinite and infeasible payback on the investment
} 
The relationship between the steam flow rate and power generation is linear. Despite generating more power at a higher steam flow rate, the payback on investment will not be feasible unless there is some serious revamp in the cost of natural gas and electricity usage. Steam pressure had a minimal impact on power generation; it also had the same impact in case of payback on investment period on investment. Steam temperature and turbine outlet pressure had an important relationship on power generation and payback on the investment period. However, for this facility, the minimum turbine outlet pressure (maximum energy transfer) is not enough for higher annual cost savings than that of the cost incurred.

Figure 5-7 shows the impact of natural gas and electricity usage cost in the payback on investment period on investment. These two parameters are by far the biggest influencers on the payback on investment period on investment. If the cost of natural gas is less than $\$ 2.00 / \mathrm{MMBtu}$, then the project will have a positive and desirable payback on investment. Similarly, when the cost of electricity usage is more than $\$ 0.14 / \mathrm{kWh}$, then the facility will exhibit desirable payback on investment. The payback on investment would be desirable as the annual cost savings will exceed the annual cost incurred in the facility.

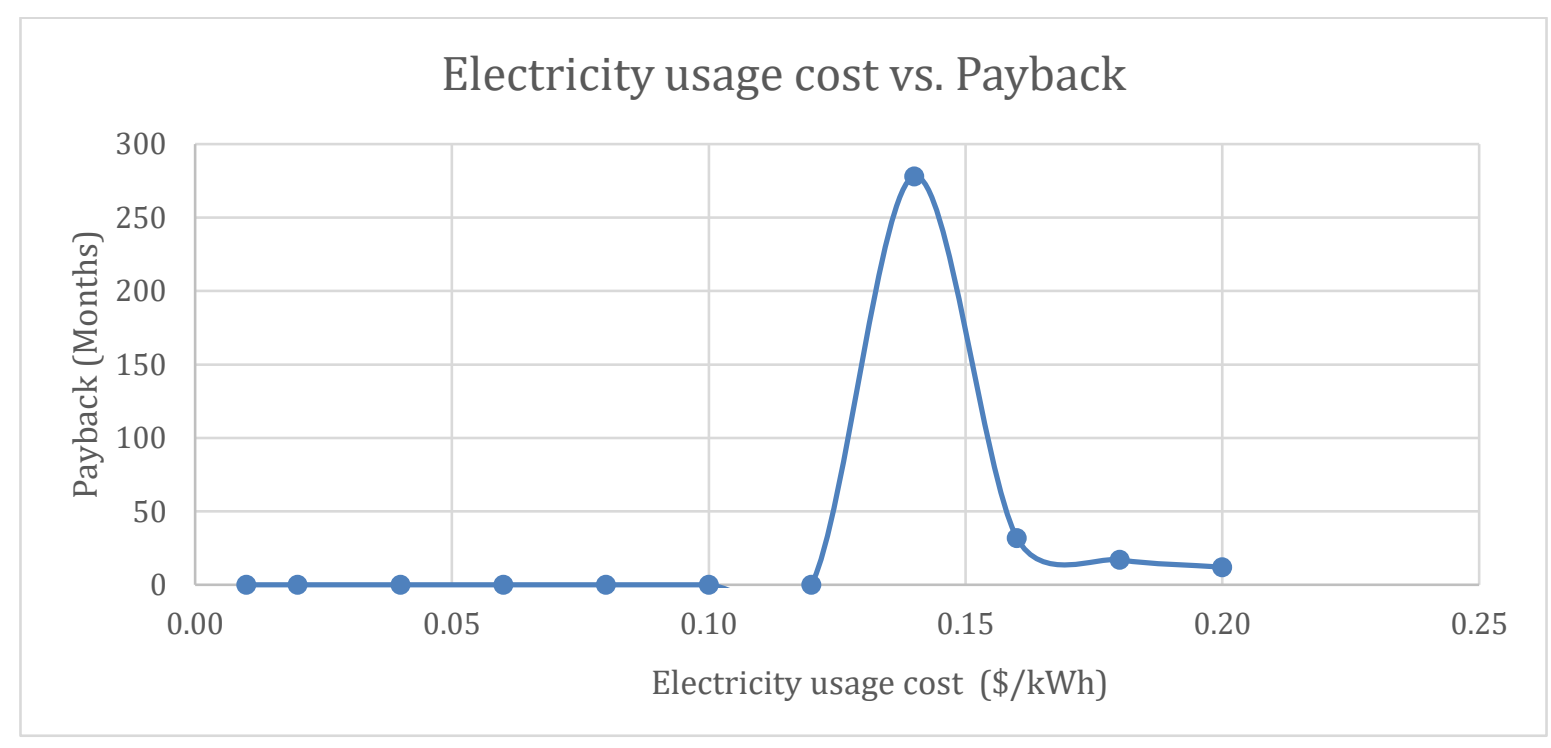




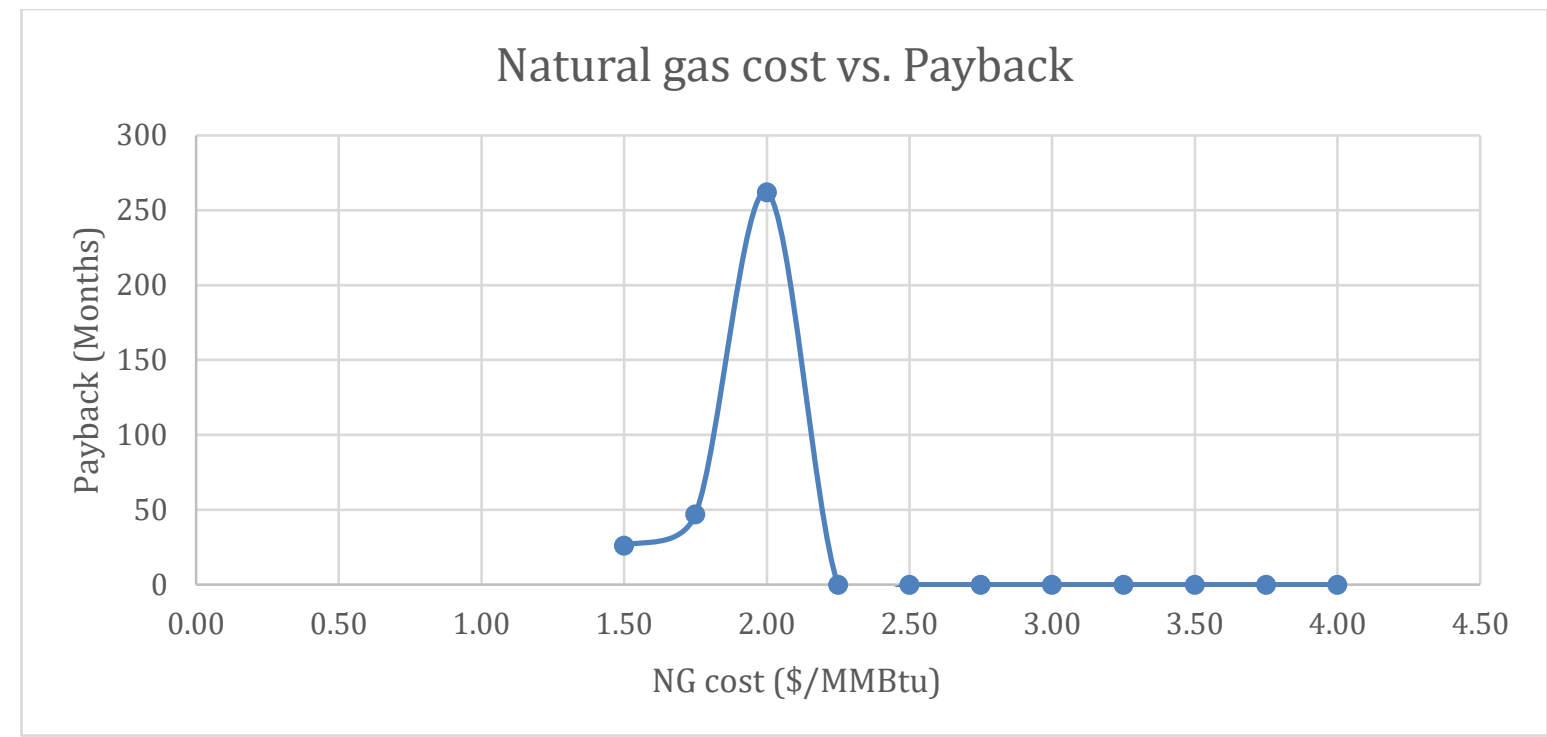

Figure 5-7: Sensitivity analysis on payback on investment period to NG and electricity usage $\operatorname{cost}^{2}$

Figure 5-8 shows the relationship between the payback on investment period, natural gas cost, and electricity usage cost. It can be inferred from the figure that a lower natural gas cost and a higher electricity usage cost is vital to achieving better savings and payback on investment. For the facility, the most optimal natural gas and electricity usage cost are $\$ 2.75 / \mathrm{MMBtu}$ and $\$ 0.14 / \mathrm{kWh}$ for a 4 years payback on investment. There is a better payback on investment outcomes at various energy and fuel costs; however, those costs are not in the control of the facility, therefore, the analysis is only carried out for information on the range of costs.

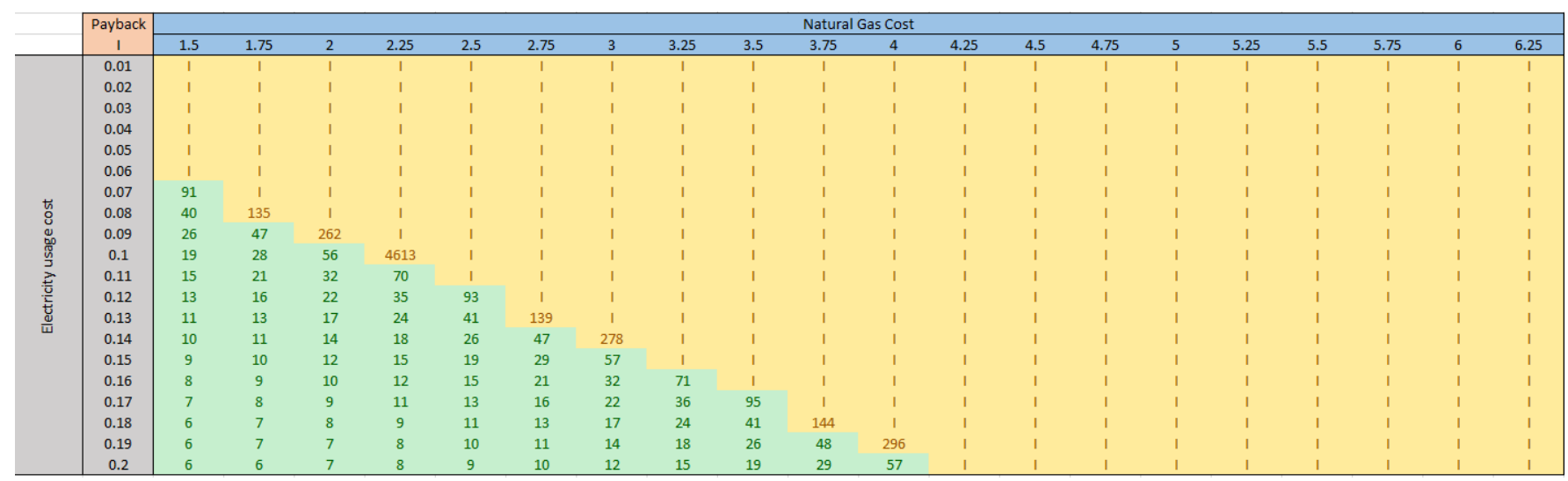

Figure 5-8: Pinch analysis between the payback on investment period, natural gas cost and electricity usage cost

${ }^{2}$ Zero months payback in the graphs suggest infinite and infeasible payback on the investment 


\subsubsection{Key findings}

Table 5-1 shows the key findings for the range of input parameters in this case study.

Table 5-1: Key findings for the Boiler-based CHP system

\begin{tabular}{|c|c|}
\hline Variable & Ranges for payback less than 4 years \\
\hline Steam Mass flow rate & Infeasible \\
\hline Steam Pressure & Infeasible \\
\hline Steam Temperature & Infeasible \\
\hline Turbine exit pressure & Infeasible \\
\hline Electricity Demand Cost & Infeasible \\
\hline Natural Gas Cost & $<=\$ 2.75 / \mathrm{MMBtu}$ \\
\hline Electricity Cost & $>=\$ 0.14 / \mathrm{kWh}$ \\
\hline
\end{tabular}

Table 5-1 shows the ranges of values for the input variables for which the facility will achieve a payback on the investment of less than 4 years for the boiler-based CHP system. For the current facility with its existing steam boilers, the process is infeasible at all the flowrates, steam pressure and temperature and the turbine exit pressure. However, if the price of utilities change to the content in Table 5-1, then the facility will achieve a desirable payback. The optimum values of natural gas and electricity cost are less than $\$ 2.75 / \mathrm{MMBtu}$ and greater than $>=\$ 0.14 / \mathrm{kWh}$.

\subsection{Gas turbine-based CHP system}

The gas turbine-based CHP system is verified in the sections below by utilizing the input parameters from a case study performed for a CHP system. The verification process is described below.

\subsubsection{Verification process and block diagram}

COGENTEC for the gas turbine is based on literature and previous case studies. It is a supplementary DSS designed to help industries and power plants that have gas-turbines for power generation. Therefore, an actual case study could not be performed to verify the workings of COGENTEC. However, a case study performed by the University of Massachusetts Amherst on a CHP system of $16 \mathrm{MW}_{\mathrm{e}}$ capacity [55]. The numbers on the case study are run through 
COGENTEC to verify the capability and accuracy of COGENTEC. The gas turbine used in the case study is a packaged unit comprised of an inlet air compressor, a combustion chamber, and a gas turbine. The hot turbine outlet temperature is utilized by a waste heat recovery boiler to generate steam at a rate of $100,000 \mathrm{lbs} / \mathrm{hr}$. The operating pressure and temperature of the steam is 600 psig and $750^{\circ} \mathrm{F}$. Figure 5-9 shows the input parameters entered in COGENTEC by referring to the case study.

\begin{tabular}{|c|c|}
\hline \multicolumn{2}{|l|}{ Enter Gas Turbine Paramters } \\
\hline Gas Turbine Rated Capacity & $16 \mathrm{MW}$ \\
\hline Mass flow rate of inlet air & $394733 \mathrm{lbs} . / \mathrm{hr}$. \\
\hline Temperature of Inlet air & $59^{\circ} \mathrm{F}$ \\
\hline Pressure of Inlet air & 14.7 psia \\
\hline Isentropic efficiency of Compressor & $65 \%$ \\
\hline Pressure ratio of compressor & 19.1 \\
\hline Mechanical transmission efficiency & $99 \%$ \\
\hline Generator Efficiency & $98 \%$ \\
\hline Excess Air Percentage & $200 \%$ \\
\hline Isentropic Efficiency of Turbine & $70 \%$ \\
\hline Pressure Losses in Combustion Chamber & $2 \%$ \\
\hline Pressure Losses in Heat exchanger air-side & $3 \%$ \\
\hline Gas Turbine Outlet Pressure Loss & $4 \%$ \\
\hline \multicolumn{2}{|l|}{ Enter Waste Heat Boiler Paramters } \\
\hline \multirow{5}{*}{$\begin{array}{l}\text { WHB Heat Exchanger Efficiency } \\
\text { Mass flow rate of Water } \\
\text { Steam Temperature Required } \\
\text { Steam Pressure } \\
\text { Boiler Blowdown \% }\end{array}$} & $80 \%$ \\
\hline & 100000 lbs./hr. \\
\hline & $7500^{\circ} \mathrm{F}$ \\
\hline & 600 psig \\
\hline & $2 \%$ \\
\hline \multicolumn{2}{|l|}{ 3. Turbine and Deaerator } \\
\hline \multirow{4}{*}{$\begin{array}{l}\text { Turbine Type } \\
\text { Enter Turbine Outlet Pressure } \\
\text { Enter makeup water temperature } \\
\text { Enter Deaerator Vent Rate }\end{array}$} & Backpressure Turbine \\
\hline & 15 psig \\
\hline & $60{ }^{\circ} \mathrm{F}$ \\
\hline & $1.00 \% \%$ \\
\hline \multicolumn{2}{|l|}{ 4. HVAC } \\
\hline \multirow{4}{*}{$\begin{array}{l}\text { HVAC Rated CFM } \\
\text { Average Winter Temperature } \\
\text { HVAC Coefficient Of Performance } \\
\text { HVAC Total Capacity }\end{array}$} & $20,000 \mid \mathrm{ft} 3 / \mathrm{min}$ \\
\hline & $45{ }^{\circ} \mathrm{F}$ \\
\hline & 4 \\
\hline & 400 Ton \\
\hline \multicolumn{2}{|l|}{ 5. Net Metering } \\
\hline \multirow{4}{*}{$\begin{array}{l}\text { Scope for Net Metering } \\
\text { Capital Cost } \\
\text { Cost of Electricity Sold } \\
\% \text { of Generated Electricity Sold }\end{array}$} & Yes \\
\hline & $1,500,000.00$ \\
\hline & 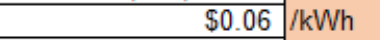 \\
\hline & $60 \%$ \\
\hline
\end{tabular}

Figure 5-9: Input values with the UMass Amherst Case study [55]

The case study did not showcase a few important parameters such as excess air \%, compressor efficiency, and turbine efficiency. The excess air percentage of the gas turbine package is estimated as per the typical gas turbine excess air \%. Similarly, the turbine isentropic efficiency and the 
compressor efficiency has also been entered as per other cases with typical gas turbines systems. The output from COGENTEC and the case study are shown in Figures 5-10 and 5-11.

It can be seen from the two figures that the total power output is within the range of $176 \mathrm{~kW}$. Based on the unavailability of all the data, the closeness of the net output power generation makes COGENTEC substantially adequate. Similarly, the turbine outlet temperature of COGENTEC and the case study is $987^{\circ} \mathrm{F}$ and $907^{\circ} \mathrm{F}$. The case study used all its steam for several steam headers that have their respective backpressure steam turbines of $3.5 \mathrm{MW}_{\mathrm{e}}$ and $2 \mathrm{MW}_{\mathrm{e}}$ capacity. Unsurprisingly, when a backpressure turbine (600/15 psig) is introduced in COGENTEC, the power generation $\left(5.8 \mathrm{MW}_{\mathrm{e}}\right)$ is closely equivalent to that of the case study $\left(5.5 \mathrm{MW}_{\mathrm{e}}\right)$. There is a discrepancy in the power generation which is due to losses prevalent by using two steam turbines. In COGENTEC, the outlet steam from the backpressure turbine is used for an absorption chilling system, comfort heating, and an Organic Kalina cycle (ORC). Studies have been carried out by utilizing geothermal water with a temperature range of $100-300^{\circ} \mathrm{F}$ to operate an ORC. The utilization of a new cycle increases the overall efficiency of the CHP system.

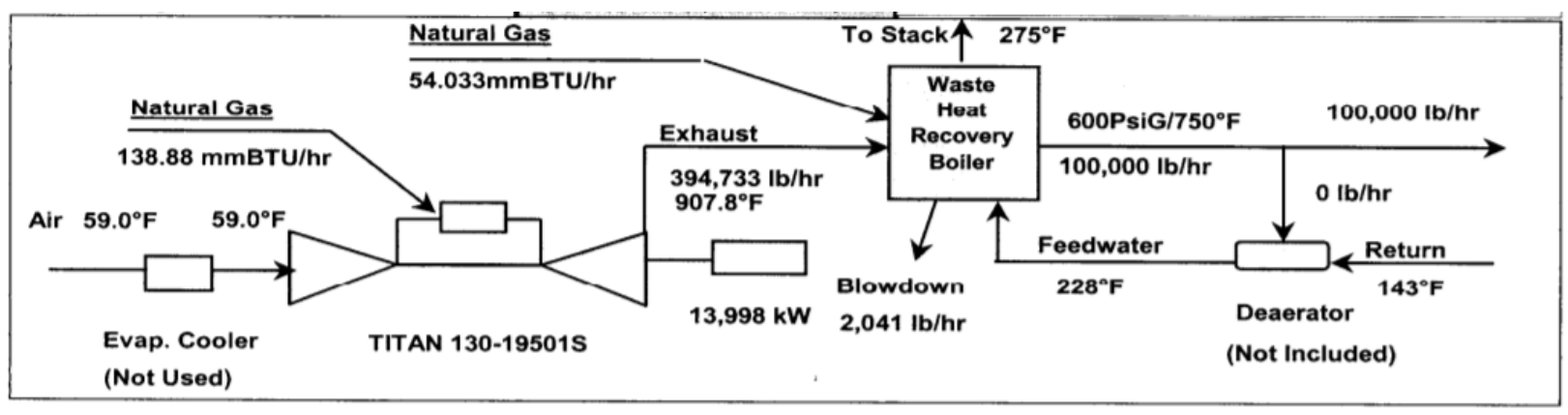

Figure 5-10: Case study input and output parameters [55] 


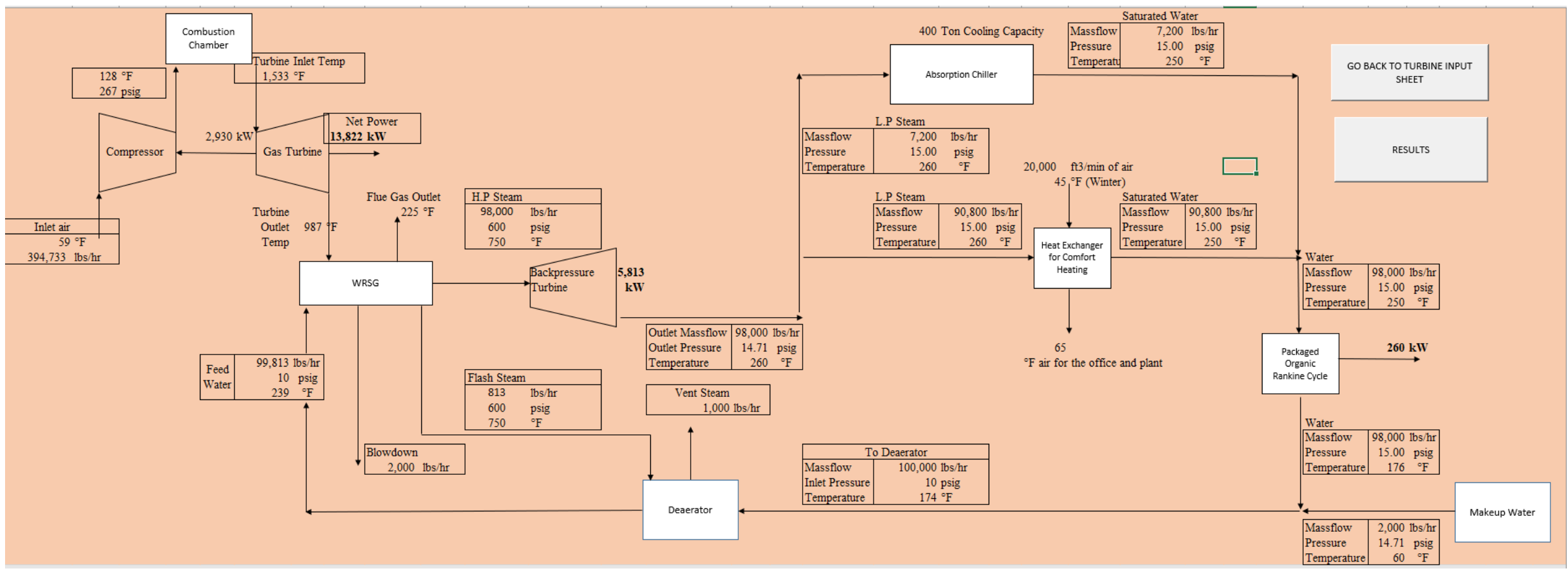

Figure 5-11: Gas-turbine based CHP system output 


\subsubsection{Results}

The implementation of a gas turbine-based CHP system is lucrative in terms of economics. Since the gas turbine systems are highly efficient and they use a significantly lower amount of fuel while compared to combustion-air, the total fuel cost is overshadowed by the respective energy cost savings. Natural gas cost savings for comfort heating can be higher if the facility is operating an HVAC system of higher capacity. The total electricity savings from the gas turbine is astronomical when compared with the natural gas cost incurred to operate the turbine. Due to this fact, a gas turbine-based CHP system is economically beneficial. The total payback on investment period on investment is less than 2 years for the case study.

\begin{tabular}{|l|lr|l}
\hline \multicolumn{4}{|c}{ Economics } \\
\hline NG Cost Savings from HVAC Boiler & $\$$ & $7,762.52$ & $/ \mathrm{yr}$ \\
\hline Electricty Savings from Absorption Chiller & $\$$ & $153,622.51$ & $/ \mathrm{yr}$ \\
\hline Total Electricity Savings from Turbines & $\$ 17,428,232.95$ & $/ \mathrm{yr}$ \\
\hline Total Demand Savings & $\$$ & $3,581,143.76$ & $/ \mathrm{yr}$ \\
\hline Cost Savings from Selling Electricity & $\$$ & $6,274,163.86$ & \\
\hline Natural Gas Cost & $\$(4,074,445.96)$ & $/ \mathrm{yr}$ \\
\hline Water Usage Cost & $\$$ & $(176,200.00)$ & $/ \mathrm{yr}$ \\
\hline Gas Turbine Cost & $\$(24,382,742.14)$ & \\
\hline Steam Turbine Cost & $\$(3,126,715.74)$ & \\
\hline ORC cost & $\$$ & $(390,137.14)$ & \\
\hline HRSG cost & $\$$ & $(300,000.00)$ & \\
\hline Absorption Chiller cost & $\$$ & $(720,000.00)$ & \\
\hline Net Metering Capital Cost & $\$(1,500,000.00)$ & \\
\hline \multicolumn{3}{|l|}{} & \\
\hline Total Savings & $\$ 21,170,761.73$ & $/ \mathrm{yr}$ \\
\hline Total Expenditures Per Year & $\$(4,250,645.96)$ & $/ \mathrm{yr}$ \\
\hline Capital Cost & $\$(28,979,595.02)$ & \\
\hline Payback & \multicolumn{3}{|c}{} \\
\hline
\end{tabular}

Figure 5-12: Results

\subsubsection{Sensitivity analysis}

As performed with the boiler-based CHP, pinch analysis is carried out in the gas turbine-based CHP system as well. The graphs are readily available in the results spreadsheet, and they are modified every time the user enters/modifies the values of the input parameters. The input parameters chosen for the analysis are inlet air mass flow rate, inlet air temperature, compressor efficiency, the pressure ratio of the compressor, excess air percentage, waste heat boiler steam quantity, waste heat boiler steam pressure and temperature. Similarly, the output parameters that 
are considered for the analysis are total power generation by the system and payback on investment period on investment. These two parameters are considered as they are at the forefront of the technical and economical capability of the system. Therefore, they have been chosen for the analysis. Figures 5-13, 5-14, and 5-15 show the graphs for the analysis carried out. 


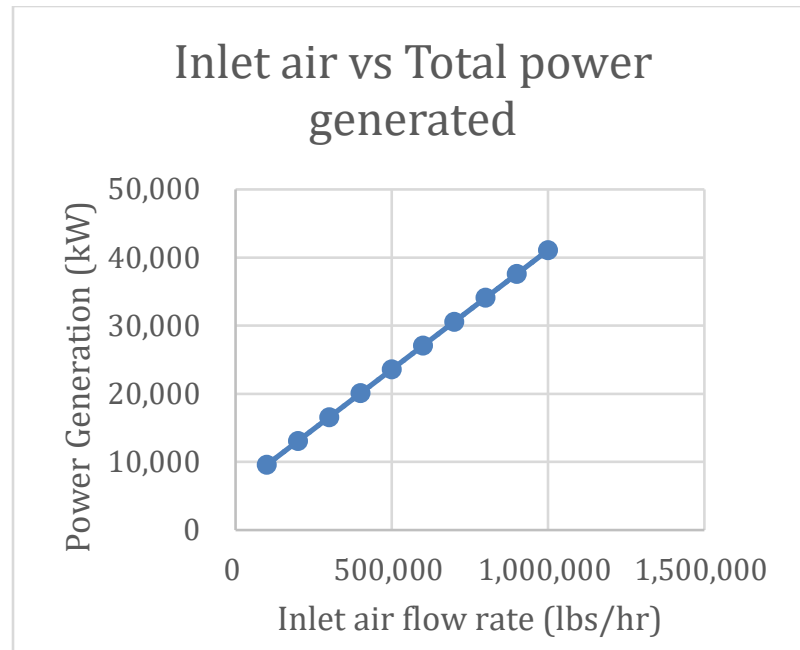
Inlet air temperature vs. Total power generated
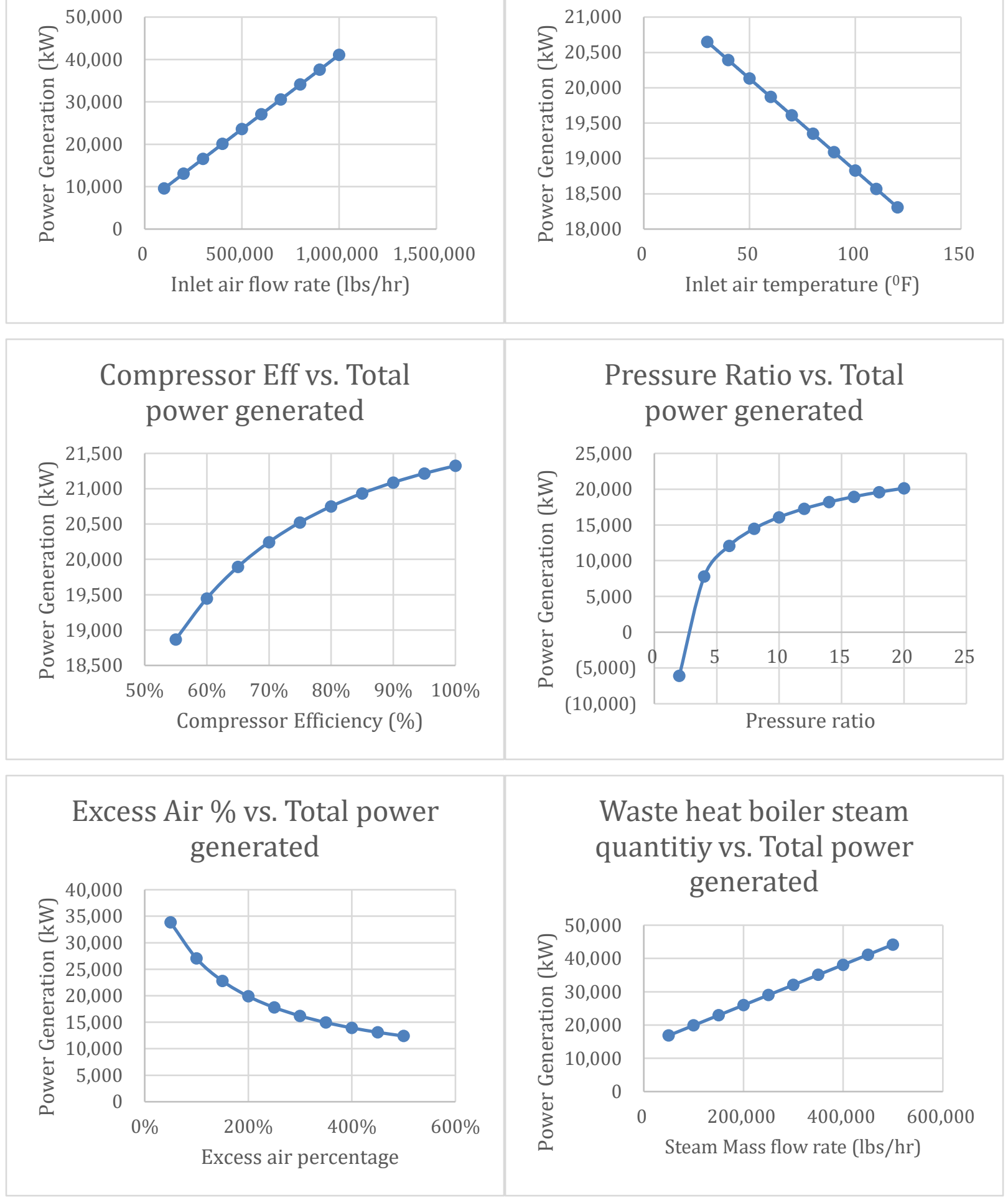

Figure 5-13: Gas Turbine Pinch analysis graphs - 1 


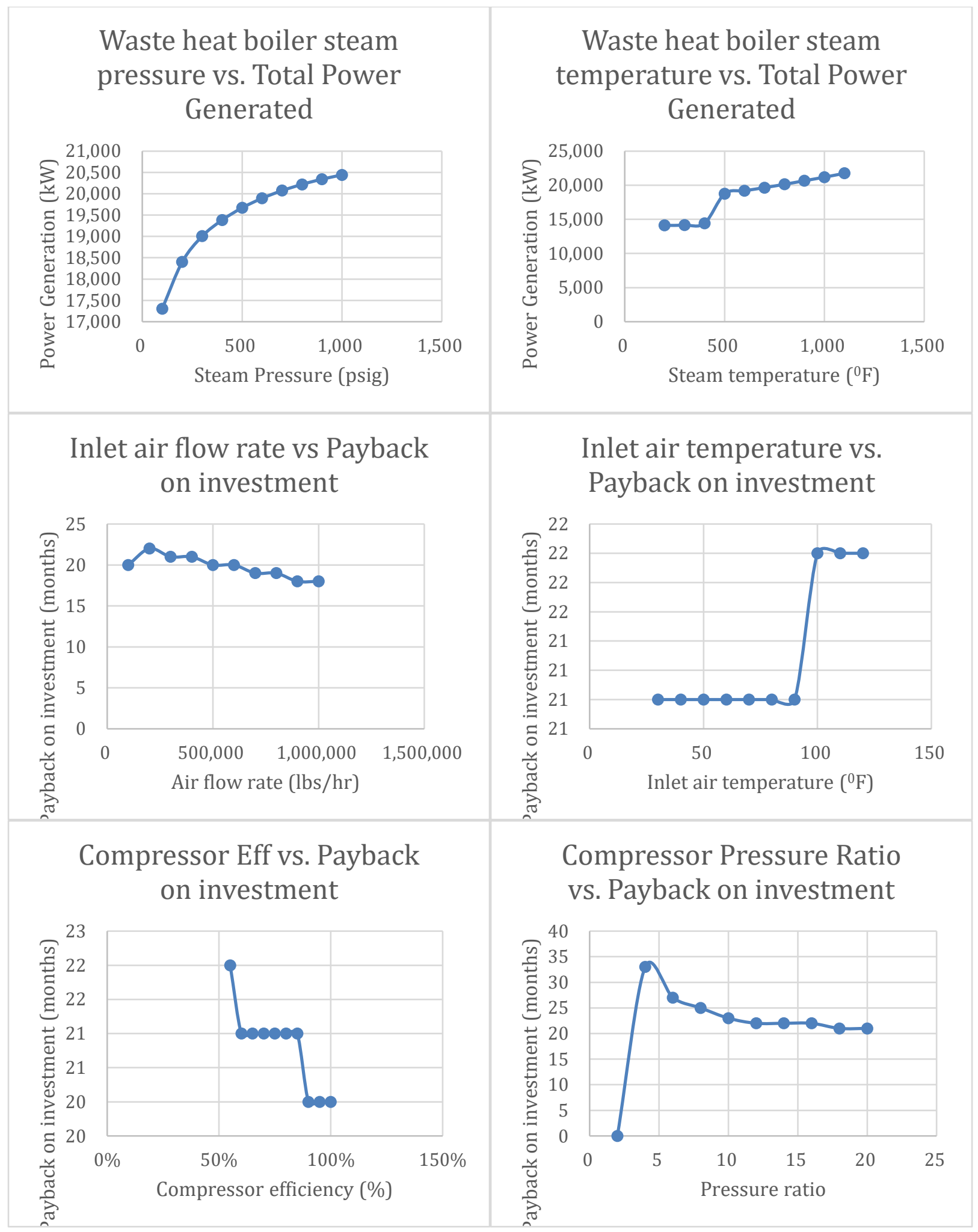

Figure 5-14: Gas Turbine Pinch analysis graphs - 2 

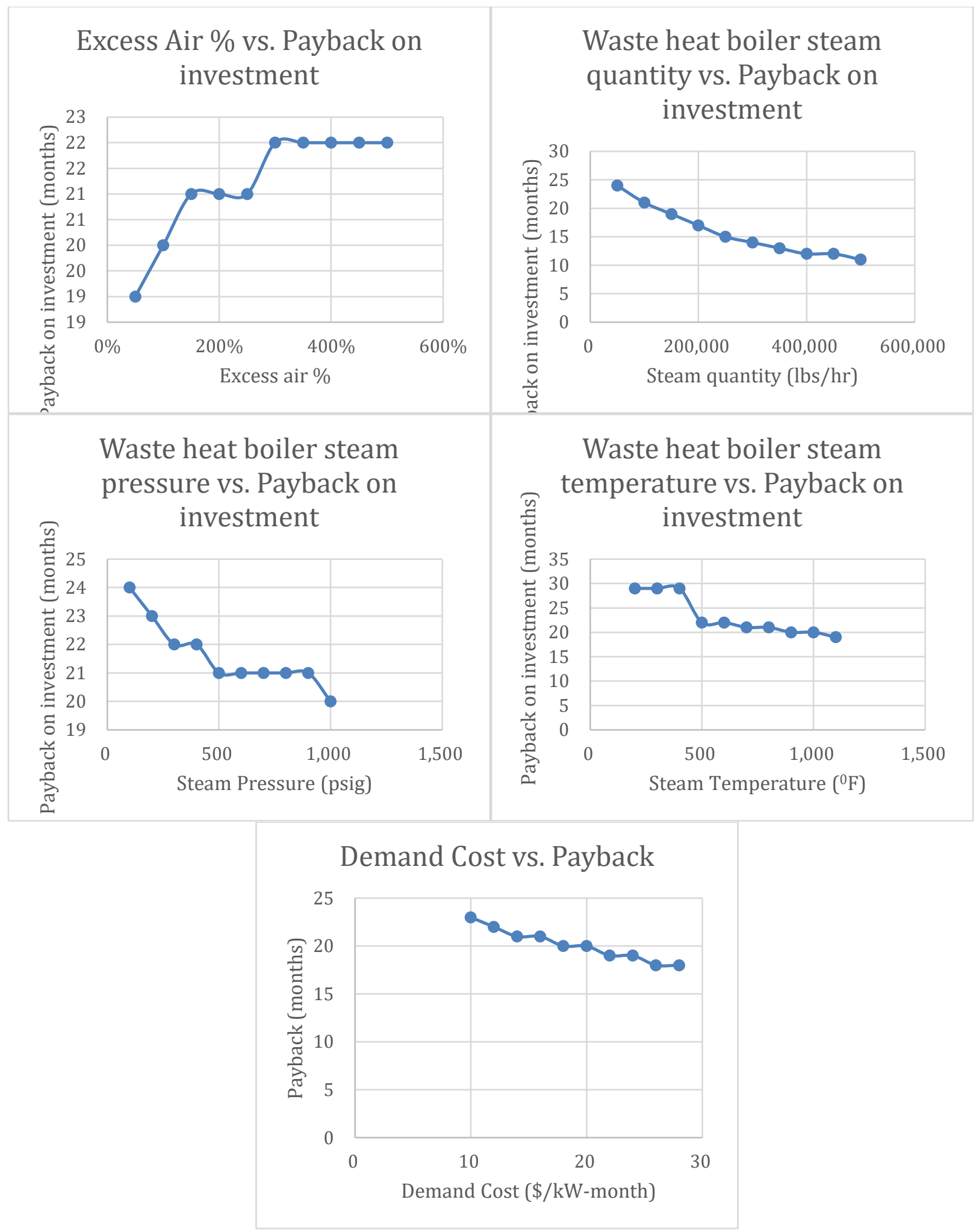

Figure 5-15: Gas turbine Pinch analysis graph - 3 
It can be inferred from the above graphs that the amount of inlet air, its temperature, the pressure ratio of the compressor, and the waste heat boiler steam quantity are the major parameters that influence the power generation and payback on investment. Out of those input parameters, based on the graphs in the above figures, the waste heat boiler steam flow rate is the parameter that has the most impact on the payback on investment period on investment. The waste heat boiler steam is run through a steam turbine that generates electricity. At present, the facility utilizes 100,000 $\mathrm{lbs} / \mathrm{hr}$ of steam. If the steam production is increased to $400,000 \mathrm{lbs} / \mathrm{hr}$, the payback on the investment period can be cut into half (10 months) as the more electrical energy will be generated.

\begin{tabular}{|c|c|c|c|c|c|c|c|c|c|c|c|c|c|c|c|c|}
\hline & \multirow{2}{*}{\begin{tabular}{|r|} 
Payback \\
21 \\
\end{tabular}} & \multicolumn{15}{|c|}{ Natural Gas } \\
\hline & & 1.50 & 1.75 & 2.00 & 2.25 & 2.50 & 2.75 & 3.00 & 3.25 & 3.50 & 3.75 & 4.00 & 4.25 & 4.50 & 4.75 & 5.00 \\
\hline \multirow{16}{*}{$\begin{array}{c}\text { Electricity } \\
\text { Cost }\end{array}$} & 0.05 & 35 & 36 & 37 & 38 & 40 & 41 & 43 & 45 & 47 & 49 & 52 & 54 & 57 & 61 & 65 \\
\hline & 0.06 & 30 & 30 & 31 & 32 & 33 & 34 & 36 & 37 & 38 & 40 & 41 & 43 & 45 & 47 & 49 \\
\hline & 0.07 & 26 & 27 & 27 & 28 & 29 & 29 & 30 & 31 & 32 & 33 & 34 & 35 & 37 & 38 & 39 \\
\hline & 0.08 & 23 & 23 & 24 & 25 & 25 & 26 & 26 & 27 & 28 & 29 & 29 & 30 & 31 & 32 & 33 \\
\hline & 0.09 & 21 & 21 & 22 & 22 & 22 & 23 & 23 & 24 & 24 & 25 & 26 & 26 & 27 & 28 & 28 \\
\hline & 0.10 & 19 & 19 & 19 & 20 & 20 & 21 & 21 & 21 & 22 & 22 & 23 & 23 & 24 & 24 & 25 \\
\hline & 0.11 & 17 & 18 & 18 & 18 & 18 & 19 & 19 & 19 & 20 & 20 & 21 & 21 & 21 & 22 & 22 \\
\hline & 0.12 & 16 & 16 & 16 & 17 & 17 & 17 & 17 & 18 & 18 & 18 & 19 & 19 & 19 & 20 & 20 \\
\hline & 0.13 & 15 & 15 & 15 & 15 & 16 & 16 & 16 & 16 & 17 & 17 & 17 & 17 & 18 & 18 & 18 \\
\hline & 0.14 & 14 & 14 & 14 & 14 & 15 & 15 & 15 & 15 & 15 & 16 & 16 & 16 & 16 & 17 & 17 \\
\hline & 0.15 & 13 & 13 & 13 & 13 & 14 & 14 & 14 & 14 & 14 & 15 & 15 & 15 & 15 & 15 & 16 \\
\hline & 0.16 & 12 & 12 & 13 & 13 & 13 & 13 & 13 & 13 & 13 & 14 & 14 & 14 & 14 & 14 & 15 \\
\hline & 0.17 & 12 & 12 & 12 & 12 & 12 & 12 & 12 & 13 & 13 & 13 & 13 & 13 & 13 & 13 & 14 \\
\hline & 0.18 & 11 & 11 & 11 & 11 & 11 & 12 & 12 & 12 & 12 & 12 & 12 & 12 & 12 & 13 & 13 \\
\hline & 0.19 & 10 & 11 & 11 & 11 & 11 & 11 & 11 & 11 & 11 & 11 & 12 & 12 & 12 & 12 & 12 \\
\hline & 0.20 & 10 & 10 & 10 & 10 & 10 & 10 & 11 & 11 & 11 & 11 & 11 & 11 & 11 & 11 & 11 \\
\hline
\end{tabular}

Figure 5-16: Impact of varying electricity and natural gas cost on payback on investment

In the case study, the varying cost of energy and fuel cost does play a role in changing payback on investment. However, as the impact of natural gas cost on the gas turbine-based CHP is minimal, the project has a lot of green areas even at highly varying fuel and electricity costs. Even at the high cost of natural gas $(\$ 5 / \mathrm{MMBtu})$ and a low cost of electricity usage $(\$ 0.05 / \mathrm{kWh})$, the payback on investment is computed to be 5.5 years. Therefore, the project is viable for the case study.

\subsubsection{Key findings}

Table 5-2 shows the key findings related to the input parameters in this case study.

Table 5-2: Key findings for the gas turbine-based cogeneration system

\begin{tabular}{|c|c|}
\hline Variables & Ranges of input variables for a payback less than 21 months \\
\hline Inlet air mass flow rate & $>=500,000 \mathrm{lbs} / \mathrm{hr}$ \\
\hline Inlet air temperature & \#NA \\
\hline
\end{tabular}




\begin{tabular}{|c|c|}
\hline Variables & Ranges of input variables for a payback less than 21 months \\
\hline Excess air percentage & $<=150 \%$ \\
\hline Compressor efficiency & $>=90 \%$ \\
\hline Compressor pressure ratio & $\# \mathrm{NA}$ \\
\hline Waste heat boiler steam \\
quantity & $>100,000 \mathrm{lbs} / \mathrm{hr}$ \\
\hline Demand Cost & $>=\$ 18 / \mathrm{kW}-\mathrm{Month}$ \\
\hline Natural gas cost & $<=\$ 3.75 / \mathrm{MMBtu}$ \\
\hline Electricity usage cost & $>=\$ 0.11 / \mathrm{kWh}$ \\
\hline
\end{tabular}

Table 5-2 shows the ranges of values for the input variables for which the payback will be lesser than 21 months. 21 months is the payback under the current set of input variables. Therefore, the optimum values for which the payback is less than 21 months are calculated to get a better understanding about the variables that influence the payback on the investment the most. The most important set of parameters are the electricity cost, natural gas cost, waste heat boiler steam quantity and the compressor pressure ratio. 


\section{Conclusion and Future Work}

In this study, the effect of the operational parameters of a steam boiler and a gas turbine on the economic and technical aspects in implementing a topping cycle CHP system is studied and verified. The study was carried out by developing an MS Excel ${ }^{\mathrm{R}}$-based decision support system called "COGENTEC" in which a user can enter the input parameters related to the operations of a steam turbine or a gas turbine. The variables have been decided as per the CHP system's operations and literature survey carried out in previous studies. The study computes the results based on the input parameters and displays the results, based on savings, expenditure, and the payback on investment. Moreover, a block diagram associated with the CHP system is also computed by COGENTEC that makes it easier for the user to grasp the flow of steam/water and the energy in the system. If the payback on investment is feasible, the result tab will show the payback in months; however, if the payback is infeasible, then the result tab would display infeasible as the payback. COGENTEC lets the user select two different primary equipment. The first option is that of a boiler where the excess steam of the boiler is used to generate steam through a steam turbine. The second option is that of a gas turbine that generates electricity and the turbine exhaust is utilized for heat in the form of comfort heating, district heating, or a waste heat recovery boiler for power generation.

COGENTEC has been verified by utilizing the steam boiler operational and input parameters from a pulp and paper industry. Similarly, the gas turbine-based CHP system was verified by using the data from a case study related to a CHP system with a gas turbine and a waste heat recovery boiler for their operation. The summary of the key findings of the analysis are listed below:

1. The most important parameters for obtaining a feasible payback on investment are electricity usage and natural gas usage cost in a gas turbine and boiler-based CHP system.

2. Power generation from a steam turbine is linearly proportional to the steam generation in a steam boiler or a waste heat recovery boiler.

3. Steam pressure and temperature are directly proportional to the power generation; however, their impact is not as important as that of the steam quantity. 
4. The steam turbine outlet pressure is inversely proportional to the power generation and the payback on investment. Lower outlet pressure generates more power and lowers the payback on investment.

5. To achieve a feasible payback in the paper industry, the cost of electricity must be more than $\$ 0.14 / \mathrm{kWh}$. Similarly, the cost of natural gas must be less than $\$ 2.00 / \mathrm{MMBtu}$ for a feasible payback. For the facility under consideration in the case study, the demand cost did not influence the payback on the investment.

6. The most optimal combined cost of electricity and natural gas for a feasible payback on investment is $\$ 0.12 / \mathrm{kWh}$ and $\$ 2.5 / \mathrm{MMBtu}$. These costs would result in an eight-year payback.

7. Similarly, for a gas-turbine based CHP system case study, the optimal cost of the natural gas and electricity should be $\$ 3.00 / \mathrm{MMBtu}$ ad $\$ 0.09 / \mathrm{kWh}$ for a 2 years payback.

8. Inlet air temperature and quantity of the gas turbine are linearly dependent on the total power generation. Inlet air temperature is directly proportional to the power generation whereas the inlet air temperature is inversely proportional to the power generation.

9. The compressor pressure ratio and the waste heat boiler steam quantity are the most important parameters after the natural gas and electricity usage for a lower payback in a gas turbine-based CHP.

Future work on this research study involves the formulation of a dynamic DSS by increasing the number of parameters for the boilers and the steam turbine, and analyzing their continuous effects, if any, for the economic and technical benefits of a topping cycle CHP system. A summary of possible forthcoming work relating to this study are listed below:

1. Develop a dynamic DSS procure results of a topping cycle CHP system over time. Usage of dynamic data collection and sensors to get data over time is another step for this study.

2. COGENTEC deals in brief on the end-use and their characteristics. It can be developed to include an enumeration of different detailed end uses.

3. Usage of multiple boilers, steam turbines, and dual burners was not a part of this study. Integrating multiple equipment would result in a better embodiment of a real-life process. 
4. Time of day rates of natural gas and electricity based on the principle of distributed generation should be explored in order to provide a realistic cogeneration analysis.

5. Finally, the model can be modified to create a system based on target power required, and subsequent derivation for the energy system attributes such as boilers and steam turbines. 


\section{Bibliography}

[1] "AMO Industrial Distributed Energy: Combine Heat and Power: A Clean Energy Solution," U.S. Department of Energy, U.S. Environmental Protection Agency, August 2012.

[2] A. Abuelnuor, K. M. Saqr, S. A. Mohieldein, K. A. Dafallah, M. M. Abdullah and Y. A. Nogoud, "Exergy Analysis of Garri “2” 180 MW Combined Cycle Power Plant," Renewable and Sustainable Energy Reviews, vol. 79, no. C, pp. 960-969, 2017.

[3] B. Hedman, A. Hampson and K. Darrow, "The Opportunity for CHP in the United States," ICF International, 2013.

[4] M. Gambini, M. Vellini, T. Stilo, M. Manno and S. Bellocchi, "High-Efficiency Cogeneration Systems: The Case of the Paper Industry in Italy," Energies, vol. 12, no. 3, pp. 335-335, 2019.

[5] L. Stone, A Small Country Goes Big with Renewables: Denmark's goal to be fossil fuel free, Rocky Mountian Institute, March, 2016.

[6] S. Shafiee and E. Topal, "When will Fossil Fuel Reserves be Diminished?," Energy Policy, vol. 37, no. 1, pp. 181-189, 2009.

[7] A. Berman, Shale Gas Is Not A Revolution, Forbes, 2017.

[8] J. Wang, Y. Dai and L. Gao, "Exergy Analyses and Parametric Optimizations for Different Cogeneration Power Plants in Cement Industry," Applied Energy, vol. 86, no. 6, pp. 941948, 2009.

[9] P. Otis, "CHP Industrial Bottoming and Topping Cycle with Energy Information Administration Survey Data," U.S. Energy Information Administration, 14 August 2015. [Online]. Available: https://www.eia.gov/workingpapers/pdf/chp-Industrial_81415.pdf.

[10] M. Korobitsyn, New and Advanced Energy Conversion Technologies. Analysis of Cogeneration, Combined and Integrated Cycles, Amsterdam: Febodruk BV, Enschede, 1998.

[11] A. Poullikkas, "An Overview of Current and Future Sustainable Gas Turbine Technologies," Renewable and Sustainable Energy Reviews, vol. 9, no. 5, pp. 409-443, 2005. 
[12] G. Holdmann, "The Chena Hot Springs 400kW Geothermal Power Plant: Experience Gained During the First Year of Operation," Chena Geothermal Power Plant Report, Chena Power Plant, Alaska, pp. 1-9, 2007.

[13] A. Kalina, "Combined Cycle System with Novel Bottoming Cycle," Journal of Engineering for Gas Turbines and Power, vol. 106, pp. 737-742, 1984.

[14] J. Bujak, "Optimal Control of Energy Losses in Multi-Boiler Steam Systems," Energy, vol. 34, pp. 1260-1270, 2009.

[15] G. Harell, "Steam System Survey Guide," Oakridge National Laboratory, Oakridge, Tennessee, 2002.

[16] G. Harrel and P. Harrel, "Boiler Blowdown Energy Recovery," Energy Engineering, vol. 101, no. 5, pp. 32-42, 2004.

[17] "Combined Heat and Power Technology Fact Sheet Series - Steam Turbines," U.S. DOE's Office of Energy Efficiency and Renewable Energy (EERE), July 2016.

[18] U. S. Environmental Protection Agency, "Catalog of CHP Technologies," 2015.

[19] "Combined Heat and Power Technology Fact Sheet Series - Gas Turbines," U.S. DOE's Office of Energy Efficiency and Renewable Energy (EERE), July 2016.

[20] "Combined Heat and Power Technology - Absorption Chillers for CHP," U.S. DOE's Office of Energy Efficiency and Renewable Energy (EERE), May 2017.

[21] "Energy Tips - Steam - Steam Tip Sheet \#14," U.S. DOE's Office of Energy Efficiency and Renewable Energy (EERE), January 2006.

[22] L. Bird, F. Flores, C. Volpi, K. Ardani, D. Manning and R. McAllister, "Review of Interconnection Practices and Cost in the Western States," National Renewable Energy Laboratory. NREL /TP-6A20-71232, Golden, CO, 2018.

[23] "Database of State Incentives for Renewables \& Efficiency (DSIRE)," N.C. State University. [Online].

[24] "Monthly Energy Review," U.S. Energy Information Administration , Washington, DC, 2019.

[25] V. Singh and R. Radermacher, "Boost Efficiency and Reliability via Cogeneration," Buildings, vol. 103, no. 6, pp. 78-81, 2009. 
[26] M. Khan and I. Tlili, "Innovative Thermodynamic Parametric Investigation of Gas and Steam Bottoming Cycles with Heat Exchanger and Heat Recovery Steam Generator: Energy and Exergy Analysis," Energy Reports, vol. 4, pp. 497-506, 2018.

[27] C. Butcher and B. Reddy, "Second Law Analysis of a Waste Heat Recovery Based Power Generation System," International Journal of Heat and Mass Transfer, vol. 50, pp. 23552363, 2007.

[28] S. Frigo, R. Gabbrielli and L. Linari, "Feasibility Study of a CHP Plant with Steam Turbine and Biomass Gasification for Tissue Paper Production," Energy Procedia, vol. 148, pp. 751$757,2018$.

[29] M. H. Ahmadi, M. A. Nazari, M. Sadeghzadeh, F. Pourfayaz, M. Ghazvini, T. Ming, J. P. Meyer and M. Sharifpur, "Thermodynamic and Economic Analysis of Performance Evaluation of all the Thermal Power Plants: A Review," Energy Science \& Engineering, vol. 7, no. 1, pp. 30-65, 2019.

[30] E. Bilgen, "Exergetic and Engineering Analyses of Gas Turbine Based Cogeneration Systems," Energy, vol. 25, pp. 1215-1229, 2000.

[31] H. Holmberg, M. Tuomaala, T. Haikonen and P. Ahtila, "Allocation of Fuel Costs and CO2Emissions to Heat and Power in an Industrial CHP Plant: Case Integrated Pulp and Paper Mill," Applied Energy, vol. 93, pp. 614-623, 2012.

[32] D. B. Ozkan, O. Kiziler and D. Bilge, "Exergy Analysis of a Cogeneration Plant," International Journal of Mechanical and Aerospace Engineering, vol. 6, no. 1, pp. 235-239, 2012.

[33] A. Beyene, "Combined Heat and Power as a Feature of Energypark," Journal of Energy Engineering, vol. 131, no. 3, pp. 173-188, 2005.

[34] R. Murugan and P. Subbarao, "Efficiency Enhancement in a Rankine Cycle Power Plant: Combined Cycle Approach," Proceedings of the Institution of Mechanical Engineers, Part a: Journal of Power and Energy, vol. 222, no. 8, pp. 753-60, 2008.

[35] V. R. Ferreira, C. M. Augusto, J. B. Ribeiro, A. R. Gaspar and J. J. Costa, "Increasing the Efficiency of High Temperature Furnaces through a Topping Cycle Cogeneration-A Case Study," Energy Efficiency, vol. 8, pp. 85-95, 2015. 
[36] M. Maheshwari and O. Singh, "Comparative Evaluation of Different Cycle Configurations having Simple Gas Turbine, Steam Turbine and Ammonia Water Turbine," Energy, vol. 168, pp. 1217-1236, 2019.

[37] K. Carpenter and J. K. Kissock, "Quantifying Savings From Improved Boiler Operation," in Mechanical and Aerospace Engineering Faculty Publications, Paper 147, 2005.

[38] P. Nag and S. De, "Design and Operation of a Heat Recovery Steam Generator with Minimum Irreversibility," Applied Thermal Engineering, vol. 17, no. 4, pp. 385-391, 1997.

[39] W. Somcharoenwattana, C. Menke, D. Kamolpus and D. Gvozdenac, "Study of Operational Parameters Improvement of Natural-Gas Cogeneration," Energy and Buildings, vol. 43, no. 4, pp. 925-934, 2011.

[40] M. Valdes, A. Rovira and M. D. Duran, "Influence of the Heat Recovery Steam Generator Design Parameters on the Thermoeconomic Performances of Combined Cycle Gas Turbine Power Plants," International Journal of Energy Research, vol. 28, pp. 1243-1254, 2004.

[41] A. Franco and N. Giannini, "A General Method for the Optimum Design of Heat Recovery Steam Generators," Energy, vol. 31, no. 15, pp. 3342-3361, 2006.

[42] F. R. P. Arrieta and E. E. S. Lora, "Influence of Ambient Temperature on Combined-Cycle Power-Plant Performance," Applied Energy, vol. 80, pp. 261-272, 2005.

[43] G. Şen, M. Nil, H. Mamur, H. Doğan, M. Karamolla, M. Karaçor, F. Kuyucuoğlu, N. Yörükeren, M. Ruhul and A. Bhuiyan, "The Effect of Ambient Temperature on Electric Power Generation in Natural Gas Combined Cycle Power Plant-A Case Study," Energy Reports, vol. 4, pp. 682-690, 2018.

[44] S.-D. Oh, H.-S. Oh and H.-Y. Kwak, "Economic Evaluation for Adoption of Cogeneration System," Applied Energy, vol. 84, pp. 266-278, 2007.

[45] A. Hampson, R. Tidball, M. Fucci and R. Weston, "Combined Heat and Power (CHP) Technical Potential in the United States," U.S. Department of Energy (U.S. DOE), Office of Energy Efficiency and Renewable Energy (EERE), Advanced Manufacturing Office, March 2016.

[46] "U.S. DOE Combined Heat and Power Installation Database," U.S. DOE's Office of Energy Efficiency and Renewable Energy (EERE), December, 2014. 
[47] C. Arzbaecher, E. Fouche, K. Parmenter and Global Energy Partners, "Industrial Waste-Heat Recovery: Benefits and Recent Advancements in Technology and Applications," ACEEE Summer Study on Energy Efficiency in Industry, 2007.

[48] M. McBrien, A. C. Serrenho and J. M. Allwood, "Potential for Energy Savings by Heat Recovery in an Integrated Steel Supply Chain," Applied Thermal Engineering, vol. 103, pp. 592-606, 2016.

[49] "Steam System Modeler Tool (SSMT)," U.S. DOE's office of Energy Efficiency and Renewable Energy (EERE), 17 March 2015. [Online].

[50] J. A. Asmar, C. Lahoud and M. Brouche, "Decision-Making Strategy for Cogeneration Power Systems Integration in the Lebanese Electricity Grid," Energy Procedia, vol. 119, pp. 801-805, 2017.

[51] W. T. Parry, J. C. Bellows, J. S. Gallagher, A. H. Harvey and R. D. Harwood, ASME International Steam Tables for Industrial Use, New York: ASME Press Books, 2014.

[52] M. P. Boyce, Gas Turbine Engineering Handbook, Fourth edition, Elsevier, 2012.

[53] S. Ogriseck, "Integration of Kalina Cycle in a Combined Heat and Power Plant, A Case Study," Applied Thermal Engineering, vol. 29, p. 2843-2848, 2009.

[54] L. Bai, "Life Cycle Assessment of Electricity Generation from Low Temperature Waste Heat: The Influence of Working Fluid," Norwegian University of Science and Technology, Trondheim, 2012.

[55] J. Burbank, "Case Study: 16 MW Combined Cycle Cogeneration Plant for a University Campus," Massachusetts Energy Efficiency Partnership, 2013. 